\title{
Physical training of school children with spastic cerebral palsy
}

Citation for published version (APA):

Berg-Emons, H. J. G. (1996). Physical training of school children with spastic cerebral palsy. [Doctoral Thesis, Maastricht University]. Universiteit Maastricht. https://doi.org/10.26481/dis.19960619hb

Document status and date:

Published: 01/01/1996

DOI:

10.26481/dis.19960619hb

Document Version:

Publisher's PDF, also known as Version of record

\section{Please check the document version of this publication:}

- A submitted manuscript is the version of the article upon submission and before peer-review. There can be important differences between the submitted version and the official published version of record.

People interested in the research are advised to contact the author for the final version of the publication, or visit the DOI to the publisher's website.

- The final author version and the galley proof are versions of the publication after peer review.

- The final published version features the final layout of the paper including the volume, issue and page numbers.

Link to publication

\footnotetext{
General rights rights.

- You may freely distribute the URL identifying the publication in the public portal. please follow below link for the End User Agreement:

www.umlib.nl/taverne-license

Take down policy

If you believe that this document breaches copyright please contact us at:

repository@maastrichtuniversity.nl

providing details and we will investigate your claim.
}

Copyright and moral rights for the publications made accessible in the public portal are retained by the authors and/or other copyright owners and it is a condition of accessing publications that users recognise and abide by the legal requirements associated with these

- Users may download and print one copy of any publication from the public portal for the purpose of private study or research.

- You may not further distribute the material or use it for any profit-making activity or commercial gain

If the publication is distributed under the terms of Article $25 \mathrm{fa}$ of the Dutch Copyright Act, indicated by the "Taverne" license above, 


\section{Physical training of school children with spastic cerebral palsy}


ISBN 90-9009532-2

- Rita van den Berg-Emons, Hulst 1996

Vormgeving: Rita van den Berg-Emons

Omslagillustratie: Ineke Steijaert, aquarel n.a.v. "L'oiseau bleu", een allegorisch toneelstuk van Maurice Maeterlinck (1909) over de kinderen Mytyl en Tytyl die op zoek zijn naar de blauwe vogel van het geluk voor een verlamd buurmeisje. Zij gaan de hele wereld door, maar ze slagen er niet in de blauwe vogel te bemachtigen. Thuisgekomen geven ze dan hun kostbaarste bezit, hun tortelduif, aan het buurmeisje 'et quand elle a vu l'oiseau, elle a sauté'. Hiermee wilde Maeterlinck tot uiting brengen dat alleen met de volledige inzet van de persoonlijkheid en door het beste te geven wat men heeft, hulp te bieden is aan zieken en gehandicapten.

Druk: Datawyse Maastricht / Krips Repro Meppel 


\title{
Physical training of school children with spastic cerebral palsy
}

\author{
PROEFSCHRIFT
}

\author{
ter verkrijging van de graad van doctor \\ aan de Rijksuniversiteit Limburg te Maastricht, \\ op gezag van de Rector Magnificus, Prof. mr. M.J. Cohen, \\ volgens het besluit van het College van Dekanen, \\ in het openbaar te verdedigen \\ op woensdag 19 juni 1996 om 14.00 uur
}

door

Hendrika Johanna Gerarda van den Berg-Emons

geboren op 14 januari 1966 te Oploo 


\section{Promotores:}

Prof. dr. ir. W.H.M. Saris

Prof. dr. A. Huson (Technische Universiteit Eindhoven)

\section{Co-promotor:}

Dr. M.A. van Baak

\section{Beoordelingscommissie:}

Prof. dr. H. Kuipers (voorzitter)

Prof. W.H. Dietz (New England Medical Center, Boston)

Prof. dr. J. Drukker

Dr. I. de Groot (Revalidatie Centrum Amsterdam)

Prof dr. ir. J.D. Janssen

Het onderzoek beschreven in dit proefschrift werd mede mogelijk gemaakt door subsidies van:

- 'Moederstichting ter Behartiging van de Belangen van het Gebrekkige kind'

- 'De Drie Lichten' 


\section{Contents}

Chapter 1 Introduction

Chapter 2 Daily physical activity of school children with spastic diplegia and of healthy control subjects

Chapter 3 Heart rate monitoring to assess energy expenditure in children with reduced physical activity

Chapter 4 Skinfold measurements in cerebral palsy and healthy controls

Chapter 5 Reliability of tests to determine peak aerobic power, anaerobic power, and isokinetic muscle strength in spastic cerebral palsied children and healthy controls

Chapter 6 General description of the training study

Chapter 7 Physical training of school children with spastic cerebral palsy: effects on daily physical activity and fat mass

Chapter 8 Physical training of school children with spastic curebral palsy: effects on aerobic power, anaerobic power and isokinetic muscle strength

Chapter 9 Physical training of school children with spastic cerebral palsy: effects on spasticity and mechanical efficiency

Chapter 10 General discussion and conclusions

Summary

Samenvatting

Abbreviations

Nawoord

Curriculum vitae

Publications 
-

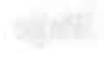

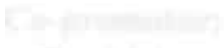

Thas

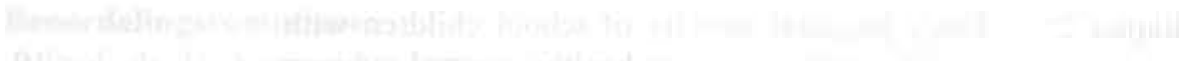

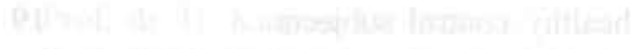

11. 


\section{Introduction}

Cerebral palsy (CP) is the most common motor disorder in childhood (47), with birth prevalence rates close to 2 per 1000 (44). Ingram (32) published in 1966 the following definition: ' $\mathrm{CP}$ is an inclusive term used to describe a number of chronic, non-progressive disorders of motor function, which occur in young children as a result of disease of the brain.' In spite of the wide variety of the clinical picture, all cases of $\mathrm{CP}$ have an abnormal muscle tone and impaired coordination of muscle action, resulting in inability to maintain normal balance, perform normal purposeful movements and acquire normal skills (12). The spastic form, characterized by a velocity-dependent increase in tonic stretch reflexes with exaggerated tendon jerks (34), accounts for approximately two-third to threequarter of all children with $\mathrm{CP}(27)$.

Beside the disturbed development of motor skills, associated disorders such as visual, hearing, and cognitive deficits, speech and language difficulties, epilepsy and parietal sensory deficits frequently exist (3). Therefore, the management of $\mathrm{CP}$ involves much more than that of a motor deficit. A team approach is needed, the skills and experience of pediatrician, physiotherapist, speech therapist, psychologist, teacher, ophthalmologist. ear, nose and throat and orthopedic surgeon being combined to facilitate the child's optimal development (14).

Many potential insults to the immature brain may cause cerebral palsy. However, often the cause is uncertain. The factors involved may be classified as prenatal, perinatal, or postnatal $(3,12,14,43,59)$. Prenatal factors include antepartum hemorrhage, toxemia of pregnancy, intra-uterine infections and cerebral maldevelopment. Factors operating at the time of birth and in the newborn period include difficult, prolonged and traumatic delivery, neonatal asphyxia, jaundice, and hypoglycemia. Prematurity, postmaturity and multiple pregnancy are also important factors. Trauma and infections of the nervous system (meningitis, encephalitis, brain abscess) are among postnatal causes (14). 


\section{Negative spiral}

Subjects with spastic CP have a distinctly subnormal aerobic power, anaerobic power, and mechanical efficiency (ME) in comparison with healthy peers $(5,7,15,16,20,21,33,38-40,45)$. Directly measured maximal aerobic power is 10 to $30 \%$ lower than in controls $(4,39,40)$. Children with moderate to severe $C P$ have values for anaerobic power 3 to 4 SDs below the normal mean (45). ME in CP has been found to be about $15 \%(33,38)$, whereas ME in healthy controls is on average $22-25 \%(5,38)$. Low muscle force has also been reported $(15,18)$.

The low general fitness and reduced $\mathrm{ME}$ in $\mathrm{CP}$ is partly a direct consequence of the motor disorder, but also low physical activity (PA) may be an important causal factor. This low PA might also explain the frequently observed adiposity in CP $(2,9,15,22,24,48)$. Gradually then, a negative spiral may develop: hypoactivity $\rightarrow$ reduction in functional ability and increase in body fat $\rightarrow$ further hypoactivity. Besides detrimental effects on the performance of activities, low PA may also affect normal growth and increase the chance for developing coronary heart disease $(\mathrm{CHD})$ in later life.

Therefore, it can be hypothesized that increasing the level of daily PA in CP children by special sports programs, may be a valuable therapeutic measure in addition to the traditional rehabilitation programs. However, before introducing such programs in the CP population, it has to be established whether and to what extent hypoactivity exists in young $\mathrm{CP}$ children. It seems logical to assume that C.P children, and particularly the more severely affected, have low levels of daily PA. However, a handicapped child with motor difficulties, experiences physical strain no matter what gross activity he or she attempts. Therefore. total daily energy expenditure (TEE) in these children may be higher than expected from their activity pattern; even 'relative' hyperactivity may exist. Adding sports programs to the traditional rehabilitation programs might then result in excess activity and consequently overload of the handicapped locomotor system.

In young children with $\mathrm{CP}$, comparison of the level of PA with that of healthy peers has not been performed. The only study on PA we are aware of is that of Bandini et al. (2) in CP adolescents (15-20 years). It was concluded that the ratio of TEE to resting metabolic rate (TEE/RMR, an index for the level of daily PA) in nonambulatory $\mathrm{CP}$ subjects was significantly lower than in healthy controls; PA levels in ambulant CP adolescents were found to be normal. Since pre-adolescent children have more leisure time, and thus much more opportunities to be physically active, it is of importance to evaluate whether lack of PA is common among this age group.

\section{Level of daily PA}

TEE is usually divided into 3 major compartments: 1] basal, resting, or sleeping metabolic rate (respectively BMR, RMR, SMR), 2] diet induced thermogenesis (DIT), and 3] the energy costs of PA. 
The terms BMR, RMR, and SMR all refer to energy exchange, measured under similar, but nevertheless somewhat different conditions. BMR is defined as the energy expenditure measured in the postabsorptive state under highly standardized conditions (46) and accounts for $60-75 \%$ of TEE (49). RMR is the energy expenditure required by the body in a resting state; SMR is defined as the energy expenditure measured during a period of sleep. Differences measured between BMR, SMR, and RMR in adults are small (29).

DIT is the increase in energy expenditure as a result of food intake (28), and makes up about $10 \%$ of TEE (49). The increase in energy expenditure after food ingestion is due to the energy cost of digestion, transformation and storage of the ingested nutrients, and a facultative component resulting from stimulation of sympathetic nervous system activity.

Energy expenditure for PA is the most variable factor contributing to TEE. In inactive humans the energy expended on PA is about $15 \%$ of TEE, while this can be $30 \%$ or even more in individuals who are regularly engaged in exercise.

In the present thesis, ratios of TEE to SMR and TEE to RMR were used as an index for the level of daily PA. SMR was measured in a respiration chamber, RMR was measured by means of a ventilated hood.

\section{Measurement of TEE in CP}

Measuring habitual daily PA is one of the most difficult tasks for the physiologist (54). Obtaining information on habitual PA in young children is even more complicated than in adults. In order to record movements of everyday lite, the child must be burdened with equipment for measuring a number of body functions. However, the child's normal daily activities should not be hindered.

PA can be quantified by determining energy expenditure. At the moment, the most promising field technique for measuring TEE is the doubly labeled water (DLW) technique $(50,60)$. It may bridge the gap between very precise but restrictive methods such as the respiration chamber technique and most of the current field methods which are liable to substantial errors (53). The technique measures TEE over longer periods of time by assessing the difference in disappearance rates of two stable isotopes, ${ }^{18} \mathrm{O}$ and ${ }^{2} \mathrm{H}$ (35). The method is very well applicable to children, because the disturbance is minimised to only drinking a glass of water and the collection of some urine samples. However, for largescale application the method is limited because of the relatively high cost of a single dose of doubly labeled water and the need of an expensive, highly sensitive mass-spectrometer. Furthermore, the technique provides only an overall estimate of energy expenditure for the entire observation period (54).

Heart rate (HR) monitoring is a simple and inexpensive method with little encumbrance to the subject, especially with the new developments in microelectronics. Therefore, HR monitoring has become one of the most commonly employed methods in PA studies in children (54). However, HR is not expected to be a good parameter for the prediction of oxygen uptake in inactive subjects, 
because of the influence of several factors (emotional stress, posture) on particularly the low ranges of the HR-oxygen uptake relation $(13,17)$. Therefore, it might be hypothesized that the HR method is unsuitable to predict TEE in CP children. No studies are available concerning the validity of HR monitoring to predict TEE in subjects with extremely low levels of daily PA.

\section{Measurement of body composition in $\mathrm{CP}$}

In view of the higher risk for adiposity in CP $(2,9,15,22,24,48)$ and concomitant health risks $(1,31)$, information on body composition in this population is of great importance. Because the skinfold method $(23,56)$ requires minimal subject cooperation, is of low cost and technically simple, it may be appropriate to assess body composition in CP children. The method seems to provide reasonably good estimates of body composition in healthy children $(19,56)$.

Based on the study of Berg and Isaksson (9), which suggests a higher hydration of fat-free mass (FFM) in CP, and reports on osteoporosis of the bones $(11,55)$, it may be expected that the density of FFM in CP children may be lower than in their healthy peers. As a consequence of this, available skinfold equations derived for healthy children $(23,56)$ may overestimate body fat $(\mathrm{BF})$ in the $\mathrm{CP}$ population.

\section{Training studies in CP - effects on body fat, physical fitness, spasticity, and mechanical efficiency (see also Table I).}

Most of the studies on training effects in CP concern older age groups, study populations are often heterogeneous and control groups are usually not included. Furthermore, training programs often last for a period of about 4 to 10 weeks, which may be too short to detect training-related changes.

\section{Body fat}

In the study of Berg (10), BF was increased significantly in $\mathrm{CP}$ children and adolescents (7-21 years) after a training program of 5 months. Training programs described in the study of Bar-Or et al. (4), showed no effects on BF. Dresen (22) also did not find changes in $\mathrm{BF}$ in $\mathrm{CP}$ children (6-14 years) after training (10 weeks), but significant increases in $\mathrm{BF}$ were seen in $\mathrm{CP}$ children who did not participate in a training program. It was therefore concluded that additional or more intensive PA can prevent an increase in BF.

\section{Aerobic power}

Several studies have indicated that predominantly aerobic training has pronounced effects on aerobic power in CP subjects. Berg (8) studied the effects of training (duration varying from 1.5 to 16 months) in severely handicapped $C . P$ children and adolescents (7-25 years), and found increases in peak oxygen uptake from 
$10 \%$ to more than $25 \%$. In a study of Bar-Or et al. (4) in CP adolescents (15-22 years), peak oxygen uptake was improved by $8 \%$ after a training program of 12 months. Lundberg et al. (36) found improvements of about $16 \%$ in CP adolescents (15-20 years) after 6 weeks of training. Fernandez and Pitetti (26) reported increases in peak oxygen uptake of $13 \%$ and $17 \%$, after an 8-week training program in respectively ambulatory $\mathrm{CP}$ men (mean age 29.6 years) and ambulatory CP women (mean age 33.0 years). Wormgoor and Gierlings (61) also reported significant improvements after a 4-week training program in $\mathrm{CP}$ adults (20-40 years). Increases in peak oxygen uptake during arm cranking and cycling were $21 \%$ and $19 \%$ respectively.

Dresen (22), who studied the effects of intensification of the physical education lessons and of one extra physical education lesson per week (duration 10 weeks) in CP children (6-14 years), found no effects on aerobic power. Rintala and Lyytinen (51) reported only slight improvements after a 4-month training program in mildly affected CP children (7-11 years). However, children in their study had been active in sports programs prior to the training study.

\section{Muscle strength}

Significant gains in muscle strength (isokinetic) were found by MacPhail and Kramer (increase in strength of knee flexors and extensors was 25\% (41)) and McCubbin and Shasby (increase in strength of elbow extensors was 59\% (42)) after a strength-training program ( 8 and 6 weeks respectively) in children and adolescents with CP (10-20 years). Also Damiano et al. (18) reported increases in strength of the quadriceps muscle (isometric) of $47 \%$ to $140 \%$ after a 6 -week resistance training program. Effects of a 4-week, predominantly aerobic, training program on isokinetic strength of the knee flexors and extensors in 20-40 year old $\mathrm{CP}$ subjects, were found to be limited (61).

\section{Spasticity}

Wormgoor and Gierlings (61) found significant reductions of spasticity (as measured by the Ashworth test) in the hips and knees after a 4-week training program in CP adults (20-40 years). However, from the study it is not clear whether this change is significantly different from the change in control subjects. Also Bausenwein et al. (6) reported improvements in tone regulation, coordination and maximal contraction (as measured by surface electromyography, EMG) after one training (walking or cycling) in spastic CP children (8-15 years). Spira (57) studied the effects of a 12-month training program on the H-reflex in 14 to 22 year old CP subjects. From the results it was suggested that a period of controlled general activities may reduce spasticity of the lower limbs. However, when the study population was enlarged and the follow-up extended to 12-30 months, the results became equivocal (58). No reductions of spasticity (as measured by surface EMG) were found by Rotzinger and Stoboy (52), after a one-year trampoline exercise program in diplegic $\mathrm{CP}$ children (6-8 years). Also MacPhail and Kramer (41) found no significant changes in spasticity (Ashworth test) after an 8-week strength-training program in $\mathrm{CP}$ adolescents (12-20 years). 


\section{Mechanical efficiency}

No effects of training on ME have been found in the studies of Bar-Or et al. (4), Ekblom and Lundberg (25), Lundberg and Pernow (37), and MacPhail and Kramer (41) in CP children and adolescents (7-25 years). Dresen (22) reported significant improvements in ME after intensification of the physical education lessons in CP children (6-14 years). No effects were found with one extra physical education lesson weekly.

No studies are available on the effects of training on level of daily PA and anaerobic performance in $\mathrm{CP}$.

\section{Outline of thesis}

Summarizing, from the literature the following major conclusions can be drawn:

1] Children with CP have a distinctly subnormal physical fitness and ME when compared with healthy peers and adiposity is frequently observed. This may partly be explained by low levels of daily PA. However, whether and to what extent hypoactivity exists in young CP children has not been studied.

2] In case hypoactivity exists in $\mathrm{CP}$, special sports programs which are tailored to the residual ability of the child, might be effective in increasing the level of daily PA and induce improvements in body composition, physical fitness, spasticity and ME. No studics are available on the effects of physical training on level of daily $\mathrm{PA}$ in CP children. Studies concerning training effects on body composition, aerobic power, muscle strength, spasticity and $\mathrm{ME}$ in $\mathrm{CP}$ are not numerous and controversial. Furthermore, most of these studies concern heterogeneous and older age groups, training programs often last for a relatively short period, and control groups are usually not included. No studies have been performed on effects of training on anaerobic power.

3] HR monitoring has become one of the most commonly employed methods in PA studies in children. Because the method is less accurate at low levels of daily PA, it might be hypothesized that HR monitoring is unsuitable to predict TEE in CP children. No studies exist on the validity of the HR method to predict TEE in subjects with extremely low levels of daily PA.

4] Skinfold measurements seem to provide reasonably good estimates of body composition in healthy children. However, because the density of FFM may be lower in CP children than in healthy controls. it might be questioned whether available skinfold equations derived for healthy children, are applicable in $\mathrm{CP}$ children to determine body composition. 


\begin{tabular}{|c|c|c|c|c|c|c|c|c|}
\hline \multirow[b]{2}{*}{ Reference } & \multirow[b]{2}{*}{$\begin{array}{c}\text { Age } \\
\text { subjects }(y)\end{array}$} & \multicolumn{2}{|c|}{ Training program } & \multicolumn{5}{|c|}{ Training effects } \\
\hline & & $\begin{array}{l}\text { Duration } \\
\text { (months) }\end{array}$ & $\begin{array}{l}\text { Frequency } \\
\text { (h per week) }\end{array}$ & $\mathrm{BF}$ & $\begin{array}{c}\text { Aerobic } \\
\text { power }\end{array}$ & $\begin{array}{l}\text { Muscle } \\
\text { strength }\end{array}$ & Spasticity & $\mathrm{ME}$ \\
\hline Bar-Or et al. 1976 (4) & $15-22$ & 12 & $2 \times 2$ & $=$ & + & & & $=$ \\
\hline Bausenwein et al. 1977 (6) & $8-15$ & 1 training & & & & & - & \\
\hline Berg $1970(8)$ & 7.25 & $1.5 \cdot 16$ & $3 \times 1 / 3$ & & + & & & \\
\hline Berg $1970(10)$ & $7-21$ & 5 & $3 \times 1 / 3$ & + & & & & \\
\hline Damiano et al. $1995(18)^{\circ "}$ & $6-14$ & 1.5 & $3 \times ?$ & & & + & & \\
\hline Dresen $1983(22)$ & $6-14$ & 2.5 & + & $=\S$ & $=$ & & & + \\
\hline Dresen $1983(22)$ & $6-14$ & 2.5 & T & $=\$$ & $=$ & & & $=$ \\
\hline Ekblom \& Lundberg 1968 (25) & $18-24$ & 1.5 & $2 \times 1 / 2$ & & & & & $=$ \\
\hline Femandez \& Pitetti 1993 (26) & $29-33$ & 2 & $2 \times 1 / 2$ & & + & & & \\
\hline Lundberg et al. 1967 (36) & $15-20$ & 1.5 & $2 \times 1 / 2$ & & + & & & \\
\hline Lundberg \& Pernow 1970 (37) & $15-25$ & 1.5 & $2 \times 1 / 2$ & & & & & $=$ \\
\hline MacPhail \& Kramer 1995 (41) & $12-20$ & 2 & $3 \times 3 / 4$ & & & + & $=$ & $=$ \\
\hline McCubbin \& Shasby 1985 (42) ${ }^{\bullet "}$ & $10-20$ & 1.5 & $3 \times ?$ & & & + & & \\
\hline Rintala \& Lyytinen 1988 (51) & $7-11$ & 4 & $2 \times 1$ & & $=/+$ & & & \\
\hline Rotzinger \& Stoboy 1974 (52) & $6-8$ & 12 & $?$ & & & & $=$ & \\
\hline Spira \& Bar-Or 1975 (58) & $14-22$ & $12-30$ & $2 \times 1-11 / 2$ & & & & $=$ & \\
\hline Worngoor \& Gierlings 1989 (61) & $20-40$ & 1 & $7.5-17.5$ & & + & $=$ & - & \\
\hline
\end{tabular}

• + increase; - decrease; = unchanged; =/+ slight improvement; " strength-training program

$\dagger$ intensification of school physical education lessons ( 2 per week); 9 one extra physical education lesson ( 3 per week); ${ }^{8}$ in controls increase in BF 
In the present thesis, each of these issues will be addressed. The studies described are focussed on 6 to 13 year old CP children with spastic diplegia (lower limbs are more affected than upper limbs, 30) and spastic tetraplegia (upper limbs are affected in the same degree as or more severely than lower limbs, 30). Each child has the same index number throughout the studies.

In order to determine whether special PA programs are needed in the $\mathrm{CP}$ population, a study was conducted to assess the difference in the level of daily PA between children with spastic CP and healthy controls. TEE in this part of the thesis was determined by the doubly labeled water technique. The results of this study are described in chapter 2 .

Prior to the description of the training effects, the validity and reliability of some of the used techniques is described (chapters 3 to 5). Chapter 3 reports on the usefulness of the HR method to predict TEE in CP children. TEE estimated from HR monitoring was compared with TEE determined by the doubly labeled water technique. In chapter 4, BF estimated from skinfold measurements is compared with $\mathrm{BF}$ determined from total body water measurement with the deuterium dilution $\left(\mathrm{D}_{2} \mathrm{O}\right)$ technique. Measurements were performed in both $\mathrm{CP}$ and healthy children. Chapter 5 describes the results of a study in which the reliability of tests to determine aerobic power, anaerobic power and isokinetic strength of the knee extensors and flexors was established (in both $\mathrm{CP}$ and healthy children). Also, fitness parameters in the CP children were compared with those in their healthy counterparts.

Effects of the training study (experimental controlled design) are presented in chapters 6 to 9. In chapter 6 the general design of the training study and the study population is described. The study lasted 2 years and included two 9 -month training programs, lasting from October till June/July. The first program was rather strenuous, with four 45-min exercise sessions per week (during school time). This high frequency was chosen to increase the chance of detecting training effects. The second program was, with 2 sessions weekly, practically more feasible. Training activities were aimed at exercise with large muscle groups. Chapter 7 reports on the effects of training on the level of daily PA (TEE estimated from HR) and fat mass (FM); chapter 8 on the effects on aerobic power, anaerobic power, and isokinetic strength of the knee extensors and flexors; chapter 9 on the effects on spasticity (during passive and active movements) and $\mathrm{ME}$ (during cycling and arm cranking).

\section{References}

1. Aristimuno, G. G., T. A. Foster, A. W. Voors, S. R. Srinivasan, G. S. Berenson. The influence of persistent obesity in children on cardiovascular risk factors: the Bogalusa Heart Study. Circulation 69:895-904, 1984.

2. Bandini, L. G., D. A. Schoeller, N. K. Fukagawa, L. J. Wykes, W. H. Dietz. Body composition and energy expenditure in adolescents with cerebral palsy or myelodysplasia. Pediatr. Res. 29:70-77, 1991.

3. Barabas, G., L. T. Taft. The early signs and differential diagnosis of cerebral palsy. Pediatr. Ann. 15:203-214, 1986. 
4. Bar-Or, O., O. Inbar, R. Spira. Physiological effects of a sports rehabilitation program on cerebral palsied and post-poliomyelitic adolescents. Med. Sci. in Sports 8:157-161, 1976.

5. Bar-Or, O. Pediatric sports medicine for the practitioner. From physiologic principles to clinical applications. New York: Springer Verlag, 1983.

6. Bausenwein, I., P. Reeh, D. Stadler. Sport als Therapie bei Cerebralparesen. Schriftenreihe des Bundesministers fur Jugend, Familie und Gesundheid 38, 1977.

7. Berg, K., J. Bjure. Methods for evaluation of the physical working capacity of school children with cerebral palsy. Acta Paediatr. Scand. 204(suppl):15-26, 1970.

8. Berg, K. Effect of physical training of school children with cerebral palsy. Acta Paediatr. Scand. 204(suppl):27-33, 1970.

9. Berg, K., B. Isaksson. Body composition and nutrition of school children with cerebral palsy. Acta Paediatr. Scand. 204(suppl):41-52, 1970.

10. Berg, K. Effect of physical activation and of improved nutrition on the body composition of school children with cerebral palsy. Acta Paediatr. Scand. 204(suppl):53-69, 1970.

11. Bleck, E. E. Orthopaedic management in cerebral palsy. Philadelphia: Lippincott, 1987.

12. Bobath, K. The neuropathology of cerebral palsy and its importance in treatment and diagnosis. Cerebral Palsy Bulletin 8:13-33, 1959.

13. Booyens, J., G. R. Hervey. The pulse rate as a means of measuring metabolic rate in man. Can. J. Biochem. Physiol. 38:1301-1309, 1960.

14. Brimblecombe, F., D. Bartrop. Children in health and disease. Ballière Tindall, 1978.

15. Brown, A. Review: physical fitness and cerebral palsy. Child: care, health and development 1:143-152, 1975.

16. Campbell, J., J. Ball. Energetics of walking in cerebral palsy. Orthopedic Clinics of North America 9:374-377, 1978.

17. Christensen, C. C., H. M. M. Frey, E. Foenstelien, E. Aadland, H. E. Refsum. A critical evaluation of energy expenditure estimates based on individual $\mathrm{O}_{2}$ consumption / heart rate curves and average daily heart rate. Am. J. Clin. Nutr. 37:468-472, 1983.

18. Damiano, D. L., C. L. Vaughan, M. F. Abel. Muscle response to heavy resistance exercise in children with spastic cerebral palsy. Devel. Med. Child Neurol. 37:731-739, 1995.

19. Deurenberg, P., J. J. L. Pieters, J. G. A. J. Hautvast. The assessment of the body fat percentage by skinfold thickness measurements in childhood and young adolescence. Brit. J. Nutr. 63:293-303, 1990.

20. Dresen, M. H. W., H. Vermeulen, B. J. Netelenbos, H. Krot. Physical work capacity and classroom attention of handicapped and non-handicapped children. Int. J. Rehabil. Res. 5:5$12,1982$.

21. Dresen, M. H. W., G. de Groot, J. J. Brandt Corstius, G. H. B. Krediet, M. G. H. Meyer. Physical work capacity and daily physical activities of handicapped and non-handicapped children. Eur. J. Appl. Physiol. 48:241-251, 1982.

22. Dresen, M. H. W. Physical training of handicapped children. Physical and psychological effects. [Thesis] Amsterdam, 1983.

23. Durnin, J. V. G. A., M. M. Rahaman. The assessment of the amount of fat in the human body from measurements of skinfold thickness. Brit. J. Nutr. 21:681-689, 1967.

24. Eddy, T. P., A. L. Nicholson, E. F. Wheeler. Energy expenditures and dietary intakes in cerebral palsy. Dev. Med. Child Neurol. 7:377-386, 1965.

25. Ekblom, B., A. Lundberg. Effect of physical training on adolescents with severe motor handicaps. Acta Paediatr. Scand. 57:17-23, 1968.

26. Fernandez, J. E., K. H. Pitetti. Training of ambulatory individuals with cerebral palsy. Arch. Phys. Med. Rehabil. 74:468-472, 1993.

27. Gamstorp, I. Pediatric Neurology. London: Butterworths, 1985.

28. Garrow, J. R. Energy balance and obesity in man. Ansterdam: Elsevier/North-Holland Publishers, 1974.

29. Goldberg, G. R., A. M. Prentice, H. L. Davies, P. R. Murgatroyd. Overnight and basal metabolic rates in men and women. Eur. J. Clin. Nutr. 42:137-144, 1988. 
30. Hagberg, B., G. Hagberg, 1. Olow. The changing panorama of cerebral palsy in Sweden 1954-1970. Acta Paediatr. Scand. 64:187-192, 1975.

31. Havlik, R. J., H. B. Hubert, R. R. Fabsitz, M. Feinleib. Weight and hypertension. Ann. Intern. Med. 98(2):855-859, 1983.

32. Ingram, T. T. S. The neurology of cerebral paisy. Arch. Dis. Child 41:337-356, 1966.

33. Jones, J., J. F. McLaughlin. Mechanical efficiency of children with spastic cerebral palsy. Dev. Med. Child Neurol. 35:614-620, 1993.

34. Lance, J. W. Symposium synopsis. In: Feldman, R. G., R. R. Young, W. P. Koella (Eds) Spasticity: disordered motor control. Chicago: Year Book Medical Publications, 1980.

35. Lifson, N.; R. McClintock. Theory of use of the turnover rates of body water for measuring energy balance and material balance. $J$. Theoret. Biol. 12:46-74, 1966.

36. Lundberg, A., C-O. Ovenfors, B. Saltin. Effect of physical training on school children with cerebral palsy. Acta Paediatr. Scand. 56:182-188, 1967.

37. Lundberg, A., B. Pernow. The effect of physical training on oxygen utilization and lactate formation in the exercising muscle of adolescents with motor handicaps. Scand. $J$. Clin. Lab. Inv. 26:89-96, 1970.

38. Lundberg, A. Mechanical efficiency in bicycle ergometer work of young adults with cerebral palsy. Dev. Med. Child Neurol. 17:434-439, 1975.

39. Lundberg, A. Maximal aerobic capacity of young people with spastic cerebral palsy. Dev. Med. Child Neurol. 20:205-210, 1978.

40. Lundberg, A. Longitudinal study of physical working capacity of young people with spastic cerebral palsy. Dev. Med. Child Neurol. 26:328-334, 1984.

41. MacPhail, H. E. A., J. F. Kramer. Effect of isokinetic strength training on functional ability and walking efficiency in adolescents with cerebral palsy. Dev. Med. Child Neurol. 37:763$775,1995$.

42. McCubbin, J. A., G. B. Shasby. Effects of isokinetic exercise on adolescents with cerebral palsy. Adapted Physical Activity Quarterly' 2:56-64, 1985.

43. Minear, W. L. A classification of cerebral palsy. Pediatrics 18:841-852, 1954.

44. Paneth, N., J. Kiely. The frequency of cerebral palsy: a review of population studies in industrialised nations since 1950. In: Stanley, F., E. Alberman (Eds.) The epidemiology of the cerebral palsies. Clinics in Developmental Medicine No. 87. Philadelphia: Lippincott: 46-56, 1984.

45. Parker, D. F., L. Carriere, H. Hebestreit, O. Bar-Or. Anaerobic endurance and peak muscle power in children with spastic cerebral palsy. Am. J. Dis. Child. 146:1069-1073, 1992.

46. Passmore, R., M. A. Eastwood. Human nutrition and dietitics. Edinburgh: Churchill Livingstone, 1986.

47. Pharoah, P. O. D. The epidemiology of chronic disability in childhood. Int. Rehab. Med. 7:11-17, 1985.

48. Phelps, W. M. Dietary requirements in cerebral palsy. J. Am. Diet. Assoc. 27:869-876, 1951.

49. Poehlmann, E. T., S. Horton. Regulation of energy expenditure in aging humans. Annu. Rev. Nutr. 10:255-275, 1990.

50. Prentice, A. M. (Ed). The doubly labeled water method for measuring energy expenditure, technical recommendations for use in humans. A consensus report by the IDECG working group. Vienna: Int. Atomic Energy Agency, 1990.

51. Rintala, P., H. Lyytinen. De effecten van lichamelijke activiteiten op de lichamelijke conditie en motorische vaardigheden bij kinderen met infantiele encephalopathie. Bewegen \& Hulpverlening 3:200-207, 1988 [Dutch].

52. Rotzinger, H., H. Stoboy. Comparison between clinical judgement and electromyographic investigations of the effect of a special training program for CP-children. Acta Paediatr. Belgica 28(suppl):121-128, 1974. 
53. Saris, W. H. M. The assessment and evaluation of daily physical activity in children. A review. Acta Paediatr. Scand. 318(suppl):37-48, 1985.

54. Saris, W. H. M. Habitual physical activity in children: methodology and findings in health and disease. Med. Sci. Sports Exerc. 18:253-263, 1986.

55. Shaw, N. J., C. P. White, W. D. Fraser, L. Rosenbloom. Osteopenia in cerebral palsy, Arch. Dis. Child. 71:235-238, 1994.

56. Slaughter, M. H., T. G. Lohman, R. A. Boileau, C. A. Horswill, R. J. Srillman, M. D. van Loan, D. A. Bemben. Skinfold equations for estimation of body fatness in children and youth. Hum. Biol. 60(5):709-723, 1988.

57. Spira, R. Contribution of the H-reflex to the study of spasticity in adolescents. Dev. Med. Child Neurol. 16:150-157, 1974.

58. Spira, R., O. Bar-Or. An investigation of the ambulation problems associated with severe motor paralysis in adolescents. Influence of physical conditioning and adapted sports activities. Final report. Tel-Aviv: Z. Sohar-Cohen, 1975.

59. Stanley, F. J. The aetiology of cerebral palsy. Review article. Early Hum. Dev. 36:81-88, 1994.

60. Westerterp, K. R., H. N. Lafeber, E. J. Sulkers, P. J. J. Sauer. Comparison of short term indirect calorimetry and doubly labeled water method for the assessment of energy expenditure in preterm infants. Biol. Neonate 60:75-82, 1991.

61. Wormgoor, M. E. A., Y. H. J. Gierlings. Revalidatie van lichamelijk gehandicapten met behulp van sportactiviteiten in Noorwegen. Bewegen \& Hulpverlening 3:219-238, 1989 [Dutch]. 


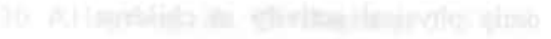

74:

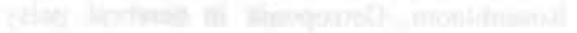




\title{
Daily physical activity of school children with spastic diplegia and of healthy control subjects
}

H. J. (i. van den Berg-Emons', W. H. M. Saris, D. C. de Barbanson', K. R. Westerterp ${ }^{2}$, A. IIuson!, and M. A. van Baak ${ }^{2}$

Departments of Movement Sciences' and Human Biology". I Iniversity of I imburg. PO Box 616. 6200 MD, Maastricht, The Netherlands

J. Pediatr. 127:578-584, 1995.

\begin{abstract}
To assess whether school children with spastic cerebral palsy $(\mathrm{CP})$ need extra physical exercise to achieve sufficient levels of daily physical activity (PA), activity levels of these children were compared with those of healthy controls. Total daily energy expenditure (TEE) and sleeping metabolic rate (SMR) were meisured by the doubly labeled water (DLW) technique and respiration chamber in children with spastic diplegia (5 boys and 5 girls; mean $\pm \mathrm{SD}$ age $8.0 \pm 1.4 \mathrm{y}$; 9 ambulant, 1 wheelchair-bound) and in healthy children (5 boys and 5 girls; mean \pm age $8.4 \pm 1.0 \mathrm{y}$ ). TEE/SMR was used as an index for the level of daily PA. TEE/SMR under normal daily conditions in the CP children (mean $\pm \mathrm{SD}$ $1.56 \pm 0.19)$ was significantly lower $(\mathrm{p}<0.05)$ than in their healthy peers (mean \pm SD $1.83 \pm 0.23$ ) and was similar to TEE/SMR in a room-sized chamber. We conclude that children with spastic diplegia are considerably less active than their healthy peers and recommend special PA programs in this population.
\end{abstract}

\section{Introduction}

Disease often causes hypoactivity, which in turn leads to a reduction in functional ability and further hypoactivity (2). A tendency to fatigue and weak muscles is 
characteristic of spastic cerebral palsy (CP) $(4,5)$. Directly measured maximal aerobic power of children and adolescents with $\mathrm{CP}$ is 10 to $30 \%$ lower than in controls (2). An excess of body fat (BF) in children with $\mathrm{CP}$ has also been reported $(8,19)$.

Hypoactivity may partly cause this decreased physical fitness and sports programs might therefore be effective in children with CP. However, whether and to what extent hypoactivity is a problem in young $\mathrm{CP}$ children is not clear. Because of the probably high physiologic stress of ordinary functional activities, such as ambulation, climbing stairs and wheelchair-driving, total daily energy expenditure (TEE) in CP children might be higher than expected from their activity pattern; it is possible that 'relative' hyperactivity may exist. Adding physical exercise to the normal school activities and therapy program might then result in excess activity and consequently reduce the functional abilitity of the child.

Bandini et al. (1) measured resting metabolic rate (RMR) and TEE in adolescents with $\mathrm{CP}$, using a ventilated hood and the doubly labeled water (DLW) technique; they concluded that the ratio of TEE to RMR in nonambulatory CP subjects was significantly lower than in healthy controls. In young children with $\mathrm{CP}$, systematic comparison of physical activity (PA) with that of healthy controls has not been done. Since pre-adolescent children have much more leisure time, it is of importance to evaluate whether lack of PA is also common among this age group. Therefore, the aim of the present study was to assess the difference in daily PA between children with spastic CP (diplegia) and healthy school children to determine whether special PA programs are needed in the CP population.

\section{Subjects and methods}

\section{Subjects}

Ten CP children ( 5 boys and 5 girls) with spastic diplegia (legs and feet more affected than arms and hands, classification according to Hagberg (in Olow and Berg, 18) and 10 healthy children ( 5 boys and 5 girls) volunteered to participate. In 2 children, the diplegia was combined with ataxia. Nine $\mathrm{CP}$ children were ambulant; one was wheelchair-bound. Seven CP children were day-students at the elementary school at the children's rehabilitation center Franciscusoord (normal intelligence and mild mental retardation); the other $3 \mathrm{CP}$ children and all the healthy children were from elementary schools in and around Maastricht (normal intelligence). All children were Caucasian and between 6 and 10 years of age. The children and their parents were informed of all aspects of the study and written consent was obtained. The study was approved by the Medical Ethics Committee of the University of Limburg.

\section{Energy expenditure measurements}

TEE in normal daily conditions $\left(\mathrm{TEE}_{\mathrm{dlw}}\right)$ was measured using the doubly labeled water $\left({ }^{2} \mathrm{H}_{2}{ }^{18} \mathrm{O}\right)$ technique (15), which measures TEE over longer periods of time 
by assessing the difference in disappearance rates of two stable isotopes, ${ }^{18} \mathrm{O}$ and ${ }^{2} \mathrm{H}$. Measurements were performed in the spring, between April and June, during a normal school period, according to the method described by Westerterp et al. (33). Individually calculated doses (mixture of 5 atom percent ${ }^{2} \mathrm{H}_{2} \mathrm{O}$ and 10 atom percent $\mathrm{H}_{2}{ }^{18} \mathrm{O}$ ), which were expected to create an excess of about $350 \mathrm{ppm}{ }^{18} \mathrm{O}$ and $265 \mathrm{ppm}{ }^{2} \mathrm{H}$ in the body water in the healthy children $(3.9 \mathrm{~g}$ per L body water) and about $300 \mathrm{ppm}{ }^{18} \mathrm{O}$ and $150 \mathrm{ppm}{ }^{2} \mathrm{H}$ in the $\mathrm{CP}$ children $(3.5 \mathrm{~g}$ per L body water), were administered orally to the children in the evening, after a baseline urine sample was collected. Different doses were used in the healthy children and $\mathrm{CP}$ children because in the course of the study we found that lower (and therefore less expensive) isotope doses were as accurate in the assessment of TFE as the originally used relatively high doses. To avoid spillage of isotope due to oral motor problems (CP children), a straw was used and children were asked to drink the water slowly. After emptying the dosage bottle it was rinsed with 50 $\mathrm{ml}$ tap water which was consumed through the same straw. In none of the children loss of isotope was observed. Further urine samples were collected on day 1 in the morning after the first voiding, and in the evening at $19 \mathrm{~h}$ on days 1 , $7,8,14$ and 15 . It was assumed that the children were in a steady state of body composition during the two weeks of measurement. Isotopes in the urine samples were measured in duplicate with an isotope ratio mass spectrometer (Aqua Sira, VG Isogas. Middlewich, Cheshire, England). The ${ }^{18} \mathrm{O}$ analyses were reproducible within $0.4 \mathrm{ppm}$ and ${ }^{2} \mathrm{H}$ within $0.2 \mathrm{ppm}$. Excesses of ${ }^{18} \mathrm{O}$ ranged from 304 to 348 $\mathrm{ppm}$ in the CP children and from 261 to $423 \mathrm{ppm}$ in the healthy children. Excesses of ${ }^{2} \mathrm{H}$ ranged from 153 to $174 \mathrm{ppm}$ (CP group) and from 185 to 285 ppm (healthy group). Mean $\mathrm{TEE}_{\mathrm{dlw}}$ over 14 days was calculated using an estimated fixed respiratory quotient (RQ) of 0.85 and the equation (25):

$\mathrm{r}_{\mathrm{CO} 2}=(\mathrm{N} / 2.078)\left(1.01 \mathrm{k}_{\mathrm{O}}-1.04 \mathrm{k}_{\mathrm{H}}\right)-0.0264 \mathrm{r}_{\mathrm{Git}}$,

where $\mathrm{r}_{\mathrm{CO} 2}=\mathrm{CO}_{2}$ production rate $(\mathrm{mol} / \mathrm{d}), \mathrm{N}=$ total body water $(\mathrm{mol}) ; \mathrm{k}_{\mathrm{O}}=$ elimination rate ${ }^{18} \mathrm{O} ; \mathrm{k}_{\mathrm{H}}=$ elimination rate ${ }^{2} \mathrm{H} ; \mathrm{r}_{\mathrm{Gr}}=$ correction factor for evaporative water loss, estimated by formula $\mathrm{r}_{\mathrm{Gf}}=1.05 \mathrm{~N}\left(\mathrm{k}_{\mathrm{O}}-\mathrm{k}_{\mathrm{H}}\right)$.

TEE in laboratory conditions ( $\mathrm{TEE}_{\mathrm{cal}}$ ) was measured in all the healthy children and in $6 \mathrm{CP}$ children ( 4 boys and 2 girls) during a 24h stay in a respiration chamber. In $4 \mathrm{CP}$ children it was not possible to perform $24 \mathrm{~h}$ measurements because they needed care or did not want to stay in the chamber for a day and night. The respiration chamber (26), an open-circuit indirect calorimeter $\left(14 \mathrm{~m}^{3}\right)$, was furnished with a bed, chair, table, TV, telephone, intercom and toilet. Air temperature was maintained at $20{ }^{\circ} \mathrm{C}$ during the day and at $18{ }^{\circ} \mathrm{C}$ during the night. The chamber was ventilated with fresh air at about $40 \mathrm{~L} / \mathrm{min}$. Volume of the outgoing air was determined by means of a dry gas meter (Schlumberger type G6, Dordrecht. The Netherlands) and gas was analyzed with a paramagnetic $\mathrm{O}_{2}$ analyzer (Servomex type OA 184, Crowborough. England) and an infrared $\mathrm{CO}_{2}$ analyzer (Hartman \& Braun type URAS 3G, Frankfurt, Germany). An on-line micro-computer controlled the gas sampling system and calculated $\mathrm{TEE}_{\mathrm{cal}}$ automatically according to Weir (31):

$\mathrm{E}(\mathrm{kcal})=3.9 \times \mathrm{O}_{2}(\mathrm{~L})+1.1 \times \mathrm{CO}_{2}(\mathrm{~L})$, 
where $\mathrm{E}=$ energy expenditure, $\mathrm{O}_{2}=$ oxygen consumption and $\mathrm{CO}_{2}=$ carbon dioxide production.

To make the daily programs as uniform as possible, activities such as board games, drawing and watching TV were scheduled. Food was offered at libitum according to the normal diet at fixed times.

Sleeping metabolic rate (SMR) was measured in the $10 \mathrm{CP}$ children and the 10 healthy children in the respiration chamber from $3.00 \mathrm{~h}$ to $6.00 \mathrm{~h}$, when subjects were asleep.

Level of daily PA. The ratio of TEE to SMR was calculated and used as an index for the level of daily PA in the calorimeter $\left(\mathrm{TEE}_{\mathrm{cal}} / \mathrm{SMR}\right)$ and under free-living conditions (TEE $\mathrm{diw}_{\mathrm{w}} / \mathrm{SMR}$ ).

\section{Body composition measurements}

Body weight was obtained in the morning, before the children consumed any food/drink and while wearing under-clothing, with an electronic balance (August Sauter $\mathrm{GmbH}$, Albstadt, Germany). CP children who were unable to stand upright were measured while sitting on a chair, using the same balance.

Height measurements were taken with subjects standing against a wall, or if unable to stand, while lying on a bed with a wooden T-square or a flexible tape.

Percentage $B F$ was calculated from the mean total body water (TBW), measured by ${ }^{18} \mathrm{O}$ and ${ }^{2} \mathrm{H}$ dilution spaces, assuming that the ${ }^{18} \mathrm{O}$ dilution space $=1.01$ TBW and ${ }^{2} \mathrm{H}$ dilution space $=1.04 \mathrm{TBW}$ (23), and that water is $76 \%$ (boys) and $77 \%$ (girls) of the fat-free mass (FFM) (9).

\section{Statistical analysis}

Data are expressed as mean $\pm \mathrm{SD}$. Comparisons between data were made using the Wilcoxon test for paired observations and the Mann-Whitney $U$ test lor unpaired observations $(\alpha=0.05)$. Regression techniques were used to assess the relationship between SMR and FFM and between TEE $_{\text {dlw }}$ and FFM.

\section{Results}

There were no significant differences in characteristics between the $\mathrm{CP}$ boys and $C P$ girls (Table I). The healthy girls had significantly $(p<0.05)$ more BF than the healthy boys. Body mass index (BMI) in the CP boys was significantly $(\mathrm{p}<0.05)$ higher than in the healthy boys, whereas the difference in BF between the $\mathrm{CP}$ and healthy boys was not statistically significant $(p=0.06)$. CP girls were significantly 
$(\mathrm{p}<0.05)$ fatter than the healthy girls, but BMI was similar in the girls of the two groups.

Table I. Characteristics of the CP and healthy children

\begin{tabular}{|c|c|c|c|c|c|c|}
\hline & \multicolumn{3}{|c|}{ boys } & \multicolumn{3}{|c|}{ girls } \\
\hline & $\begin{array}{c}C P \\
(n=5)\end{array}$ & & $\begin{array}{l}\text { Healthy } \\
(n=5)\end{array}$ & $\begin{array}{c}C P \\
(n=5)\end{array}$ & & $\begin{array}{l}\text { Healthy } \\
(n=5)\end{array}$ \\
\hline A.ge $(y)$ & $7.8 \pm 1.6$ & & $8.4 \pm 1.0$ & $8.2 \pm 1.2$ & & $8.4 \pm 1.0$ \\
\hline Height $(\mathrm{cm})$ & $125.5 \pm 11.4$ & & $133.3 \pm 5.7$ & $123.9 \pm 11.3$ & & $133.0 \pm 3.2$ \\
\hline Weight $(\mathrm{kg})$ & $31.0 \pm 9.3$ & & $27.8 \pm 2.5$ & $26.5 \pm 6.7$ & & $28.3 \pm 2.0$ \\
\hline $\mathrm{BMI}^{*}\left(\mathrm{~kg} / \mathrm{m}^{2}\right)$ & $19.2 \pm 2.5$ & $\dagger$ & $15.7 \pm 0.9$ & $17.0 \pm 1.7$ & & $16.0 \pm 1.4$ \\
\hline $\mathrm{TBW}^{*}(\mathrm{~L})$ & $18.5 \pm 4.4$ & & $18.2 \pm 1.6$ & $14.6 \pm 2.3$ & & $17.4 \pm 1.0$ \\
\hline Fat $(\%)$ & $20.0 \pm 5.8$ & $\S$ & $13.6 \pm 2.7$ & $26.9 \pm 6.3$ & + & $20.2 \pm 3.6$ \\
\hline $\mathrm{FFM}^{*}(\mathrm{~kg})$ & $24.4 \pm 5.8$ & & $24.0 \pm 2.0$ & $19.0 \pm 3.0$ & & $22.5 \pm 1.3$ \\
\hline $\begin{array}{l}\text { Sports } \\
(\min / w k)\end{array}$ & $78 \pm 79$ & & $126 \pm 81$ & $48 \pm 56$ & & $60 \pm 0$ \\
\hline
\end{tabular}

Values are mean \pm SD

- BMI: body mass index, TBW: total body water, FFM: fat-free mass, Sports: Organized sports activities (outside school); $\uparrow p<0.05$, significantly different between $C P$ and healthy; $\S p=0.06$

SMR in the CP group ranged from 3.2 to $7.2 \mathrm{MJ} / \mathrm{d}$ and in the healthy group from 4.2 to $5.5 \mathrm{MJ} / \mathrm{d}$. Mean SMR did not differ between the groups $(4.6 \pm 1.3 \mathrm{MJ} / \mathrm{d}$ in the $\mathrm{CP}$ children and $4.7 \pm 0.4 \mathrm{MJ} / \mathrm{d}$ in the healthy children). Respiratory quotients during sleep were similar in the $\mathrm{CP}$ group $(0.85 \pm 0.05)$ and the healthy group $(0.84 \pm 0.06)$. TEE dlw $_{\text {in }}$ in the CP group ranged from 5.0 to $10.2 \mathrm{MJ} / \mathrm{d}$ and in the healthy group from 6.9 to $11.3 \mathrm{MJ} / \mathrm{d}$. On average, $T E E_{\text {dlw }}$ was significantly $(p<0.05)$ lower in the CP children $(7.0 \pm 1.7 \mathrm{MJ} / \mathrm{d})$ than in the healthy children $(8.5 \pm 1.3 \mathrm{MJ} / \mathrm{d})$.

Figures 1 and 2 show respectively the SMR:FFM and TEE $_{\text {dlw }}$ :FFM relationships in both the CP and healthy children. The lack of correlation in the healthy children is probably due to the small range of FFM in these children (FFM in healthy children varied from 19.9 to $27.8 \mathrm{~kg}$, in $\mathrm{CP}$ children from 15.4 to 32.9 $\mathrm{kg}$ ). Because regression points of the healthy children scattered round the regression lines of the $\mathrm{CP}$ children, one regression equation was calculated for the whole study population ( $\mathrm{CP}$ and healthy children together) for the SMR:FFM relation $(\mathrm{SMR}=0.20545 \mathrm{FFM}+0.0030129 ; \mathrm{r}=0.86, \mathrm{p}<0.001)$ and for the $\mathrm{TEE}_{\mathrm{dlw}}: \mathrm{FFM}$ relation $\left(\mathrm{TEE}_{\mathrm{dlw}}=0.30347 \mathrm{FFM}+0.94451 ; \mathrm{r}=0.73, \mathrm{p}<0.001\right)$. Because the $x$ and $y$ intercepts of these regressions did not differ significantly from zero, energy expenditure (EE) was divided by FFM to make comparisons between the $\mathrm{CP}$ and healthy children. SMR per $\mathrm{kg} \mathrm{FFM} \mathrm{was} \mathrm{similar} \mathrm{in} \mathrm{both}$ groups $\left(0.21 \pm 0.02 \mathrm{MJ} / \mathrm{kgFFM} \cdot \mathrm{d}^{-1}\right.$ in the $\mathrm{CP}$ children and $0.20 \pm 0.03$ $\mathrm{MJ} / \mathrm{kgFFM}-\mathrm{d}^{-\mathrm{I}}$ in the healthy children). TEE $\mathrm{dlw}_{\mathrm{w}}$ per $\mathrm{kg}$ FFM was $0.32 \pm 0.03$ 
Fig. I. SMR versus FFM in $10 \mathrm{CP}$ children and 10 healthy controls

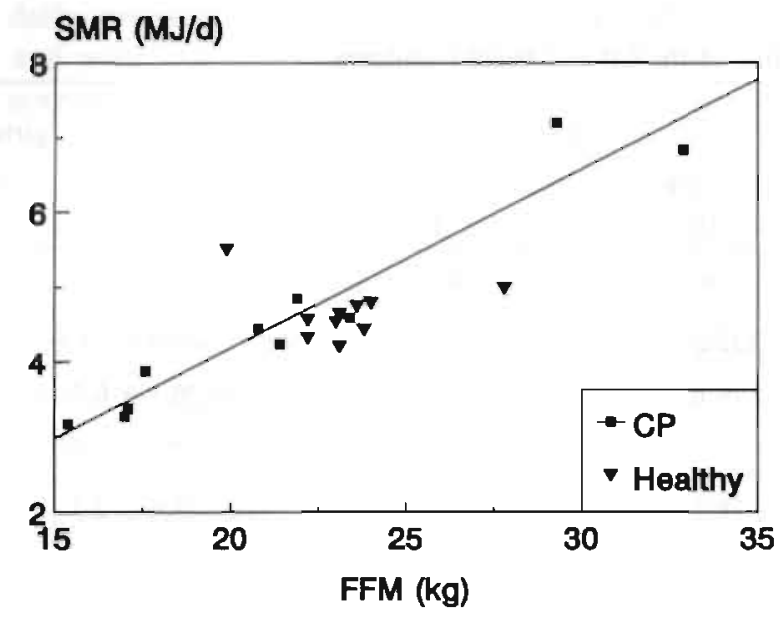

CP: $\mathrm{SMR}=0.24009 \mathrm{FFM}-0.62522 ; \mathrm{r}=0.96(\mathrm{p}<0.001)$ $\mathrm{H}: r=-0.11(\mathrm{~ns})$

Fig. 2. TEE $\mathrm{dlw}_{\mathrm{w}}$ versus FFM in $10 \mathrm{CP}$ children and 10 healthy controls

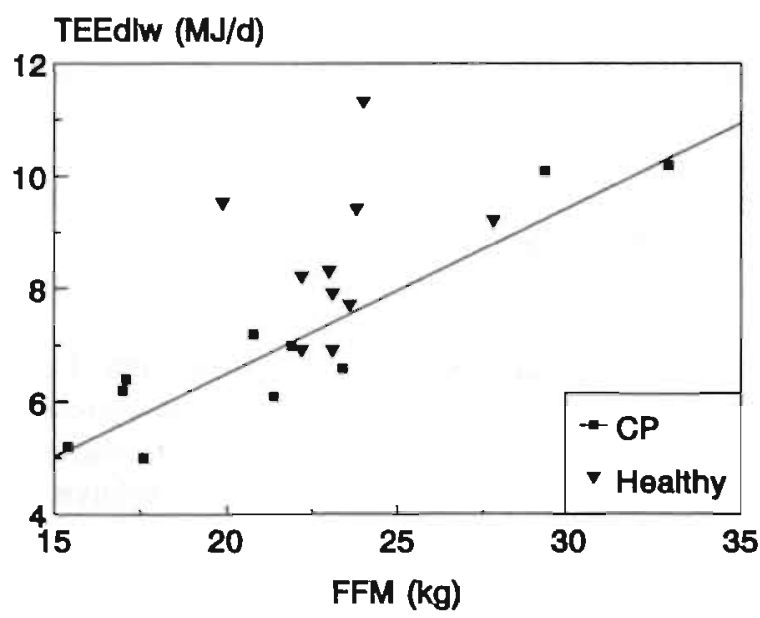

CP: TEE $_{d l w}=0.29595$ FFM $+0.58391 ; r=0.93(p<0.001)$ $\mathrm{H}: \mathrm{r}=0.19$ (ns) 
$\mathrm{MJ} / \mathrm{kgFFM} \cdot \mathrm{d}^{-1}$ in the CP children and $0.37 \pm 0.06 \mathrm{MJ} / \mathrm{kgFFM} \cdot \mathrm{d}^{-1}$ in the healthy children $(\mathrm{p}=0.13)$.

Table II shows the calculated TEE to SMR ratios in the respiration chamber and under normal daily conditions. TEE cul $/ \mathrm{SMR}$ was similar in the $\mathrm{CP}$ and healthy children. $\mathrm{TEE}_{\mathrm{dl} / \mathrm{SMR}} / \mathrm{S}$ in the healthy children was $25 \pm 17 \%$ (range $+1.8 \%$ to $+58.4 \%)$ higher $(\mathrm{p}<0.01)$ than $\mathrm{TEE}_{\mathrm{cal}} / \mathrm{SMR}$, whereas $\mathrm{TEE}_{\mathrm{dtw}} / \mathrm{SMR}$ and $\mathrm{TEE}_{\mathrm{cal}} / \mathrm{SMR}$ in the $6 \mathrm{CP}$ children did not differ $(1.47 \pm 0.07$ and $1.46 \pm 0.14$ respectively). $\mathrm{TEE}_{\mathrm{dlv}} / \mathrm{SMR}$ ranged from 1.29 to 1.90 in the $\mathrm{CP}$ group and from 1.60 to 2.36 in the healthy group, and was on average $15 \%$ lower $(p<0.05)$ in the CP group than in their healthy peers. The lowest $\mathrm{TEE}_{\mathrm{dw}} / \mathrm{SMR}$ (1.29) was found in the non-ambulant $\mathrm{CP}$ child. TEE $\mathrm{dlw}_{\mathrm{w}} / \mathrm{SMR}$ of the 9 ambulant $\mathrm{CP}$ children was $1.59 \pm 0.18$ and was significantly $(\mathrm{p}<0.05)$ lower than $\mathrm{TEE}_{\mathrm{dl} w} / \mathrm{SMR}$ of the healthy children. Four $\mathrm{CP}$ children had $\mathrm{TEE}_{\mathrm{dlw}}$ to $\mathrm{SMR}$ ratios within the range of ratios in the healthy children.

Table II. TEE to SMR ratios in the respiration chamber (TEE al $_{\text {SMR) }}$ and under normal daily conditions ( $\mathrm{TEE}_{\mathrm{dlw}} / \mathrm{SMR}$ ) in $\mathrm{CP}$ and healthy children

\begin{tabular}{llccccc}
\hline & & $\mathrm{n}$ & $\mathrm{TEE}_{\mathrm{cal}} / \mathrm{SMR}$ & & $\mathrm{TEE}_{\mathrm{dlw}} / \mathrm{SMR}$ & $\mathrm{n}$ \\
\hline \multirow{2}{*}{ Total } & $\mathrm{CP}$ & 6 & $1.46 \pm 0.14^{\circ}$ & & $1.56 \pm 0.19$ & 10 \\
& & & & & $\dagger$ & \\
& Healthy & 10 & $1.47 \pm 0.09$ & $\S$ & $1.83 \pm 0.23$ & 10 \\
\hline \multirow{2}{*}{ Boys } & $\mathrm{CP}$ & & - & & $1.57 \pm 0.18$ & 5 \\
& & & & $\uparrow$ & $\uparrow$ & \\
& Healthy & 5 & $1.46 \pm 0.05$ & $\dagger$ & $1.95 \pm 0.27$ & 5 \\
\hline & $\mathrm{CP}$ & & - & & $1.54 \pm 0.21$ & 5
\end{tabular}

Girls

Healthy $\quad 5 \quad 1.47 \pm 0.12$

$+$

$1.71 \pm 0.07$

5

Values are mean $\pm \mathrm{SD} ;{ }^{*} \mathrm{TEE}_{\mathrm{di}} / \mathrm{SMR}$ of these 6 children was (mean $\pm \mathrm{SD}$ ) $1.47 \pm 0.07$; $\dagger \mathrm{p}<0.05, \S \mathrm{p}<0.01$, . $\mathrm{p}=0.08$

\section{Discussion}

Height and weight of the healthy children in this study are representative of the Dutch population (21). The CP children tended to be smaller and were fatter than their healthy peers, in agreement with previous reports $(8,19,27)$. Because of the relatively long interval between the administration of DLW and the urine sampling (12-14 hours), BF as determined from TBW may be an underestimation of the actual BF due to gradual dilution of the isotope enrichment (17). However, in healthy adults, the overnight protocol has been shown to give the same results as hydrodensitometry (17). 
Both CP children and healthy children had gymnastic or swimming lessons at school on average 2 times per week $(45 \mathrm{~min})$. Although there are no reference values regarding organized sports activities in The Netherlands, we have no indications that the level of sports activities of the group of healthy children differs from the norm.

The intercepts of the SMR:FFM relation in the present study did not differ from zero, in agreement with findings of Weinsier et al. (30) in healthy infants and preschoolers. SMR (in absolute units and per kg FFM) did not differ between the CP group and healthy group. Therefore, the increased tone of spastic muscles, which also exists during sleep (11), has no measurable effect on SMR. Wakoh et al. (29) measured basal metabolic rate (BMR) in 11 children with different types and degrees of spasticity. In 9 children, EE was far below the value expected for their age. Bandini et al. (1) found a significantly lower RMR in adolescents with spastic quadraparesis than in control subjects. However, metabolic rates in both the study of Wakoh et al. (29) and Bandini et al. (1) were not normalized for body size and composition.

The DLW technique has been validated in adults (20) and infants (32), and is well suited to measure TEE in children, especially in children with handicaps, because all that is required is drinking a glass of labeled water and the collection of some urine samples (22). Using a fixed RQ for the calculation of EE over longer periods of time has been shown to produce minimal error (error in estimation is $1 \%$ for each 0.01 unit deviation) (24).

The $\mathrm{TEE}_{\mathrm{dlw}}$ measured in the healthy children is in good agreement with $\mathrm{TEE}_{\mathrm{dlw}}$ data of 7 and 9 year old children living in Northern Ireland (16) and in England (6). Most nutritional studies in CP children are based on dietary intakes. and often report low daily energy requirements (but with great inter-individual variations) $(3,8,10,12-14,19)$. The results of the present study, in which free-living energy expenditure was measured directly with DLW, contirm this low energy requirement in young children with spastic CP. Per kg FFM, differences between the CP and healthy children were not statistically significant, in agreement with previous reports $(8,10)$.

The TEE to SMR ratio is an expression of the amount of energy expended above resting and represents the energy spent on activity and the thermic effect of food (34). Because there are no indications that diet-induced thermogenesis differs between $C P$ and healthy children, differences in TEE to SMR ratios between the two groups are probably due to differences in levels of PA. $\mathrm{TEE}_{\mathrm{cal}} / \mathrm{SMR}$ did not differ between the CP children and the healthy children, indicating that levels of PA in a room-sized chamber are similar in $\mathrm{CP}$ and healthy children. TEE cil $_{\text {ial }} / \mathrm{SMR}$ measured in the present study is similar to ratios found in healthy adults during a stay in a respiration chamber (28).

$\mathrm{TEE}_{\mathrm{dw}} / \mathrm{SMR}$ in the healthy children was on average $25 \%(\mathrm{p}<0.01)$ greater than $\mathrm{TEE}_{\text {cal }} / \mathrm{SMR}$, in agreement with results found in healthy adult males (age 25-61 y) (28). In the $\mathrm{CP}$ children, $\mathrm{TEE}_{\mathrm{dl} / \mathrm{W}} / \mathrm{SMR}$ did not differ from $\mathrm{TEE}_{\mathrm{cal}} / \mathrm{SMR}$. Apparently, children with spastic diplegia are, in contrast with healthy subjects, not more physically active under free-living conditions than in a room-sized chamber. 
Bandini et al. (1) reported a $30 \%$ lower $\mathrm{TEE}_{\mathrm{dfw}} / \mathrm{RMR}$ in non-ambulant $\mathrm{CP}$ adolescents than in healthy controls, but no differences were found in $T E E_{d \mathrm{dw}} / \mathrm{RMR}$ between ambulant $\mathrm{CP}$ adolescents and their healthy peers. In the present study, the lowest $T E E_{\mathrm{dlw}} / \mathrm{SMR}$ was found in the wheelchair-bound child, but $\mathrm{TEE}_{\mathrm{dll}} / \mathrm{SMR}$ of the ambulant $\mathrm{CP}$ children was also significantly lower than in their healthy controls. This discrepancy between the findings of the present study and that of Bandini et al. (1) may be explained by the fact that levels of daily PA in healthy children gradually decrease with increasing age (7). Differences in PA between $\mathrm{CP}$ and healthy subjects may thus be smaller during adolescence than in childhood.

We conclude that, even at young ages, ambulant children with spastic diplegia are considerably less active than their healthy peers. Habitual activity patterns in these children, including physical education classes and physical therapy, are not intense enough to achieve optimum levels of daily PA. It is to be expected that $\mathrm{CP}$ children who are more severely affected than the children of this study, and not able to ambulate, will have even lower levels of daily PA. Besides detrimental effects on activities of daily life, the low levels of PA in CP children may also reduce the effectiveness of rehabilitation programs, in which a great deal of surgical. physiotherapeutic and educational effort is invested. We recommend increasing the daily PA in CP children by special sports programs, adjusted to the residual ability of each child, to give them opportunities for more normal growth and development.

\section{Acknowledgements}

We thank all the children and their parents who participated in this study and the children's rehabilitation center Franciscusoord for their cooperation. We also thank Loek Wouters and Paul Schoffelen for their help during data collection and analysis.

\section{References}

1. Bandini, L.G., D. A. Schoeller, N. K. Fukagawa, L. J. Wykes, W. H. Dietz. Body composition and energy expenditure in adolescents with cerebral palsy or myelodysplasia. Pediatr. Res. 29:70-77, 1991 .

2. Bar-Or, O. Pediatric sports medicine for the practitioner. From physiologic principles to clinical applications. New York: Springer-Verlag, 1983.

3. Berg, K., B. Isaksson. Body composition and nutrition of school children with cerebral palsy. Acta Paediatr. Scand. 204(suppl):41-52, 1970.

4. Brinkmann, J. R., T. A. Hoskins. Physical conditioning and altered self-concept in rehabilitated hemiplegic patients. Phys. Ther. 59:859-865, 1979.

5. Brown, A. Review: Physical fitness and cerebral palsy. Child: care, health and development 1:143-152, 1975.

6. Davies, P. S. W., M. B. E. Livingstone, A. M. Prentice, et al. Total energy expenditure during childhood and adolescence. [abstr] Proc. Nutr. Soc: 50:14a, 1991 
7. Dutch Nutrition Board. Recommended daily allowances. The Hague, 1992:27 [Dutch].

8. Eddy, T. P., A. L. Nicholson, E. F. Wheeler. Energy expenditures and dietary intakes in cerebral palsy. Dev. Med. Child Neurol. 7:377-386, 1965.

9. Fomon, S. J., F. Haschke, E. E. Ziegler, S. E. Nelson. Body composition of reference children from birth to 10 years. Am. J. Clin. Nutr. 35:1169-1175, 1982.

10. Fried, M. D., P. B. Pencharz. Energy and nutrient intakes of children with spastic quadriplegia. J. Pediatr. 119:947-949, 1991.

11. Gamstorp, I. Paediatric Neurology. London: Butterworths, 1985:274-293.

12. Hammond, M. I., M. N. Lewis, E. W. Johnson. A nutritional study of cerebral palsied children. J. Am. Dietet. Assoc. 49:196-201, 1966.

13. Karle, I. P., R. E. Bleiler, M. A. Ohlson. Nutritional status of cerebral palsied children. $J$. Am. Dietet. Assoc. 38:22-26, 1961.

14. Leamy, C. M. A study of the food intake of a group of children with cerebral palsy in the Lakeville Sanatorium. Am. J. Public Health 43:1310-1317, 1953.

15. Lifson, N., R. McClintock. Theory of use of the tumover rates of body water for measuring energy and material balance. J. Theoret. Biol. 12:46-74, 1966.

16. Livingstone, M. B. E., W. A. Coward, A. M. Prentice, et al. Daily energy expenditure in free-living children: comparison of heart-rate monitoring with the doubly labeled water $\left({ }^{2} \mathrm{H}_{2}{ }^{18} \mathrm{O}\right)$ method. Am. J. Clin. Nutr. 56:343-352, 1992.

17. Marken Lichtenbelt van, W. D., K. R. Westerterp, L. Wouters. Deuterium dilution as a method for determining total body water: effect of test protocol and sampling time. $B r . J$. Nutr. 72:491-497, 1994.

18. Olow, I., K. Berg. School children with cerebral palsy at Bräcke Östergård Pediatric Habilitation Centre. Acta Paediatr. Scand. 204(suppl):7-13, 1970.

19. Phelps, W. M. Dietary requirements in cerebral palsy. J. Amer. Diet. Assoc. 27:869-876, 1951.

20. Prentice, A. M. (ed). The doubly labeled water method for measuring energy expenditure, technicul recommendations for use in humans. A consensus report by the IDECG working group. Vienna: Int Atomic Energy Agency, 1990.

21. Roede, M. J., J. C. van Wieringen. Growth diagrams 1980. Netherlands third nationwide survey. Tijdsch. Soc. Gezondheidszorg 63(suppl):1-34, 1985.

22. Saris, W. H. M. Habitual physical activity in children: methodology and findings in health and disease. Med. Sci. Sports Exerc. 18:253-263, 1986.

23. Schoeller, D. A., E. Van Santen, D. W. Peterson, W. Dietz, J. Jaspan, P. D. Klein. Total body water measurement in humans with ${ }^{18} \mathrm{O}$ and ${ }^{2} \mathrm{H}$ labeled water. Am. J. Clin. Nutr. 33:2686-2693, 1980.

24. Schoeller, D. A. Energy expenditure from doubly labeled water: some fundamental considerations in humans. Am. J. Clin. Nutr. 38:999-1005, 1983.

25. Schoeller, D. A., E. Ravusssin, Y. Schutz, K. J. Acheson, P. Baertschi, E. Jequier. Energy expenditure by doubly labeled water: validation in humans and proposed calculation. Am. J. Physiol. 250:R823-830, 1986.

26. Schoffelen, P. F. M., W. H. M. Saris, K. R. Westerterp, F. Ten Hoor. Evaluation of an automatic indirect calorimeter for measurement of energy balance in man. In: Van Es, A. J. $H$, , ed. Human energy metabolism: Physical activity and energy expenditure measurements in epidemiological research based upon direct and indirect calorimetry, Euro Nut Report 5. Wageningen: The Netherlands Nutrition Foundation, 1984:51-54.

27. Tubis, J. S. P. Saturen, G. Larios, A. O. Posniak. Study of growth patterns in cerebral palsy. Arch. Phys. Med. Rehabil. 42:475-481, 1961.

28. Verboeket- van de Venne, W. P. H. G. Pattern of food intake, diet composition and human energy metabolism. An experimental approach. [thesis] Maastricht, 1993.

29. Wakoh, T., J. C. Hillman, M. Reiss. Energy metabolism of spastic children. Int. J. N'urupsy'h. 1:185-188, 1965. 
30. Weinsier, R. L., Y. Schutz, D. Bracco. Reexamination of the relationship of resting metabolic rate to fat-free mass and to the metabolically active components of fat-free mass in humans. Am. J. Clin. Nutr. 55:790-794, 1992.

31. Weir, J. B. New methods for calculating metabolic rate with special reference to protein metabolism. J. Physiol. 109:1-9, 1949.

32. Westerterp, K. R., H. N. Lafeber, E. J. Sulkers, P. J. J. Sauer. Comparison of short term indirect calorimetry and doubly labeled water method for the assessment of energy expenditure in preterm infants. Biol. Neonate 60:75-82, 1991.

33. Westerterp, K. R., L. Wouters, W. D. van Marken Lichtenbelt. The Maastricht protocol for the measurement of body composition and energy expenditure with labeled water. Obesity Research 3(suppl):49-57. 1995.

34. World Health Organization. Energy and protein requirements. Report of a joint FAO/WHO/UNU expert consultation. Technical Report Series 724. Geneva: World Health Organization, 1985. 



\section{Heart rate monitoring to assess energy expenditu- re in children with reduced physical activity}

H. J. G. van den Berg-Emons '. W. 11. M. Saris², K. R. Westerterp', and M. A. van Baak $^{2}$

Departments of Movement Sciences' and Human Biology". University of limburg, PO Box 616. 6200 MD Maastricht, The Netherlands

Med. Sci. Sports Exerc. [in press].

\section{Abstract}

The aim of the study was to assess whether heart rate (HR) monitoring is suitable to estimate total daily energy expenditure (TEE) in spastic cerebral palsied (CP) children, who are known to have very low levels of daily physical activity (PA). TEE predicted from $\mathrm{HR}$ recording ( $\mathrm{TEE}_{\mathrm{hr}}$, measured over 2 or 3 days) was therefore compared with TEE measured by doubly labeled water (TEE diw $_{\text {, }}$ measured over 14 days) in 9 children with spastic diplegia/tetraplegia (mean \pm SD age $10.7 \pm 1.6 \mathrm{y}$ ). At group level, there was no difference in $\mathrm{TEE}_{\mathrm{dlw}}(7.4 \pm 2.1$ $\mathrm{MJ} / \mathrm{d})$ and $\mathrm{TEE}_{\mathrm{hr}}(7.4 \pm 2.2 \mathrm{MJ} / \mathrm{d})$. Spearman correlation between both methods was $0.88 \quad(p<0.001)$. Individual estimates of $\mathrm{TEE}_{\mathrm{hr}}$ ranged from $-16.9 \%$ to $+20.0 \%$, with $5 \mathrm{TEE}_{\mathrm{hr}}$ values within $\pm 10 \%$ of $\mathrm{TEE}_{\mathrm{dlw}}$. It was concluded that also in children with low levels of daily PA, HR monitoring (3 sampling days is preferable) can provide a close group estimate of TEE. At individual level, the method is not suitable.

\section{Introduction}

Physical activity (PA) is generally considered to be an important factor in the growth and development of children and adolescents (17). Also the relevance of 
PA to clinical pediatrics has been gaining increasing attention, be it in diagnosis, prevention, management or etiology (2).

Measuring daily PA is one of the most difficult tasks for the physiologist (11) and probably even more difficult in children than in adults. A problem encountered in measuring PA is the presence of contradictory aims. On the one hand it is desirable to record the normal daily movements of a child, which usually means that the subject must be burdened with equipment for measuring a number of body functions. On the other hand, the child's normal daily activities should not be hindered (17).

PA can be quantified by determining energy expenditure (EE). At the moment, the doubly labeled water (DLW) technique seems to be the most accurate lowinterference technique for measuring total daily energy expenditure (TEE). However, for large-scale application the method is limited because of its cost. Furthermore, the technique provides only an overall estimate of EE for the entire observation period (17).

Heart rate (HR) monitoring is a simple and inexpensive method with little inconvenience to the subject, especially with the new developments in microelectronics. Therefore, HR monitoring has become one of the most commonly employed methods in PA studies in children (17). There are, however, certain disadvantages in using this method of prediction: the relationship between HR and oxygen consumption (VO2) is dependent upon the type of exercise (8) and, furthermore, the method is less accurate at low levels of PA because of the influence of several factors (emotional stress, posture) on the HR-VO2 relation $(4,7)$. Disadvantages of the HR method have been established in adults with metabolic disorders (7), healthy adults $(4-6,8,14,21,22,24)$ and healthy children $(9,15)$.

Children with spastic cerebral palsy (CP) have very low levels of daily PA (3). Therefore, it might be hypothesized that the HR method is unsuitable to predict TEE in these children. The aim of the present study was to compare HR monitoring with the DLW technique for the measurement of TEE in children with spastic CP. As far as we know, no studies exist concerning the validity of HR monitoring to predict TEE in a group of subjects with such low levels of daily $\mathrm{PA}$, as children with spastic $\mathrm{CP}$ are known to have.

\section{Subjects and methods}

\section{Subjects}

Nine CP children ( 5 boys and 4 girls) with spastic diplegia $(n=6)$ or spastic tetraplegia $(n=3)$ volunteered to participate as subjects. All children were between 8 and 13 years of age and were attending the elementary school at the children's rehabilitation center Franciscusoord in Valkenburg (normal intelligence and mild mental retardation). Three children were ambulant; 6 children were wheelchairbound. All children were Caucasian and participated in a 9-month sports program with 45-min aerobic exercise sessions (cycling, wheelchair-driving, running) two 
times per week. The children and their parents were informed of all aspects of the study and written consent was obtained. The study was approved by the Medical Ethics Committees of the University of Limburg and the Cooperating Rehabilitation Centers Limburg.

\section{The doubly labeled water technique}

TEE was measured using the doubly labeled water technique $\left(\operatorname{TEE}_{\mathrm{dlw}}\right)$. This technique measures TEE over longer periods of time by assessing the difference in disappearance rates of two stable isotopes, ${ }^{18} \mathrm{O}$ and ${ }^{2} \mathrm{H}(13)$. Measurements were performed in the spring from April to June, during a normal school period. Individually calculated doses of ${ }^{2} \mathrm{H}_{2}{ }^{18} \mathrm{O}$, which were expected to create an excess of about $300 \mathrm{ppm}{ }^{18} \mathrm{O}$ and $150 \mathrm{ppm}{ }^{2} \mathrm{H}$ in the body water, were administered orally to the children in the evening of day 0 , after collecting a baseline urine sample. To avoid spillage of isotope due to oral motor problems, a straw was used and children were asked to drink the water slowly. After emptying the dosage bottle, it was rinsed with $50 \mathrm{ml}$ tapwater which was consumed through the same straw. In none of the children loss of isotope was observed. Further urine samples were collected on day 1,8 and 15 in the morning after the first voiding and before going to bed at night. Isotope abundances in the urine samples were measured with an isotope ratio mass spectrometer (Aqua Sira, VG Isogas, Middlewich, Cheshire, England). The ${ }^{18} \mathrm{O}$ analyses were reproducible within 0.4 $\mathrm{ppm}$ and ${ }^{2} \mathrm{H}$ within $0.2 \mathrm{ppm}$. Excesses of ${ }^{18} \mathrm{O}$ and ${ }^{2} \mathrm{H}$ ranged from 282 to $388 \mathrm{ppm}$ and from 136 to $178 \mathrm{ppm}$ respectively. Mean TEE $\mathrm{dlw}_{\mathrm{w}}$ over 14 days was calculated using an estimated fixed respiratory quotient (RQ) of 0.85 and the equation (20): $\mathrm{r}_{\mathrm{CO} 2}=(\mathrm{N} / 2.078)\left(1.01 \mathrm{k}_{\mathrm{O}}-1.04 \mathrm{k}_{\mathrm{H}}\right)-0.0264 \mathrm{r}_{\mathrm{Gf}}$, where $\mathrm{r}_{\mathrm{CO} 2}=\mathrm{CO}_{2}$ production rate $(\mathrm{mol} / \mathrm{d}), \mathrm{N}=$ total body water $(\mathrm{mol}) ; \mathrm{k}_{\mathrm{O}}=$ elimination rate ${ }^{18} \mathrm{O} ; \mathrm{k}_{\mathrm{H}}$ = elimination rate ${ }^{2} \mathrm{H} ; \mathrm{r}_{\mathrm{Gf}}=$ correction factor for evaporative water loss, estimated by formula $r_{\mathrm{Gf}}=1.05 \mathrm{~N}\left(\mathrm{k}_{\mathrm{O}}-\mathrm{k}_{\mathrm{H}}\right)$.

\section{Heart rate monitoring}

HR was monitored during the isotope-measurement period with a Sport Tester or Sport Tester PE3000 (Polar Electro, Kempele, Finland). The HR transmitter was attached to the chest with two disposable pregelled electrodes or if possible with an electrode belt. Plasters were used to consolidate the attachment. The receiver was worn on the wrist, with the function keys masked. Pulse was recorded at 1min intervals. Data were retrieved via an interface unit and microcomputer.

Sampling days included two school days (one with physical training during school time and one without) and one weekend day. HR was measured during waking hours; EE at night was assumed to be equal to resting metabolic rate (RMR). Because of malfunction of some HR recorders, a number of measurements was too short to estimate TEE from HR. However, all children had $\geq 2 \mathrm{~d}$ of complete HR recordings and 4 subjects completed $3 \mathrm{~d}$. 


\section{Subject calibration}

Each subject was individually calibrated under standardized conditions to establish the relation between $\mathrm{HR}$ and $\mathrm{VO}_{2}$. In the ambulant children, 4 calibration points were obtained by simultaneous measurements of $\mathrm{HR}$ and $\mathrm{VO}_{2}$ during sitting, standing, and cycling on a mechanically braked ergometer (Universal Ergostat Fleisch, Metabo, Epalinges, Switzerland) at $30 \%$ and at $70 \%$ of their previously determined peak aerobic capacity. $\mathrm{VO}_{2}$ was measured using a mask connected to a Jaeger EOS-sprint analyzer (Jaeger Nederland, Breda, The Netherlands) and heart rates were taken from an ECG monitor. A preliminary equilibration period of $2 \mathrm{~min}$ was allowed for each activity, followed by a 4-min sampling period. The calibration point for each activity was computed as the mean of the 4-min sampling period of the $\mathrm{HR}$ and $\mathrm{VO}_{2}$. In the wheelchair-bound children, 2 calibration points were obtained: during sitting and during arm cranking. Arm cranking tests were performed on the Fleisch ergometer with 1 arm, while the children were sitting in their own wheelchair beside the ergometer. It turned out to be impossible to perform $\mathrm{VO}_{2}$ measurements while cranking with two arms, because, when sitting behind the ergometer, the distance between cranks and face was so small that the cranks constantly hit the tube that connected the mask with the analyzer. Children performed the arm cranking tests at about $30 \%$ of their peak aerobic capacity for work with 2 arms. It was impossible to measure $\mathrm{HR}$ and $\mathrm{VO}_{2}$ at higher intensities, because, when the resistarce was increased, the children lowered their cranking speed and showed no increases in $\mathrm{HR}$ and $\mathrm{VO}_{2}$.

\section{Resting metabolic rate}

In all the subjects, RMR was determined under standard conditions in a comfortably warm room by an open-circuit ventilated hood system (Oxycon Beta, Mijnhardt, The Netherlands). The children arrived by car at the university between 7:30 and 8:15 AM, having fasted for 12 hours. They were transported to the ventilated hood room in wheelchairs. After a period of $5 \mathrm{~min}$ bed rest, RMR was measured during $20 \mathrm{~min}$ while the children were watching TV or listened to stories (supine position). RMR was calculated according to the formula of Weir (25).

\section{Estimation of energy expenditure by the heart rate method}

TEE was calculated from HR (TEE ${ }_{\mathrm{hr}}$ ) using a modification of the method of Saris (18), as was validated by Spurr et al (22). This requires the definition of a 'FLEX' HR for each subject, above which there is a strong relation between HR and $\mathrm{VO}_{2}$, and below which the two variables are rather poorly correlated.

In the present study, FLEX HR in the ambulant children was defined as the mean of the highest HR for the standing activity and the lowest HR of the exercise activities. EE during rest was calculated as the mean $\mathrm{VO}_{2}$ of lying (ventilated hood), sitting, and standing. EE for periods of the daytime when the HR was $\leq$ FLEX HR, was calculated on basis of this mean $\mathrm{VO}_{2}$. When HR was above FLEX HR, EE was derived from the minute-by-minute recorded HR and the subject's calibration curve obtained on the bicycle. In the wheelchair-bound 
children, FLEX HR was defined as the mean HR for sitting. For periods of the daytime when the HR was $\leq$ FLEX HR, EE was calculated on basis of the mean $\mathrm{VO}_{2}$ of lying (ventilated hood) and sitting; when the HR was above the FLEX $H R$, EE was calculated from the HR recordings and the individual calibration curves obtained from $\mathrm{HR}$ and $\mathrm{VO}_{2}$ measurements during sitting and arm cranking. $\mathrm{TEE}_{\mathrm{hr}}$ was computed by summing the estimated EE from HR (using an energy equivalent of $20.50 \mathrm{~kJ} / \mathrm{L}$ ) and adding $\mathrm{EE}$ at night (-RMR).

\section{Body composition}

Body weight and total body water (TBW) were measured at the start of the experimental period and redetermined at the end.

Body weight was obtained in the mornings of day 1 and day 16 , before consuming any food/drink and while wearing under-clothing, with an electronic balance (August Sauter GmbH, Albstadt, West-Germany). Children who were unable to stand upright, were measured while sitting on a chair, using the same balance.

At the start of the experimental period, TBW was assessed by analysing the urine samples collected on the evening of day 0 (baseline sample) and on the morning of day 1 after the first voiding. At the end of the experimental period, i.e. before going to bed at night on day $15, a{ }^{2} \mathrm{H}_{2} \mathrm{O}$ (deuterium) dilution was orally administered to the children, after emptying the bladder (baseline urine sample). The dosage was expected to create an excess of $100 \mathrm{ppm}{ }^{2} \mathrm{H}$. A second urine sample was collected on day 16 in the moming, after the first voiding. TBW from deuterium dilution $\left(\mathrm{D}_{2} \mathrm{O}\right)$ was calculated as the deuterium dilution space divided by 1.04 , to account for the overestimate of TBW due to proton exchange which occurs between the tracer and nonaqueous hydrogen of body solids (12). Percentage body fat (BF) was calculated from TBW, assuming that water is $75 \%$ (boys) and 76\% (girls) of the fat-free mass (FFM) (10).

Height measurements were taken once during the experimental period. Subjects were measured while standing against a wall, or if unable to stand independently, while lying on a bed with a wooden T-square or a flexible tape. Physical characteristics of the subjects are presented in Table I.

\section{Statistical analysis}

Comparisons between data were made using the Wilcoxon test for paired observations $(\alpha=0.05)$. Agreement between methods was assessed with the method of Altman and Bland (1). Dispersion between HR sampling days was expressed as the coefficient of variation $(\mathrm{CV})$. Bivariate correlations were performed by Spearman's rank order correlation $\left(r_{s}\right)$. 
Table $L$. Characteristics of the 9 cerebral palsied children

\begin{tabular}{lcc}
\hline & Mean \pm SD & range \\
\hline Age $(\mathrm{y})$ & $10.7 \pm 1.6$ & $8-13$ \\
Weight $(\mathrm{kg})$ & $38.6 \pm 12.0$ & $30.2-71.6$ \\
Height $(\mathrm{cm})$ & $138.9 \pm 10.4$ & $130.0-166.0$ \\
TBW $^{*}(\mathrm{~L})$ & $19.3 \pm 6.1$ & $13.8-35.7$ \\
FFM $^{\dagger}(\mathrm{kg})$ & $25.5 \pm 8.0$ & $18.2-47.0$ \\
Fat $^{(\%)}$ & $33.8 \pm 6.1$ & $25.2-44.1$ \\
BMI $^{\dagger}\left(\mathrm{kg} / \mathrm{m}^{2}\right)$ & $19.6 \pm 2.6$ & $10.6-26.0$ \\
\hline
\end{tabular}

- TBW: total body water; ' FFM: fat-free mass: "BMI: body mass index

\section{Results}

Individual results of the HR monitoring and the DLW method are presented in Table II. Four children completed 3 days (one weekend day and two school days) of HR recording; four children completed only two school days and one child had one complete school day and one weekend day. Because the $C V$ in $T E E_{h r}$ between the sampling days was relatively small $\left(5 \%\right.$, mean $\mathrm{TEE}_{\mathrm{hr}}=7.1 \mathrm{MJ} / \mathrm{d}$; pooled $\mathrm{SD}=0.35 \mathrm{MJ} / \mathrm{d}$ ), the average (unweighted) $\mathrm{TEE}_{\mathrm{hr}}$ of the sampling days was used for comparison with $\mathrm{TEE}_{\mathrm{dlw}}$. Daytime $\mathrm{HR}$ was $15.6 \pm 18.1 \%$ above $(\mathrm{p}=0.07$ ) sitting HR (range $-13.3 \%$ to $+42.9 \%$ ). FLEX HR was on average $4.0 \pm$ $12.9 \%$ lower (ns) than daytime HR (range $-27.6 \%$ to $+15.3 \%$ ). On average, the children spent $54.1 \pm 32.0 \%$ of the daytime at HR > FLEX HR. There was no significant correlation between percentage of time spent above FLEX HR and the discrepancy between HR monitoring and the DLW method, nor between level of daily PA (calculated as $\mathrm{TEE}_{\mathrm{dtw}} / \mathrm{RMR}$ ) and the discrepancy between the methods. At group level, there was no difference in $\mathrm{TEE}_{\mathrm{dlw}}$ and $\mathrm{TEE}_{\mathrm{hr}}$. Spearman correlation between both methods was $0.88(\mathrm{p}<0.001)$. Individual estimates of $1 \mathrm{EE}_{\mathrm{hr}}$ ranged from $-16.9 \%$ to $+20.0 \%(-2.1 \mathrm{MJ} / \mathrm{d}$ to $+1.8 \mathrm{MJ} / \mathrm{d})$, with $5(=56 \%) \mathrm{TEE}_{\mathrm{hr}}$ values lying within $\pm 10 \%$ of $\mathrm{TEE}_{\mathrm{dlw}}$. Intra-individual differences between the methods were larger $(\mathrm{p}=0.05)$ in the children with 2 sampling days $(13.5 \pm 6.3 \%)$ than in the children with 3 sampling days $(5.9 \pm 5.8 \%)$. In 6 children, $\mathrm{TEE}_{\mathrm{hs}}$ was lower than corresponding $\mathrm{TEE}_{\mathrm{dlw}}$. There was no statistically significant difference in $T_{E E_{\mathrm{hr}}}$ of the school day with a training session and the school day without training $(n=8)$. Spearman correlation between $T E E_{h r}$ of the two school days was 0.98 $(p<0.001)$. There was also no significant difference in $T_{E} E_{h r}$ of the school days and the weekend day, but this comparison could only be made in 5 children. 
Table II. Total energy expenditure (TEE) estimated from heart rate (HR) monitoring (TEE $\mathrm{h}_{\mathrm{hr}}$ ) and from doubly labeled water $\left(\mathrm{TEE}_{\mathrm{dI} w}\right)$ in 9 cerebral palsied children

HR

\begin{tabular}{|c|c|c|c|c|c|c|c|}
\hline $\mathrm{Nr}$ & $\begin{array}{l}\text { Sitting } \\
\text { b/s/min }\end{array}$ & $\begin{array}{c}\text { Daytime } \\
\text { bts/min }\end{array}$ & $\begin{array}{c}\text { FLEX } \\
\text { bisimin }\end{array}$ & $\begin{array}{c}\mathrm{TEE}_{\mathrm{hi}} \cdot \\
M . / / d\end{array}$ & $\begin{array}{c}\mathrm{TEE}_{\mathrm{dlw}} \\
M J / d\end{array}$ & $\begin{array}{c}\triangle \mathrm{TEE}^{\dagger} \\
\% \\
\end{array}$ & $\begin{array}{l}T_{E E_{\text {di }} /} \\
\text { RMR }^{\S}\end{array}$ \\
\hline $1^{5}$ & 77 & 110 & 105 & 11.3 & 9.5 & +18.9 & 1.61 \\
\hline $5^{1}$ & 82 & 94 & 93 & 10.3 & 12.4 & -16.9 & 1.68 \\
\hline 11 & 76 & 105 & 76 & 8.4 & 7.0 & +20.0 & 1.08 \\
\hline 12 & 103 & 92 & 103 & 4.2 & 5.0 & -16.0 & 1.19 \\
\hline 13 & 92 & 108 & 92 & 5.8 & 6.2 & -6.5 & 1.15 \\
\hline 15 & 113 & 98 & 113 & 6.0 & 6.1 & -1.6 & 1.04 \\
\hline 17 & 98 & 109 & 98 & 7.1 & 6.9 & +2.9 & 1.15 \\
\hline 18 & 87 & 98 & 87 & 6.0 & 6.2 & -3.2 & 1.19 \\
\hline $20^{4}$ & 74 & 94 & 100 & 7.1 & 7.5 & -5.3 & 1.41 \\
\hline$x+S D$ & $89 \pm 13$ & $101 \pm 7$ & $96 \pm 10$ & $7.4 \pm 2.2$ & $7.4 \pm 2.1$ & $-0.9 \pm 12.4$ & $1.28 \pm 0.22$ \\
\hline
\end{tabular}

- average HR over the sampling days numbers 1,5,11,13,20: 2 sampling days, numbers $12,15,17,18: 3$ sampling days $) ;{ }^{+} \Delta \mathrm{TEE}=\left(\mathrm{TEE}_{\mathrm{hir}}-\mathrm{TEE}_{\mathrm{dlw}}\right) / \mathrm{TEE}_{\mathrm{dlw}} \times 100 ;{ }^{5} \mathrm{TEE}_{\mathrm{dlw}} / \mathrm{RMR}$ : index for level of daily physical activity, RMR: resting metabolic rate; ' ambulant

In Figure 1, the difference in TEE between HR monitoring and the DLW method is plotted against the average measurement according to Altman and Bland (1). There was no significant relation between the difference and the average.

Fig. 1. Difference in total daily energy expenditure (TEE) determined by the doubly labeled water method $\left(\mathrm{TEE}_{\mathrm{d} \mid \mathrm{w}}\right)$ and heart rate monitoring $\left(\mathrm{TEE}_{\mathrm{hr}}\right)$ versus average TEE

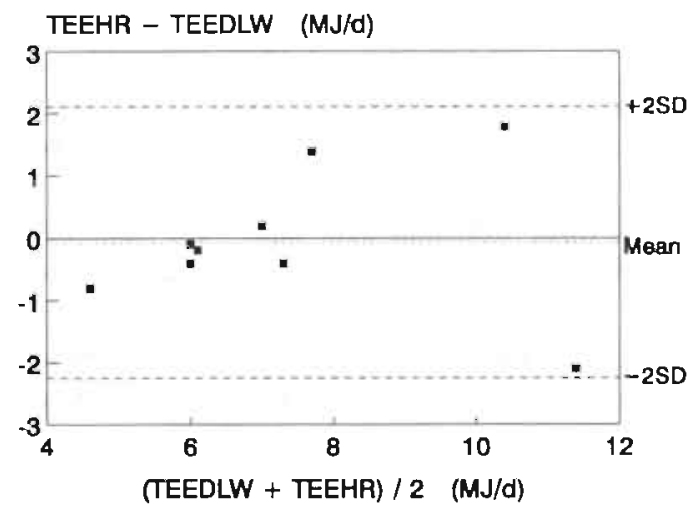

Relative bias $-0.07 \mathrm{MJ} / \mathrm{d}$; estimate of error $1.09 \mathrm{MJ} / \mathrm{d}$ 


\section{Discussion}

In order to assess whether HR monitoring is suitable to estimate TEE in children with very low levels of daily PA, TEE predicted from HR was compared with TEE measured by DLW in 9 children with spastic CP.

The ratio of $\mathrm{TEE}_{\text {dlw }}$ to RMR (= index for the level of daily PA) in the CP children was $1.28 \pm 0.22$ (Table II). Although different methods were used to assess PA, comparison with studies in healthy children indicates that the $\mathrm{CP}$ children are considerably less active than healthy children (PA levels in healthy children in the Netherlands (3) and Northern Ireland (15) were found to be respectively $1.83 \pm$ 0.23 and $1.77 \pm 0.21$ ). The low PA in the CP children is in agreement with our previous study in diplegic CP children (3).

The DLW method has been validated in adults (16) and infants (26) and is considered to be the gold standard for measurements of EE. Using a fixed RQ for the calculation of EE over longer periods of time, has been shown to produce minimal error (error in estimation is $1 \%$ for each unit RQ) (19). The Sport Tester PE3000 has been validated against ECG heart rates in children in laboratory and field settings (23). It was concluded that the device provides valid readings of children's HR across a wide range of exercise involving upper- and lower-body movements.

Because of earlier measurements, the children of the present study were familiar with the calibration procedure. Therefore, the calibration was not an event of high excitement for them. In spite of this, 2 children (Table II, numbers 12,15 ) had a high HR during sitting (was even higher than daytime HR), probably still due to emotional stress during the calibration.

In the ambulant $\mathrm{CP}$ children, the calibration activity for the active part of the HR-curve was cycling. No significant difference was found in the $\mathrm{HR}-\mathrm{VO}_{2}$ relationship between walking on a treadmill and cycling in 6 ambulant CP children (including the ambulant children of the present study) measured in our laboratory.

The low $\mathrm{TEE}_{\text {dlw }}$ to $\mathrm{RMR}$ ratio in the $\mathrm{CP}$ group ( $1.28 \pm 0.22$. Table II) seems to be in contrast with the mean HR during daytime $(101 \mathrm{bts} / \mathrm{min})$ and the percentage of the daytime spent at HR > FLEX HR (54.1\%): in healthy, more active children (PA index $=1.77 \pm 0.21$ ) in Northern Ireland (15), mean daytime HR and percentage of daytime spent at HR > FLEX HR were respectively $104 \mathrm{bts} / \mathrm{min}$ and $41.3 \%$. However, both studies cannot be compared properly because the slopes of the regression lines between $\mathrm{HR}$ and $\mathrm{VO}_{2}$ may differ between $\mathrm{CP}$ and healthy children and the definition of the FLEX HR differs between the studies.

The $\mathrm{TEE}_{\mathrm{dlw}}$ to $\mathrm{RMR}$ ratios in $2 \mathrm{CP}$ children (numbers 11 and 15 , Table II) were extremely low. These children were severely affected, but the measured ratio in these children may be an underestimation of their actual ratio. Possibly, these children were not fully 'at rest' during the RMR measurement.

Because of the low levels of daily PA in CP children, it is to be expected that the HR method is less suitable in these children than in healthy children with relatively high activity levels or adults with intermediate levels. The limited number of calibration activities at different intensities that are possible in severely 
affected wheelchair-bound children and the fact that, for practical reasons, no calibration points could be obtained for wheelchair-driving and arm cranking had to be performed with one arm, might further decrease the accuracy of the HR method in CP children. However, the results of the present study do not confirm this hypothesis. At group level, HR monitoring resulted in a good prediction of TEE. Individual $\mathrm{TEE}_{\mathrm{hr}}$ and $\mathrm{TEE}_{\text {dlw }}$ discrepancies ranged from $-16.9 \%$ to $+20.0 \%$, but are similar to discrepancies found in healthy children and adults (Table III). Apparently, the low activity level in CP children and the limitations in calibration activities, do not result in poorer accuracy of the HR method in CP children than in healthy subjects. No significant correlation was found between percentage of time spent at HR > FLEX HR or TEE dlw to RMR ratio and the discrepancy between $\mathrm{TEE}_{\mathrm{lr}}$ and $\mathrm{TEE}_{\mathrm{dlw} \text { - }}$ This may be due to the small number of subjects. However, from the studies presented in Table III, also no tendency can be seen that the level of PA is a limiting factor in the accuracy of predicting TEE from HR.

Table III. Validation studies (using doubly labeled water (dlw) or indirect calorimetry (cal) as reference method) of heart rate monitoring for the estimation of total daily energy expenditure (TEE) in healthy subjects

\begin{tabular}{|c|c|c|c|c|c|}
\hline Study & $\mathrm{N}$ & Age $(y)$ & $\begin{array}{l}\text { Mean activity } \\
\text { level }\end{array}$ & $\begin{array}{c}\text { Mean } \triangle \mathrm{TEE}^{\dagger}(\%) \\
\text { (range) }\end{array}$ & $\begin{array}{l}\% \text { of subjects } \\
\text { within } \pm 10 \%\end{array}$ \\
\hline $\begin{array}{l}\text { Spurr et al, } \\
1988(22)\end{array}$ & 22 & $18-66$ & $\mathrm{TEE}_{\mathrm{ca}} / \mathrm{BMR}=1.52$ & $+2.5(-15$ to +20$)$ & 68 \\
\hline $\begin{array}{l}\text { Ceesay et al, } \\
1989(6)\end{array}$ & 20 & $17-36$ & $\mathrm{TEE}_{\mathrm{cal}} / \mathrm{BMR}=1.64$ & $-1.2(-1 \mid$ to +11$)$ & 85 \\
\hline $\begin{array}{l}\text { Schulz et al, } \\
1989(21)\end{array}$ & 6 & $20-30$ & $\mathrm{TEE}_{\mathrm{dllw}} / \mathrm{RMR}=1.94$ & $-12.7(-29$ to +7$)$ & 64 \\
\hline $\begin{array}{l}\text { Livingstone } \\
\text { et al, } 1990 \\
\text { (14) }\end{array}$ & 14 & $17-46$ & $\mathrm{TEE}_{\mathrm{dlw}} / \mathrm{BMR}=1.86$ & $+2.0(-22$ to +52$)$ & 64 \\
\hline $\begin{array}{l}\text { Livingstone } \\
\text { et al, } 1992 \\
\text { (15) }\end{array}$ & $\begin{array}{c}11 \\
9 \\
10 \\
6\end{array}$ & $\begin{array}{c}7 \\
9 \\
12 \\
15\end{array}$ & $\begin{array}{l}\mathrm{TEE}_{\mathrm{dlw}} / \mathrm{BMR}=1.67 \\
\mathrm{TEE}_{\mathrm{dlw}} / \mathrm{BMR}=1.95 \\
\mathrm{TEE}_{\mathrm{dlw}} / \mathrm{BMR}=1.70 \\
\mathrm{TEE}_{\mathrm{dlw}} / \mathrm{BMR}=1.74\end{array}$ & $\begin{array}{l}-3.5(-17 \text { to }+19) \\
-9.2(-14 \text { to }-1) \\
-1.5(-14 \text { to }+10) \\
+3.5(-5 \text { to }+13)\end{array}$ & $\begin{array}{l}36 \\
56 \\
90 \\
8.3\end{array}$ \\
\hline $\begin{array}{l}\text { Emons et al, } \\
1992(9)\end{array}$ & 16 & $7-11$ & $\mathrm{TEE}_{\text {cal }} / \mathrm{SMR}=1.43$ & $+10.4(-23$ to +35$)$ & 38 \\
\hline $\begin{array}{l}\text { Emons et al, } \\
1992(9)\end{array}$ & 9 & $7-10$ & $\mathrm{TEE}_{\mathrm{d} \mathrm{w}} / \mathrm{SMR}=1.85$ & $+12.3(-12$ to +42$)$ & 44 \\
\hline
\end{tabular}

BMR: basal metabolic rate, RMR: resting metabolic rate, SMR: sleeping metabolic rate

$\checkmark T E E=\left(T_{E E}-T_{\mathrm{br}} \mathrm{TEE}_{\text {reference }}\right) / \mathrm{TEE}_{\text {reference }} \times 100$

Saris (17) suggested that one of the inaccuracies of the minute-by-minute HR method might be due to a slower return of HR to resting levels than the return of $\mathrm{VO}_{2}$ after bouts of activity. It may be possible that the relatively few bouts of activity in $\mathrm{CP}$ children, compensate for the possibly decreased accuracy of the 
HR method due to low activity levels and limitations in calibration activities in this group.

In conciusion, results of the present study indicate that the HR method can provide a close group estimate of TEE in spastic CP children with extremely low levels of daily PA ( 3 sampling days is preferable). Apparently, in contrast with what was expected, low PA does not necessarily result in poor accuracy of the HR method. The method is limited in the prediction of TEE in individuals, but in comparison with the expensive DLW method, HR monitoring seems to be the most suitable method in large-scale activity studies to predict TEE for groups with reduced PA (for example in rehabilitation research).

\section{Acknowledgements}

We wish to express our thanks to all the children and their parents who participated in this study and the staff of the children's rehabilitation center Franciscusoord (Valkenburg a/d Geul). We also thank Carola Leygraaf and Loek Wouters for their help during data collection and analysis.

\section{References}

I. Altman, D. G., J. M. Bland. Measurement in medicine: the analysis of method comparison studies. The Statistician 32:307-317, 1983.

2. Bar-Or, O. Pediatric sports medicine for the practitioner. From physiologic principles to clinical applications. New York: Springer Verlag, 1983.

3. Berg-Emons van den, H. J. G, W. H. M. Saris, D. C. de Barbanson, K. R. Westerterp, A. Huson, M. A. van Baak. Daily physical activity of school children with spastic diplegia and of healthy control subjects. J. Pediatr. 127:578-584, 1995.

4. Booyens, J., G. R. Hervey. The pulse rate as a means of measuring metabolic rate in man. Can. J. Biochem. Physiol. 38:1301-1309, 1960.

5. Bradfield, R. B., P. B. Huntzicker, G. J. Fruehan. Simultaneous comparison of respirometer and heart-rate telemetry techniques as measures of human energy expenditure. $\mathrm{Am}$. J. (' $\mathrm{lm}$. Nutr. 6:696-700, 1969.

6. Ceesay, S. M., A. M. Prentice, K. C. Day, et al. The use of heart rate monitoring in the estimation of energy expenditure: a validation study using indirect whole-body calorimetry. Br. J. Nutr. 61:175-186, 1989.

7. Christensen, C. C., H. M. M. Frey, E. Foenstelien, E. Aadland, H. E. Refsum. A critical evaluation of energy expenditure estimates based on individual $O_{2}$ consumption / heart rate curves and average daily heart rate. Am. J. Clin. Nutr. 37:468-472, 1983.

8. Dauncey, M. J., W. P. T. James. Assessment of the heart-rate method for determining energy expenditure in man, using a whole-body calorimeter. Br. J. Nutr. 42:1-13, 1979.

9. Emons, H. J. G., D. C. Groenenboom, K. R. Westerterp, W. H. M. Saris. Comparison of heart rate monitoring combined with indirect calorimetry and the doubly labelled water $\left({ }^{2} \mathrm{H}_{2}{ }^{18} \mathrm{O}\right)$ method for the measurement of energy expenditure in children. Eur. J. Appl. Physiol. 65:99-103, 1992.

10. Fomon, S. J., F. Hascke, E. E. Ziegler, S. E. Nelson. Body composition of reference children from birth to age 10 years. Am. J. Clin. Nutr. 35:1169-1175, 1982. 
11. Garrow, J. R. Energy balance and obesity in man. Amsterdam: Elsevier/North-Holland Publishers, 1974.

12. Haggarty, P., B. A. McGaw, M. F. Fuller, S. L. Christie, W. W. Wong. Water hydrogen incorporation into body fat in pigs: effect on double-triple-labeled water method. $\mathrm{Am} . \mathrm{J}$. Physiol. 260:R629-R634, 1991.

13. Lifson, N., R. McClintock. Theory of use of the turnover rates of body water for measuring energy balance and material balance. J. Theoret. Biol. 12:46-74, 1966.

14. Livingstone, M. B. E., A. M. Prentice, W. A. Coward, et al. Simultaneous measurement of free-living energy expenditure by the doubly labeled water method and heart-rate monitoring. Am. J. Clin. Nutr. 52:59-65, 1990.

15. Livingstone, M. B. E., W. A. Coward, A. M. Prentice, et al. Daily energy expenditure in free-living children: comparison of heart-rate monitoring with the doubly labeled water $\left({ }^{2} \mathrm{H}_{2}{ }^{18} \mathrm{O}\right)$ method. Am. J. Clin. Nutr. 56:343-352, 1992.

16. Prentice, A.M., ed. The doubly labeled water method for measuring energy expenditure, technical recommendations for use in humans. A consensus report by the IDECG working group. Vienna: Int Atomic Energy Agency, 1990.

17. Saris, W. H. M. Habitual physical activity in children: methodology and findings in health and disease. Med. Sci. Sports Exerc. 18:253-263, 1986.

18. Saris, W. H. M., I. Boeijen, H. Elvers, T. de Boo, R. A. Binkhorst. Determining the individual variation in energy metabolism in 8 -year-old children by two prediction methods. Nutr. Rep. Int. 26:35-42, 1982.

19. Schoeller, D. A. Energy expenditure from doubly labeled water: some fundamental considerations in humans. Am. J. Clin. Nutr. 38:999-1005, 1983.

20. Schoeller, D. A., E. Ravussin, Y. Schutz, K. J. Acheson, P. Baertschi, E. Jequier. Energy expenditure by doubly labeled water: validation in humans and proposed calculation. $A m . J$. Physiol. 250:R823-R830, 1986.

21. Schulz, S., K. R. Westerterp, K. Brück. Comparison of energy expenditure by the doubly labeled water technique with energy intake, heart rate, and activity recording in man. $\mathrm{Am}$. J. Clin. Nutr. 49:1146-1154, 1989.

22. Spurr, G. B., A. M. Prentice, P. R. Murgatroyd, G. R. Goldberg, J. C. Reina, N. T. Christman. Energy expenditure from minute-by-minute heart-rate recording: comparison with indirect calorimetry. Am. J. Clin. Nutr. 48:552-559, 1988.

23. Treiber, F. A., L. Musante, S. Hartdagan, H. Davis, M. Levy, W. B. Strong. Validation of a heart rate monitor with children in laboratory and field settings. Med. Sci. Sports Exerc. 21:338-342, 1989.

24. Washbum, R. A., H. J. Montoye. Validity of heart rate as a measure of mean daily energy expenditure. Exerc. Physiol. 2:161-172, 1986.

25. Weir, J. B. New methods for calculating metabolic rate with special reference to protein metabolism. J. Physiol. 109:1-9, 1949.

26. Westerterp, K. R., H. N. Lafeber, E. J. Sulkers, P. J. J. Sauer. Comparison of short term indirect calorimetry and doubly labeled water method for the assessment of energy expenditure in preterm infants. Biol. Neonate. 60:75-82, 1991. 



\title{
Skinfold measurements in cerebral palsy and healthy controls
}

\author{
H. J. G. van den Berg-Emons ${ }^{1}$, M. A. van Baak ${ }^{2}$, and K. R. Westerterp ${ }^{2}$
}

Departments of Movement Sciences ${ }^{1}$ and Human Biology ${ }^{2}$, University of Limburg, PO Box 616, 6200 MD Maastricht, The Netherlands

Arch. Dis. Child. [submitted].

\begin{abstract}
The aim was to assess whether body fat (BF) can be predicted adequately from skinfold measurements in comparative studies between spastic cerebral palsied (CP) children and healthy controls. The deuterium dilution technique $\left(\mathrm{D}_{2}(\mathrm{O})\right.$ was used as reference method. In contrast with what was expected, $\% \mathrm{BF}$ as predicted from skinfolds was considerably lower (with 6 to $8 \% \mathrm{BF}, \mathrm{p}<0.001$ ) than $\% \mathrm{BF}$ determined by $\mathrm{D}_{2} \mathrm{O}$ in $\mathrm{CP}$ children $(\mathrm{n}=22,10.0 \pm 1.5 \mathrm{y})$, whereas in healthy children $(n=10,8.4 \pm 1.0 \mathrm{y})$ this was not seen. A proportionally large internal fat depot and a different distribution of subcutaneous fat in CP children may be responsible for this. It was concluded that skinfold measurements are not suitable to predict $\mathrm{BF}$ in comparative studies between $\mathrm{CP}$ and healthy children.
\end{abstract}

\section{Introduction}

Information about body composition in children with spastic cerebral palsy (CP) is of great importance in relation to the higher risk of overweight in these children $(5,6,9,12,19)$ and concomitant health risks $(2,15)$. A variety of methods is available to assess body composition, all with their own advantages and limitations (18). However, only a few methods are suitable in CP children for research or clinical practice, because they require minimal subject cooperation, 
are of low cost and technically simple, and because they are portable. These methods include the measurement of skinfolds $(11,24)$, which seems to provide reasonably good estimates of body composition in healthy children $(10,24)$. However, as far as we know, no studies exist concerning the validity of this method to predict body fat $(\mathrm{BF})$ in children with spastic $\mathrm{CP}$.

Berg and Isaksson (4) found a reduced body cell mass and increased total body water (TBW) and extracellular water in spastic CP children. Low physical activity (PA), malnutrition and paresis of muscle groups were suggested as possible causes of the abnormal body composition. Osteoporosis of the bones is common in CP (especially in the severely involved patients), due to lack of the stress of weight-bearing, poor nutritional status, and anticonvulsant use $(7,22)$. Therefore, the density of the fat-free mass (FFM) in CP children may be lower than in healthy children, and it might be hypothesized that available skinfold equations derived lor healthy children $(11,24)$ overestimate $\mathrm{BF}$ in $\mathrm{CP}$ children.

The aim of the present study was to assess whether BF can be predicted adequately from skinfold measurements in comparative studies between $\mathrm{CP}$ and healthy children. The deuterium dilution $\left(D_{2} \mathrm{O}\right)$ technique was used as reference method.

\section{Subjects and methods}

\section{Subjects}

Twenty-two $C P$ children ( 11 boys and 11 girls) with spastic diplegia ( $n=18$, legs and feet more affected than arms and hands) and spastic tetraplegia ( $\mathrm{n}=4$, greater affliction of the upper part of the body than of the lower part) and 10 healthy children ( 5 boys and 5 girls) volunteered to participate. Half of the $\mathrm{CP}$ population was ambulant; the other half was wheelchair-bound. All children were between 7 and 13 years of age. Nineteen $C P$ children were day-students at the elementary school at the children's rehabilitation center Franciscusoord in Valkenburg (normal intelligence and mild mental retardation); the other $3 \mathrm{CP}$ children and the healthy children were from elementary schools in and around Maastricht (normal intelligence). Twenty CP children were Caucasian; one CP child was born in Sri Lanka and one child had a Moroccan background. The healthy children were all Caucasian. The children and their parents were informed of all aspects of the study and written consent was obtained. The study was approved by the Medical Ethics Committees of the University of Limburg and the Cooperating Rehabilitation Centers Limburg.

\section{Body composition measurements}

Body weight was obtained in the morning, after voiding and before consuming any food/drink while wearing under-clothing. with an electronic balance (August Sauter GmbH, Albstadt. West-Germany). CP children who were unable to stand upright, were measured while sitting on a chair, using the same balance. 
Height measurements were taken with subjects standing against a wall, or if unable to stand while lying on a bed, with a wooden T-square or a flexible tape.

Deuterium dilution. TBW was measured by $\mathrm{D}_{2} \mathrm{O}$. Individually calculated doses, which were expected to create an excess of about $100 \mathrm{ppm}{ }^{2} \mathrm{H}$ (CP group) and $265 \mathrm{ppm}{ }^{2} \mathrm{H}$ (healthy group, participated in a study to determine total daily energy expenditure over a 2 -week period) in the body water were administered orally in the evening, after collecting a baseline urine sample. To avoid spillage of isotope due to oral motor problems ( $\mathrm{CP}$ children), a straw was used and children were asked to drink the water slowly. After emptying the dosage bottle it was rinsed with $50 \mathrm{ml}$ tap water which was consumed through the same straw. In none of the children loss of isotope was observed. Samples of urine of the next morning (second voiding) were used for the in duplo determination of the isotopic enrichment with an Isotope Ratio Mass Spectrometer (Aqua Sira, VG Isogas Ltd, Middlewich, Cheshire, England). The ${ }^{2} \mathrm{H}$ analyses were reproducible within 0.2 $\mathrm{ppm}$. Isotopic excesses ranged from 92 to $114 \mathrm{ppm}{ }^{2} \mathrm{H}$ in the $\mathrm{CP}$ group and from 185 to $271 \mathrm{ppm}{ }^{2} \mathrm{H}$ in the healthy group. TBW from $\mathrm{D}_{2} \mathrm{O}$ was calculated as the deuterium dilution space divided by 1.04 , to account for the overestimate of TBW due to proton exchange which occurs between the tracer and nonaqueous hydrogen of body solids (14). Percentage $\mathrm{BF}\left(\% \mathrm{BF}_{\mathrm{D} 2 \mathrm{O}}\right)$ was calculated from TBW using age-related water proportions of FFM as suggested by Fomon et al. (13) ( $76 \%$ and $77 \%$ for healthy boys respectively healthy girls, and $75 \%$ and $77 \%$ for $\mathrm{CP}$ boys respectively $\mathrm{CP}$ girls).

Skinfold measurements. Four skinfold measurements (triceps, biceps, subscapular and suprailiac) were taken twice on the non-dominant side of the body with a Harpenden caliper which recorded to the nearest $0.1 \mathrm{~mm}$. Skinfold measurements were performed in both groups of children by the same investigator. The mean of the 2 measurements was used as representative value for each site. Two different equations (derived for healthy children) were used to predict BF from skinfold thicknesses:

A] Equations of Durnin and Rahaman (11) (skinA), which are based on estimates of fatness derived from the two-component model of hydrodensitometry (assumes a constant composition of FFM):

-boys: $y=1.1533-0.0643 x$

-girls: $y=1.1369-0.0598 x$, where $y=$ body density $(\mathrm{kg} / \mathrm{L})$ and $x$ is the logarithmic value of the sum of the 4 skinfolds in $\mathrm{mm}$. Percentage $\mathrm{BF}$ was calculated from body density, using the Siri equation (23):

$\% \mathrm{BF}_{\text {skinA }}=[(4.95 /$ density $)-4.5] * 100$

B] Equations of Slaughter et al. (24) (skinB), which are based on estimates of fatness derived from a multicomponent model (takes into account TBW and bone mineral in addition to body density):

-boys: $\% \mathrm{BF}_{\text {skinB }}=1.21$ (triceps + subscapular) -0.008 (triceps + subscapular) ${ }^{2}-1.7$ -girls: $\% \mathrm{BF}_{\text {skinB }}=1.33$ (triceps + subscapular) $-0.013\left(\right.$ triceps + subscapular) ${ }^{2}-2.5$. 


\section{Statistical analysis}

('omparisons between data were made using the Wilcoxon test for paired observations and the Mann-Whitney $U$ test for unpaired observations $(\alpha=0.05)$. Agreement between methods was assessed with the method of Altman and Bland (1). Regression techniques were used to examine the relationship between water content ol the body and sums of skinfolds. Bivariate correlations were performed by Spearman's rank order correlation $\left(r_{s}\right)$ or Pearson's product moment correlation (r).

\section{Results}

Physical characteristics of the CP and healthy group are presented in Table I. The $C P$ children were significantly older $(p<0.01)$ than the healthy children and had a significantly higher body weight $(\mathrm{p}<0.05)$ and body mass index $(\mathrm{p}<0.01)$. There were no differences in physical characteristics between the boys and girls within each group.

Table I. Physical characteristics of the study population

\begin{tabular}{lccc}
\hline & $\begin{array}{c}\text { Healthy } \\
(\mathrm{n}=10) \\
5 \delta, 5 \%\end{array}$ & $\begin{array}{c}\mathrm{CP} \\
(\mathrm{n}=22) \\
1 \delta, 119\end{array}$ \\
\hline Age $(\mathrm{y})$ & $8.4 \pm 1.0$ & $*$ & $10.0 \pm 1.5$ \\
Height $(\mathrm{cm})$ & $133.1 \pm 4.6$ & & $137.5 \pm 9.5$ \\
Weight $(\mathrm{kg})$ & $28.0 \pm 2.3$ & $\dagger$ & $35.3 \pm 10.0$ \\
BMI $\left(\mathrm{kg} / \mathrm{m}^{2}\right)^{5}$ & $15.8 \pm 1.1$ & $*$ & $18.3 \pm 2.9$ \\
\hline
\end{tabular}

Values are mean $\pm \mathrm{SD} ;{ }^{*} \mathrm{p}<0.01 ; \dagger \mathrm{p}<0.05,{ }^{\S} \mathrm{BMI}$ : body mass index

TBW was $19.0 \pm 5.0 \mathrm{~L}$ in the $\mathrm{CP}$ children and $18.0 \pm 1.4 \mathrm{~L}$ in the healthy children (ns). Per kg body weight, TBW was significantly $(\mathrm{p}<0.001)$ lower in the $\mathrm{CP}$ group $(0.54 \pm 0.06 \mathrm{~L} / \mathrm{kg})$ than in the healthy group $(0.64 \pm 0.04 \mathrm{~L} / \mathrm{kg})$. $\% \mathrm{BF}_{\mathrm{D} 2 \mathrm{O}}$ was $28.6 \pm 8.0$ in the $\mathrm{CP}$ children and $15.9 \pm 5.1$ in the healthy children $(\mathrm{p}<0.001)$. There was no significant difference in $\% \mathrm{BF}_{\mathrm{D} 20}$ between the ambulant $\mathrm{CP}$ children and wheelchair-bound CP children.

Mean sums of 4 skinfolds and 2 skinfolds (triceps and subscapular) were significantly $(p<0.01)$ higher in the CP children $(39.8 \pm 13.0 \mathrm{~mm}$ and $22.3 \pm 6.4 \mathrm{~mm}$ respectively) than in the healthy children $(25.3 \pm 7.4 \mathrm{~mm}$ and $14.2 \pm 3.5 \mathrm{~mm}$ respectively). Sums of 4 skinfolds ranged from 17.4 to $65.4 \mathrm{~mm}$ in the CP group and from 16.9 to $43.6 \mathrm{~mm}$ in the healthy group. Sums of 2 skinfolds ranged from 10.6 to $32.6 \mathrm{~mm}$ and from 9.3 to $22.3 \mathrm{~mm}$ in respectively the $\mathrm{CP}$ and healthy group. Regression lines between water per $\mathrm{kg}$ body weight and sums of 4 and 2 skinfolds are presented in respectively Figures 1 and 2 . In both the $\mathrm{CP}$ and healthy children, sums of skinfolds were negatively correlated with water per $\mathrm{kg}$ 
Fig. 1. Body water $(\mathrm{L} / \mathrm{kg})$ as measured by deuterium dilution $\left(\mathrm{D}_{2} \mathrm{O}\right)$ versus sum of 4 (triceps, biceps, subscapular, suprailiac) skinfolds ( $\mathrm{mm}$ ) in $22 \mathrm{CP}$ and 10 healthy children

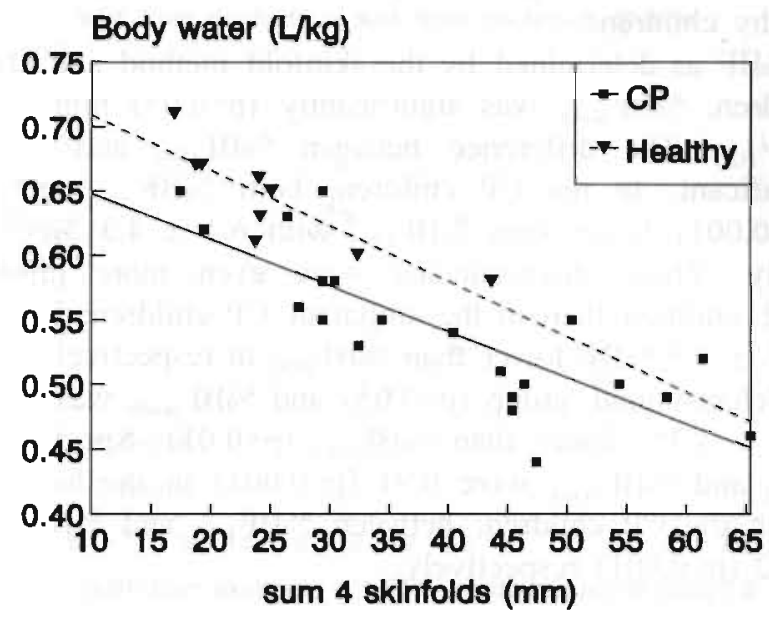

Regression lines are different $(p<0.05)$ between $C P$ and healthy; CP: $y=-0.0035849 x+0.68495, r=-0.81 \quad(p<0.001)$; healthy: $y=-0.0041965 x+0.74934, r=-0.85(p<0.001)$

Fig. 2. Body water $(\mathrm{L} / \mathrm{kg})$ as measured by deuterium dilution $\left(\mathrm{D}_{2} \mathrm{O}\right)$ versus sum of 2 (triceps, subscapular) skinfolds $(\mathrm{mm})$ in $22 \mathrm{CP}$ and 10 healthy children

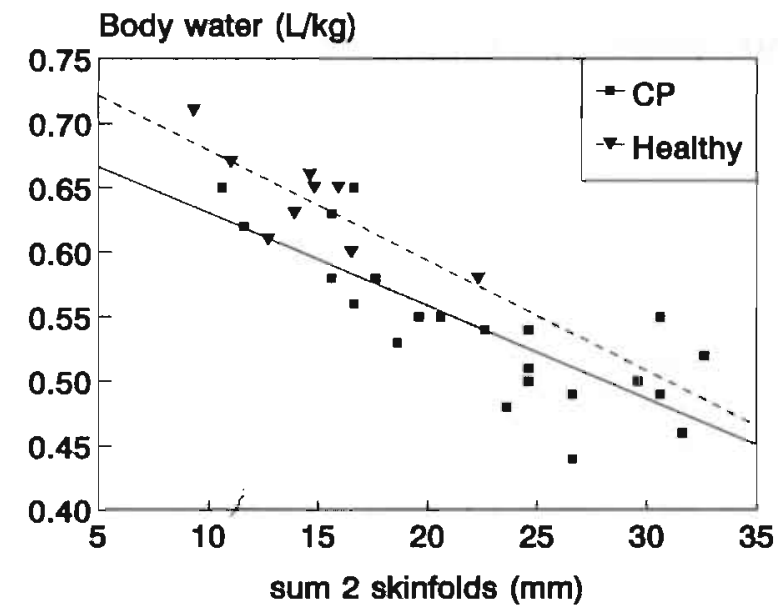

Regression lines are different $(\mathrm{p}<0.05)$ between $\mathrm{CP}$ and healthy; CP: $y=-0.0072897 x+0.70499, r=-0.80(p<0.001)$; healthy: $y=-0.0084253 x+0.76298, r=-0.81(p<0.01)$ 
body weight, but the regression lines differed significantly $(p<0.05)$ between the groups. In the CP children, sums of skinfolds were related to a lower water per $\mathrm{kg}$ body weight and thus to higher body fatness than comparable sums of skinfolds in the healthy children.

In Table II, \%BF as determined by the skinfold method and $\mathrm{D}_{2} \mathrm{O}$ is shown. In the healthy children, $\% \mathrm{BF}_{\text {skinA }}$ was significantly $(\mathrm{p}<0.05)$ higher with $1.5 \pm 1.6$ $\% \mathrm{BF}$ than $\% \mathrm{BF}_{\mathrm{D} 20}$. The difference between $\% \mathrm{BF}_{\mathrm{D} 20}$ and $\% \mathrm{BF}_{\text {skinB }}$ was not statistically significant. In the $\mathrm{CP}$ children, both $\% \mathrm{BF}_{\text {skinA }}$ and $\% \mathrm{BF}_{\text {skinB }}$ were significantly $(\mathrm{p}<0.001)$ lower than $\% \mathrm{BF}_{\mathrm{D} 20}$ with $6.1 \pm 4.3 \% \mathrm{BF}$ and $8.4 \pm 4.9$ $\% \mathrm{BF}$ respectively. These discrepancies were even more pronounced in the wheelchair-bound children than in the ambulant $\mathrm{CP}$ children: $\% \mathrm{BF}_{\text {skinA }}$ was $3.7 \pm$ $3.5 \% \mathrm{BF}$ and $8.5 \pm 3.5 \% \mathrm{BF}$ lower than $\% \mathrm{BF}_{\mathrm{D} 20}$ in respectively the ambulant $\mathrm{CP}$ group and wheelchair-bound group $(\mathrm{p}<0.05)$ and $\% \mathrm{BF}_{\text {skin }}$ was respectively $5.5 \pm$ $4.4 \%$ and $11.3 \pm 3.3 \%$ lower than $\% \mathrm{BF}_{\mathrm{D} 20}(\mathrm{p}<0.01)$. Spearman's correlations between $\% \mathrm{BF}_{\mathrm{D} 2 \mathrm{O}}$ and $\% \mathrm{BF}_{\text {skinA }}$ were $0.91(\mathrm{p}<0.001)$ in the healthy children and $0.84(\mathrm{p}<0.001)$ in the $\mathrm{CP}$ children; between $\% \mathrm{BF}_{\mathrm{D} 20}$ and $\% \mathrm{BF}_{\text {skinB }} \mathrm{r}_{\mathrm{s}}$ were 0.80 $(p<0.01)$ and $0.82(p<0.001)$ respectively.

Table II. \%BF as determined by deuterium dilution $\left(\mathrm{D}_{2} \mathrm{O}\right)$ and skinfold thicknesses (method Dumin and Rahaman (11) (skinA) and Slaughter et al. (24) (skinB))

\begin{tabular}{lcc}
\hline & $\begin{array}{c}C P \\
(n=22)\end{array}$ & $\begin{array}{c}\text { Healthy } \\
(\mathrm{n}=10)\end{array}$ \\
\hline$\% \mathrm{BF}_{\mathrm{D} 20}$ & $28.6 \pm 8.0$ & $15.9 \pm 5.1$ \\
$\% \mathrm{BF}_{\text {skinA }}$ & $22.5 \pm 6.0^{\circ}$ & $17.4 \pm 4.5^{\dagger}$ \\
$\% \mathrm{BF}_{\text {skin }}$ & $20.2 \pm 5.4^{\circ}$ & $13.7 \pm 3.2$ \\
\hline
\end{tabular}

Values are mean $\pm S D ;{ }^{\circ} p<0.001,{ }^{\dagger} p<0.05$; significantly different from $\% \mathrm{BF}_{\mathrm{D} 20}$

Figures 3 and 4 present the differences in \%BF between the skinfold method and the $\mathrm{D}_{2} \mathrm{O}$ technique against the average $\% \mathrm{BF}$ according to Altman and $\mathrm{Bland}(1)$. In the healthy children, no correlations existed between the difference in $\% \mathrm{BF}$ and the average $\% \mathrm{BF}$ (Figure 3 ). In the $\mathrm{CP}$ children, there was a significant correlation $(r=-0.58, p<0.01)$ between the difference in $\% \mathrm{BF}_{\text {skinB }}$ and $\% \mathrm{BF}_{\mathrm{D} 2 \mathrm{O}}$ and the average $\% \mathrm{BF}$ (Figure 4 ). 
Fig. 3. Difference in \% body fat (BF) determined by skinfold thicknesses and by deuterium. dilution $\left(\mathrm{D}_{2} \mathrm{O}\right)$ versus mean \%BF in 10 healthy children

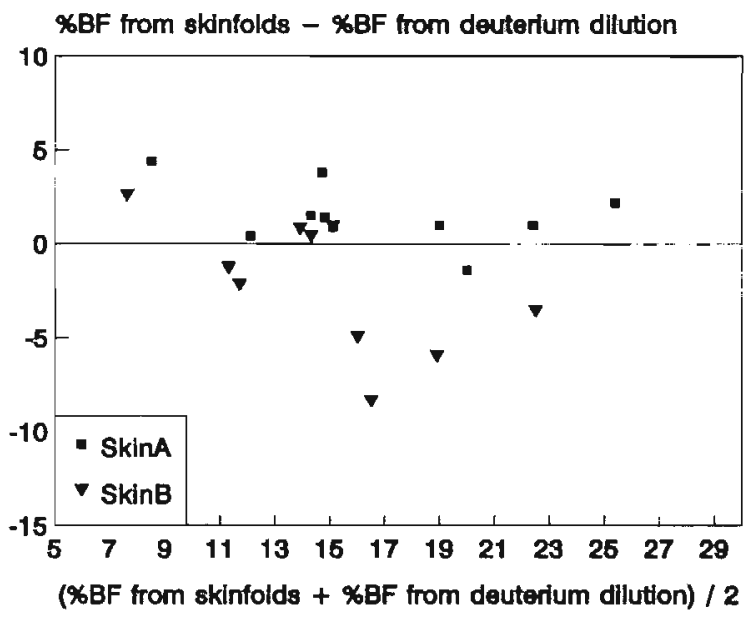

SkinA (Dumin and Rahaman (11)): relative bias $=1.5 \% \mathrm{BF}$, error $=1.6 \% \mathrm{BF}$ : SkinB (Slaughter et al. (24)): relative bias= $-2.2 \% \mathrm{BF}$, error $=3.3 \% \mathrm{BF}$

Fig. 4. Difference in \% body fat (BF) determined by skinfold thicknesses and by deuterium dilution $\left(\mathrm{D}_{2} \mathrm{O}\right)$ versus mean $\% \mathrm{BF}$ in $22 \mathrm{CP}$ children

\%BF from skinfolds - \%BF from deuterium dilution

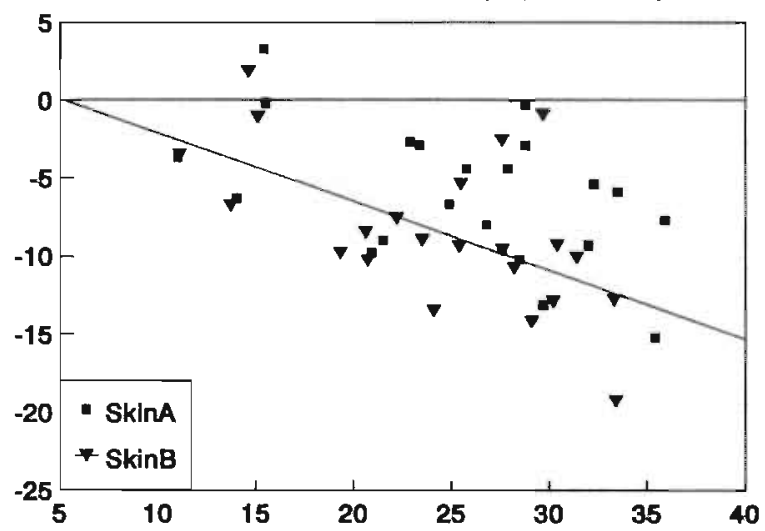

(\%BF from sidntolds + \%BF from deuterlum dilution) / 2

SkinA (Durnin and Rahaman (11)): relative bias $=-6.1 \% \mathrm{BF}$, error $=4.3 \% \mathrm{BF}$;

SkinB (Slaughter et al. (24)): $y=-0.043929 x+2.2668, \quad r=$ $-0.58(\mathrm{p}<0.01)$ 


\section{Discussion}

In order to assess whether skinfold measurements are suitable to predict $\mathrm{BF}$ in comparative studies between $\mathrm{CP}$ and healthy children, \%BF predicted from skinfold thicknesses was compared to \%BF estimated by the $\mathrm{D}_{2} \mathrm{O}$ technique.

Height and weight of the healthy children in this study are in agreement with representative samples of the Dutch population of the same age (20). The CP children are on average short for their age, which is in conformity with previously published reports $(21,26)$. and heavy for their height, which also has been found in the study of Berg and Isaksson (4) in severely handicapped CP children.

The $\mathrm{D}_{2} \mathrm{O}$ technique is not ideal as reference method in body composition studies in subjects with disturbed water balance. Also, the technique is less appropriate in children than in adults. because of the changing water-content of FFM during growth $(8,13,17)$. Based on the findings of Berg and Isaksson (4) in CP children, a higher water proportion of FFM may be expected in CP children than in healthy children. However, in case of a higher water proportion of FFM in the $\mathrm{CP}$ group of the present study, the discrepancies found in this group between $\% \mathrm{BF}$ as determined from skinfold measurements and by $\mathrm{D}_{2} \mathrm{O}$. would even be more pronounced. Therefore, although no conclusions can be drawn about the absolute amount of $\mathrm{BF}$, this study provides insight in the validity of skinfold measurements to determine $\mathrm{BF}$ in comparative studies between $\mathrm{CP}$ and healthy children.

TBW as a percentage of body weight was significantly lower $(\mathrm{p}<0.001)$ in the $\mathrm{CP}$ children than in the healthy children, in contrast with the studies of Berg and Isaksson (4) and Bandini et al. (3) in respectively CP children and CP adolescents. This lower mean water per $\mathrm{kg}$ body weight in the $\mathrm{CP}$ children of the present study, can be explained by increased $\mathrm{BF}$ in the $\mathrm{CP}$ group in comparison with the healthy group.

In the healthy group, the skinfold equations based on estimates of fatness derived from the two-component model of densitometry (11) (skinA), resulted in a significantly higher $\% \mathrm{BF}$ than $\mathrm{D}_{2} \mathrm{O}$ (Table II). No significant differences existed between $\% \mathrm{BF}_{\mathrm{D} 2 \mathrm{O}}$ and $\% \mathrm{BF}$ estimated from skinfold equations which are based on fatness derived from a multicomponent model (24) (skinB, takes into account the chemical immaturity of children). However, as described, no conclusions can be drawn from this study about the absolute amount of BF because of lack of a 'gold standard'.

From Figures 1 and 2 it can be seen that the relation between water per $\mathrm{kg}$ body weight and skinfold thickness differed between the $\mathrm{CP}$ and healthy children. In contrast with what was expected, skinfold equations derived for normal healthy children $(11,24)$, resulted in a considerably lower $\% \mathrm{BF}$ than $\% \mathrm{BF}_{220}$ in the $\mathrm{CP}$ children (Table II). This finding is in agreement with the study of Stallings et al. (25) in children with spastic quadriplegic CP. However, Stallings et al. (25) reported similar underestimations in $\mathrm{BF}$ by the skinfold method in a group of healthy control subjects.

The discrepancy in BF between the skinfold method and $\mathrm{D}_{2} \mathrm{O}$ in the $\mathrm{CP}$ group may be explained by a proportionally large internal fat depot, possibly due to 
higher levels of body fatness. It might also be hypothesized that in CP children, proportionally more subcutaneous fat is located in the lower limbs, due to decreased activity. This might also explain the significantly larger differences in $\% \mathrm{BF}$ between the skinfold method and $\mathrm{D}_{2} \mathrm{O}$ in the wheelchair group in comparison with the ambulant $\mathrm{CP}$ group. Adding lower extremity skinfolds to the regular 2 or 4 sites, might provide more accurate estimations of the subcutaneous fat in CP children. Lee (16) compared thicknesses of subcutaneous tissue of the normal and diseased limbs in adult patients with chronic hemiplegia and reported increased fatness in the paralyzed limbs, possibly due to decreased activity. However, whether this increased fatness in diseased limbs also exists in young $\mathrm{CP}$ children, has not been studied.

Based on the results of this study we conclude that skinfold equations derived for healthy children, are not suitable to predict BF in comparative studies between $\mathrm{CP}$ and healthy children. In contrast with what was expected, skinfold measurements in the $\mathrm{CP}$ children resulted in a considerably lower $\% \mathrm{BF}$ than $\mathrm{D}_{2} \mathrm{O}$, whereas in the healthy children this was not seen. A proportionally large internal fat depot and a different distribution of subcutaneous fat in CP children may be responsible for this.

\section{Acknowledgements}

We thank all the children and their parents who participated in this study and also Renate Wigger. Donnie de Barbanson and Loek Wouters for their help during data cullection and analysis. We also thank the staff of the children's rehabilitation Center Franciscusoord (Valkenburg a/d Geul) for their cooperation in this study.

\section{References}

1. Altman, D. G., J. M. Bland. Measurement in medicine: the analysis of method comparison studies. The Statisrician 32:307-317, 1983.

2. Aristimuno, G. G., T. A. Foster, A. W. Voors, S. R. Srinivasan, G. S. Berenson. The influence of persistent obesity in children on cardiovascular risk factors: the Bogalusa Heart Study. Circulation 69:895-904, 1984.

3. Bandini, L. G., D. A. Schoeller, N. K. Fukagawa, L. J. Wykes, W. H. Dietz. Body composition and energy expenditure in adolescents with cerebral palsy or myelodysplasia. Pediatr. Res. 29:70-77, 1991.

4. Berg, K., B. Isaksson. Body composition and nutrition of school children with curehral palsy. Acta Paediatr. Scand. 204(suppl):41-69, 1970.

5. Berg, K. Nutrition of children with reduced physical activity due to cerebral palsy. Bibl. Nutr. Diet. 19:12-20, 1973.

6. Berg-Emons van den, H. J. G., W. H. M. Saris, D. C. De Barbanson, K. R. Westerterp, A. Huson, M. A. van Baak. Daily physical activity of school children with spastic diplegia and of healthy control subjects. J. Pediatr. 127:578-584, 1995. 
7. Bleck, E. E. Orthopaedic management in cerebral palsy. Philadelphia: Lippincott, 1987:121-141.

8. Boileau, R. A., T. G. Lohman, M. H. Slaughter, T. E. Ball, S. B. Going, M. K. Hendrix. Hydration of the fat-free body in children during maturation. Hum. Biol. 56:651-666, 1984.

9. Brown, A. Review: Physical fitness and cerebral palsy. Child: care, health and development 1:143-152, 1975.

10. Deurenberg, P., J. J. L. Pieters, J. G. A. J. Hautvast. The assessment of the body fat percentage by skinfold thickness measurements in childhood and young adolescence. $\mathrm{Br} . J$. Nutr. 63:293-303, 1990.

11. Durnin, J. V. G. A., M. M. Rahaman. The assessment of the amount of fat in the human body from measurements of skinfold thickness. Br. J. Nutr. 21:681-689, 1967.

12. Eddy, T. P., A. L. Nicholson, E. F. Wheeler. Energy expenditures and dietary intakes in cerebral palsy. Develop. Med. Child. Neurol. 7:377-386, 1965.

13. Fomon, S. J., F. Haschke, E. E. Ziegler, S. E. Nelson. Body composition of reference children from birth to age 10 years. Am. J. Clin. Nutr. 35:1169-1175, 1982.

14. Haggarty, P., B. A. McGaw, M. F. Fuller, S. L. Christie, W. W. Wong. Water hydrogen incorporation into body fat in pigs: effect on double/triple-labeled water method. $\mathrm{Am} . \mathrm{J}$. Physiol. 260:R629-R634, 1991.

15. Havlik, R. J., H. B. Hubert, R. R. Fabsitz, M. Feinleib. Weight and hypertension. Ann. Int. Med. 98(2):855-859, 1983.

16. Lee, M. M. C. Thickening of the subcutaneous tissues in paralyzed limbs in chronic hemiplegia. Human Biol. 31:187-193, 1979.

17. Lohman, T. G. Applicability of body composition techniques and constants for children and youths. Exerc. Sports Sciences Reviews 14:325-357, 1986.

18. Lukaski, H. C. Methods for the assessment of body composition, traditional and new. Am. J. Clin. Nutr. 46:437-456, 1987.

19. Phelps, W. M. Dietary requirements in cerebral palsy. J. Amer. Diet. Assoc. 27:869876, 1951 .

20. Roede, M. J., J. C. van Wieringen. Growth diagrams 1980. Netherlands third nation-wide survey. Tijdschr. Soc. Gezondheidszorg 63(suppl):1-34, 1985.

21. Ruby, D. O., W. D. Matheny. Comments on growth of cerebral palsied children. $J$. Am. Dietet. Assoc, 40:\$25-527, 1962.

22. Shaw, N. J., C. P. White, W. D. Fraser, L. Rosenbloom. Osteopenia in cerebral palsy. Arch Dis. Child 71:235-238, 1994.

23. Siri, W. E. The gross composition of the body. Adv. Biol. Med. Physiol. 4:239-280, 1956.

24. Slaughter, M. H., T. G. Lohman, R. A. Boileau, C. A. Horswill, R. J. Stillman, M. D. van Loan, D. A. Bemben. Skinfold equations for estimation of body fatness in children and youth. Hum. Biol. 60(5):709-723, 1988.

25. Stallings, V. A., C. E. Cronk, B. S. Zemel, E. B . Charney. Body composition in children with spastic quadriplegic cerebral palsy. J. Pediatr. 126:833-839, 1995.

26. Tobis, J. S., P. Saturen, G. Larios, A. O. Posniak. Study of growth patterns in cerebral palsy. Arch. Phys. Med. Rehabil. 42:475-481, 1961. 


\section{Reliability of tests to determine peak aerobic power, anaerobic power, and isokinetic muscle strength in spastic cerebral palsied children and healthy controls}

H. J. G. van den Berg-Emons ', M. A. van Baak ${ }^{2}$, D. C. de Barbanson ${ }^{1}$, L. Speth ${ }^{3}$, and W. H. M. Saris ${ }^{2}$

Departments of Movement Sciences ${ }^{1}$ and Human Biology ${ }^{2}$, University of Limburg, PO Box 616, 6200 MD Maastricht, The Netherlands and the children's rehabilitation center Franciscusoord ${ }^{3}$, Onderstestraat 29,6301 KA Valkenburg a/d Geul, The Netherlands

Dev. Med. Child Neurol. [accepted].

\section{Abstract}

Test-retest reliability of measurements of peak aerobic power (cycle ergometer), anaerobic power (cycle ergometer), and isokinetic muscle strength of the knee (Cybex) was established in young cerebral palsied (CP) children with spastic diplegia/tetraplegia ( $\mathrm{n}=12$; mean $\pm \mathrm{SD}$ age $8.8 \pm 1.7 \mathrm{y}$ ) and in addition in healthy controls $(n=39$; mean $\pm S D$ age $9.2 \pm 2.1$ y). The cycle ergometer tests were found to be reliable in both the $\mathrm{CP}$ and healthy group (test-retest correlations varying from 0.72 to 0.96 ). The isokinetic strength test was in the $\mathrm{CP}$ group only reliable at $30 \%$, whereas in the healthy group also high test-retest correlations were found at $60 \%$ and $120 \%$. Because of the larger intra-individual differences in the CP children than in the healthy children, it is concluded that the described test protocols are, at individual level, less suitable in $\mathrm{CP}$ children than in healthy controls. 


\section{Introduction}

Cerebral palsy (CP) is an inclusive term used to describe a number of chronic, non-progressive disorders of motor function, which occur in young children as a result of disease of the brain (19). The most common form of CP is the spastic type, which accounts for approximately two-third to three-quarter of all children with $\mathrm{CP}$ (16). Proneness to fatigue and low muscle strength are characteristic as symptoms in CP $(9,10)$.

Monitoring the physical capacity of CP children is of dual importance. On the one hand, it can yield information on the functional severity and natural history of the disease. On the other hand, it can help assess the effects of therapeutic interventions such as diet, physical therapy, occupational therapy, or conditioning (3). In the present study, the reliability of tests to determine peak aerobic power, anaerobic power, and isokinetic muscle strength was established in young children with spastic $\mathrm{CP}$. In addition, results found in the $\mathrm{CP}$ children were compared to measurements in healthy controls.

\section{Subjects and methods}

\section{Subjects}

The total study group consisted of 12 children with spastic CP ( 6 boys and 6 girls) and 39 healthy children ( 22 boys and 17 girls) between 6 and 12 years of age. The CP children were classified according to the methods of Hagberg (in Olow and Berg, 24) and Cruickshank (11) by a physician at the children's rehabilitation center Franciscusoord in Valkenburg (Table I). Ten CP children were classified as diplegic (legs and feet are more affected than arms and hands); 2 were classified as tetraplegic (greater affliction of the upper part of the body than of the lower part). The CP children were attending the elementary school at Franciscusoord (normal intelligence and mild mental retardation). The healthy children were recruited from an elementary school in Maastricht (normal intelligence). The children and their parents were informed of all aspects of the study and written consent was obtained. The study was approved by the Medical Ethics Committees of the University of Limburg and the Cooperating Rehabilitation Centers Limburg.

\section{Anthropometric measurements}

Body weight was obtained (Seca Germany) while wearing under-clothing. In the ('P children a chair scale was used. Height measurements were taken while standing against a wall, or if unable to stand independently, while lying on a bed with a wooden $T$-square or a flexible tape. Thickness of 4 skinfolds (biceps, triceps, subscapular, suprailiac) was measured with a Servier caliper on the nondominant side of the body. 
Table I. Classification of the 12 cerebral palsied (CP) children

\begin{tabular}{|c|c|c|c|c|c|c|}
\hline \multirow[b]{2}{*}{$\mathrm{Nr}$} & \multirow[b]{2}{*}{$\operatorname{Sex}^{8}$} & \multicolumn{2}{|c|}{ CP classification ${ }^{*}$} & \multicolumn{3}{|c|}{ Severity } \\
\hline & & Tonus & $\begin{array}{l}\text { Abnormal } \\
\text { movements }\end{array}$ & Distribution & $\begin{array}{l}\text { Girade } \\
1-3\end{array}$ & $\begin{array}{l}\text { Way of } \\
\text { ambulation }\end{array}$ \\
\hline 1 & $M$ & hyper & - & diplegia & I & ambulant \\
\hline 2 & M & hyper & - & diplegia & 1 & ambulant \\
\hline 3 & $\mathrm{~F}$ & hyper & - & diplegia & 1 & ambulant \\
\hline 4 & M & hyper & - & diplegia & 2 & ambulant \\
\hline 5 & $\mathrm{~F}$ & hyper & - & diplegia & 1 & ambulant \\
\hline 7 & $\mathrm{~F}$ & hyper & ataxia & diplegia & 2 & ambulant \\
\hline 8 & M & hyper & ataxia & diplegia & 2 & ambulant \\
\hline 9 & $\mathrm{~F}$ & hyper & - & diplegia & 2 & wheelchair \\
\hline 10 & $\mathrm{~F}$ & hyper & - & diplegia & 2 & wheelchair \\
\hline 17 & $M$ & hyper & - & tetraplegia & 3 & wheelchair \\
\hline 23 & $\mathrm{M}$ & hyper & - & diplegia & 2 & ambulant \\
\hline 28 & $\mathrm{~F}$ & hyper & $\begin{array}{l}\text { ataxia/ } \\
\text { athethosis }\end{array}$ & tetraplegia & 3 & wheelchair \\
\hline
\end{tabular}

" according to the classification of Hagberg (in Olow and Berg. 24)

' graduation according to Cruickshank (11)

1 may appear normal except that the precision of the movement may be impaired

3 unable to care for all his bodily needs because he is unable to walk unassisted, talk clearly or has little use of his hands

2 in between 1 and 3

${ }^{8} \mathrm{M}=$-male, $\mathrm{F}=$ female

\section{Peak aerobic power}

In the CP children, 4 progressive maximal aerobic exercise tests (based on the McMaster All-Out Progressive Continuous Cycling Test, 2) were performed on a mechanically braked Monark leg cycle ergometer. The first test was a habituation test. which was also used to check the protocol and find out whether the CP children needed fixations on the pedals. This habituation test was followed by 3 'real' tests within a period of 3 weeks. The healthy children performed 2 progressive maximal aerobic exercise tests within a period of 3 weeks. Resistance was increased every $2 \mathrm{~min}$ with a variable load, depending on the abilities of the child, until the child was unable to continue pedaling. Individual protocols were constructed such that the total exercise time ranged between 8 and $12 \mathrm{~min}$. No fixed pedaling rate was required, the number of revolutions was recorded. All the tests were preceded by a warm-up of about $5 \mathrm{~min}$ and verbal encouragement was given throughout the tests. Peak aerobic power was defined as the highest power output over the 2 min of a load. When the child could not complete $2 \mathrm{~min}$ of the final load, peak power was calculated as the mean of the power of the penultimate stage and the final stage. Peak heart rate (HR, measured with a Sport Tester PE3000, Polar Electro, Finland) was defined as the highest average HR over the last min of a load. 


\section{Anaerobic power}

Anaerobic performance was measured by the Wingate Anaerobic Cycling Test (WAnT). A detailed description of this test may be found elsewhere $(4,13)$. Briefly, the WAnT is a 30-s cycling test at all-out speed, against a constant braking force. The CP children performed the WAnT 4 times on the mechanically braked Monark leg cycle ergometer. The first test was a practice session. By trial and error the force was determined which elicited the highest power (= optimal braking force). Subsequently, 3 tests were performed in each CP child, within a period of 3 weeks, using this predetermined force setting. In the healthy children, 2 tests were performed during a time span of 3 weeks. All the tests were preceded by a warm-up of about $5 \mathrm{~min}$ and verbal encouragement was given throughout the 30 -s period. Pedal revolutions were registered continuously. Two performance indices were calculated: peak power (PP, reflecting the ability of the limb muscles to produce high mechanical power in a short time) and mean power (MP, reflecting the ability to sustain high power) (4).

\section{Isokinetic muscle strength}

Muscle strength was determined by an isokinetic device (Cybex II, Ronkonkoma, USA), recording strength as torque in $\mathrm{Nm}$. Details concerning the principles of isokinetic exercise may be found elsewhere $(18,29)$. Torque determinations were made on the extensor and flexor muscles of the knees at 3 different angle speeds $(30 \%, 60 \%, 120 \%$ s). The test was conducted while the child was seated in erect position with thigh and pelvis stabilized. All measurements were performed at the damping levels recommended by the Cybex Testing Manual (12). Following 2 trial motions at each speed to familiarize the subject with the testing apparatus, each subject performed 5 maximal contractions, starting with the least affected/dominant leg (CP respectively healthy children) at the different speeds (test 1). Each subject started at an angular velocity of $30 \%$ and had brief rest intervals between the different speeds. Verbal encouragement was given to exert maximal effort. After repositioning the apparatus, the subject completed the above procedures for the opposite limb. The reliability of the test (within-day reliability) was established by repeating the protocol after a rest period of about 1.5 hour (test 2). Peak torque (PT) was defined as the maximum torque generated by the subject throughout 1 series of repetitions.

The healthy children performed the aerobic and anaerobic cycle test on the same day (with a sufficient break between the 2 tests); cycle tests in the CP children were on separate days. Isokinetic strength tests were in both groups of children on separate days. Due to practical reasons, the numbers of children differed among the 3 physical capacity tests. 


\section{Statistical analysis}

Data are presented as mean \pm SD. Comparisons between data were made using the Friedman test ( $\mathrm{k}$ related samples) and the Wilcoxon test (2 related samples) for paired observations and the Mann-Whitney $U$ test for unpaired observations $(\alpha=0.05)$. Test-retest reliability was established by Spearman's rank order correlation $\left(\mathrm{r}_{\mathrm{s}}\right)$. Because of different ranges in test-outcome between the CP and healthy children, the intra-individual difference between tests was calculated as a percentage of the mean individual test-outcome.

\section{Results}

Characteristics of the $\mathrm{CP}$ and healthy group are presented in Table II. None of the differences in characteristics between the $\mathrm{CP}$ and healthy group was statistically significant. The healthy girls had a significantly higher $(p<0.001)$ sum of 4 skinfolds than the healthy boys, whereas this difference between the CP boys and $\mathrm{CP}$ girls was not statistically significant.

Table II. Characteristics of the 12 cerebral palsied (CP) children and 39 healthy $(\mathrm{H})$ children

\begin{tabular}{|c|c|c|c|c|c|c|}
\hline & $\mathrm{n}$ & $\begin{array}{l}\text { Age } \\
(y) \\
\end{array}$ & $\begin{array}{l}\text { Height } \\
(\mathrm{cm})\end{array}$ & $\begin{array}{c}\text { Weight } \\
(\mathrm{kg}) \\
\end{array}$ & $\begin{array}{c}\text { Sum } 4 \\
\text { skinfolds } \\
(\mathrm{mm})\end{array}$ & $\begin{array}{c}\mathrm{BMI} \\
\left(\mathrm{kg} / \mathrm{mr}^{2}\right) \\
\end{array}$ \\
\hline $\mathrm{CP} \delta$ & 6 & $\begin{array}{c}8.2 \pm 1.5 \\
(7-11)\end{array}$ & $\begin{array}{r}128.8 \pm 10.3 \\
(121.0-151.0)\end{array}$ & $\begin{array}{l}30.4 \pm 12.5 \\
(20.0-57.0)\end{array}$ & $\begin{array}{l}30.0 \pm 14.6 \\
(14.0-58.0)\end{array}$ & $\begin{array}{l}17.6 \pm 3.8 \\
(13.7-25.0)\end{array}$ \\
\hline $\mathrm{CP} q$ & 6 & $\begin{array}{c}9.3 \pm 1.8 \\
(7-12)\end{array}$ & $\begin{array}{r}134.4 \pm 12.7 \\
(120.0-152.5)\end{array}$ & $\begin{array}{l}35.1 \pm 16.3 \\
(19.0-68.0)\end{array}$ & $\begin{array}{l}36.0 \pm 17.5 \\
(23.0-70.0)\end{array}$ & $\begin{array}{r}18.5 \pm 5.3 \\
(13.2-29.2)\end{array}$ \\
\hline $\mathrm{H} \delta$ & 22 & $\begin{array}{c}9.0 \pm 2.2 \\
(6-12)\end{array}$ & $\begin{array}{r}138.0 \pm 12.9 \\
(116.5-160.0)\end{array}$ & $\begin{array}{c}33.6 \pm 9.1 \\
(21.0-57.0)\end{array}$ & $\begin{array}{c}22.5 \pm 4.2 \\
(15.0-32.0) \\
+\end{array}$ & $\begin{array}{l}17.3 \pm 1.8 \\
(14.8-22.3)\end{array}$ \\
\hline 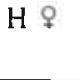 & 17 & $\begin{array}{c}9.5 \pm 1.9 \\
(6-12)\end{array}$ & $\begin{array}{r}141.3 \pm 11.6 \\
(124.5-166.5)\end{array}$ & $\begin{array}{r}36.1 \pm 7.7 \\
(25.0-52.0)\end{array}$ & $\begin{array}{l}31.2 \pm 8.0 \\
(16.0-44.0)\end{array}$ & $\begin{array}{l}17.8 \pm 1.5 \\
(14.7-20.4)\end{array}$ \\
\hline
\end{tabular}

Values are mean $\pm S D$, with ranges in parentheses; ${ }^{\circ} \mathrm{BMI}$ : body mass index; $\dagger p<0.001$

\section{Peak aerobic power}

Peak aerobic power in the $\mathrm{CP}$ children (6 boys, 4 girls; 8 diplegic, 2 tetraplegic) and in the healthy children ( 22 boys and 12 girls) did not differ significantly among the tests (Figure 1). Test-retest correlation coefficients for peak aerobic power between the first and second test were similar in the $C P$ and healthy children. However, the intra-individual difference (as a percentage of the mean power; absolute intra-individual differences were similar in the 2 groups) between the first and second test was significantly higher $(p<0.05)$ in the CP children 
(19.1 \pm 11.8 percent) than in the healthy children $(9.9 \pm 7.4$ percent $)$. Intraindividual differences between test 1 and 3 and between test 2 and 3 in the $\mathrm{CP}$ group, did not differ from the intra-individual difference between the first and second test.

Spearman's correlation between body weight and peak aerobic power was 0.73 $(p<0.01)$ in the CP group and $0.83(p<0.001)$ in the healthy group. Peak aerobic power (watt $/ \mathrm{kg}$ ) was on average 46 percent lower $(\mathrm{p}<0.001)$ in the CP children $(1.5 \pm 0.5$ watt $/ \mathrm{kg})$ than in the healthy children $(2.8 \pm 0.4$ watt $/ \mathrm{kg})$. In $3 \mathrm{CP}$ children (numbers 1,2,4, Table I), peak aerobic power per $\mathrm{kg}$ was within the range found in their healthy peers.

Peak HR occurred almost always in the final load of a test. Peak HR in the CP children was $168 \pm 15 \mathrm{bts} / \mathrm{min}$ in the first test, $167 \pm 14 \mathrm{bts} / \mathrm{min}$ in the second test, and $164 \pm 13 \mathrm{bts} / \mathrm{min}$ in the third test. Differences in peak HR among the tests were not statistically significant. Peak HR in the CP children was on average 13 percent lower $(p<0.001)$ than in the healthy children. Peak HR in the healthy children did not differ between the 2 tests $(191 \pm 12 \mathrm{bts} / \mathrm{min}$ in the first test and $190 \pm 13 \mathrm{bts} / \mathrm{min}$ in the second test).

Fig. 1. Peak aerobic power (watt) during the different tests in 10 spastic cerebral palsied (CP) children and 34 healthy children

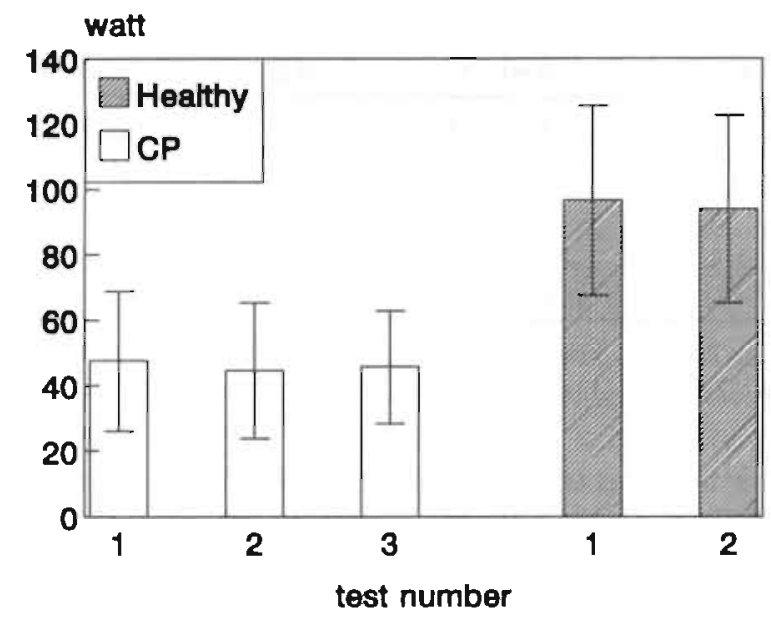

1 vs 2 CP: $r_{s}=0.92(p<0.001) \quad H: r_{s}=0.90(p<0.001)$
2 vs 3 CP: $r_{s}=0.72(p<0.01)$
I vs 3 CP: $r_{s}=0.84(p<0.01)$ 


\section{Anaerobic power}

PP in the CP children ( 6 boys, 6 girls; 10 diplegic, 2 tetraplegic) tended to increase from the first to the third test (Figure 2). This increase of 14 percent was however not statistically significant $(\mathrm{p}=0.08)$. MP in the $\mathrm{CP}$ group did not differ significantly among the tests. In the healthy children ( 22 boys and 12 girls), there were no statistically significant differences in PP and MP between the 2 tests (Figure 3). Test-retest correlation coefficients for PP and MP were similar in both groups of children (Figures 2 and 3). Mean intra-individual differences in PP and MP (as a percentage of the mean power; absolute intra-individual differences tended to be higher (ns) in the healthy group) between the first and second test were $14.2 \pm 13.4$ percent (CP) and $6.8 \pm 8.0$ percent (healthy) for PP and $12.3 \pm$ 12.1 percent (CP) and $9.7 \pm 7.2$ percent (healthy) for MP (ns). Intra-individual differences between test 1 and 3 and between test 2 and 3 in the CP group, did not differ from the intra-individual differences between the first and second test.

Spearman's correlations between body weight and anaerobic performance were $0.73(p<0.001)$ in the CP children and $0.79(p<0.001)$ in the healthy children. PP (watt $/ \mathrm{kg}$ ) was on average 55 percent lower $(\mathrm{p}<0.001)$ in the $C P$ children $(3.0 \pm$ 1.3 watt $/ \mathrm{kg}$ ) than in the healthy children $(6.6 \pm 1.0$ watt $/ \mathrm{kg}$ ). MP (watt $/ \mathrm{kg}$ ) was on average 50 percent lower $(p<0.001)$ in the CP children $(2.3 \pm 0.9$ watt $/ \mathrm{kg})$ than in the healthy children $(4.6 \pm 0.7 \mathrm{watt} / \mathrm{kg})$. Anaerobic performance was in only $2 \mathrm{CP}$ children (numbers 1 and 4, Table I) within the range found in their healthy peers.

Fig. 2. Peak anaerobic power (PP, in watt) and mean anaerobic power (MP, in watt) during 3 tests in 12 spastic cerebral palsied children

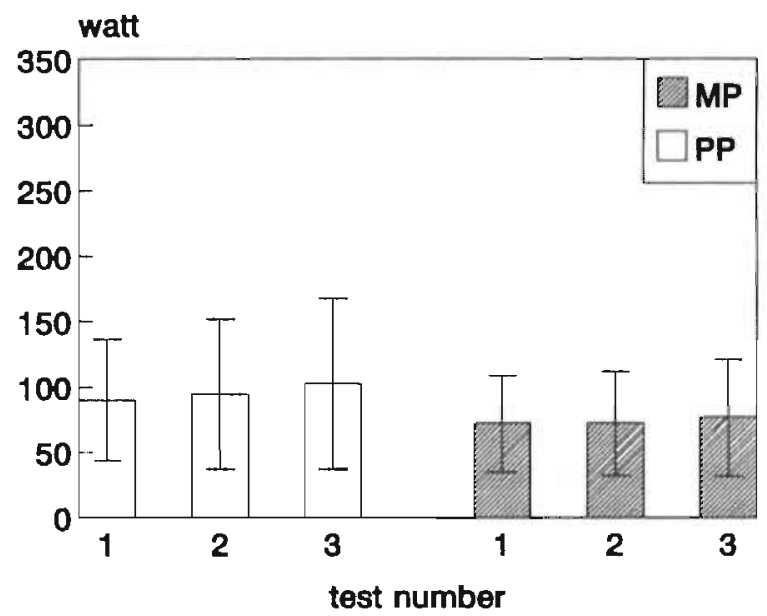

1 vs 2 PP: $r_{s}=0.90(p<0.001)$ MP: $r_{s}=0.95(p<0.001)$

2 vs 3 PP: $r_{s}=0.90(p<0.001)$ MP: $r_{s}=0.92(p<0.001)$

I vs 3 PP: $r_{s}=0.94(p<0.001)$ MP: $r_{s}=0.95(p<0.001)$ 
Fig. 3. Peak anaerobic power (PP, in watt) and mean anaerobic power (MP, in watt) during 2 tests in 34 healthy children

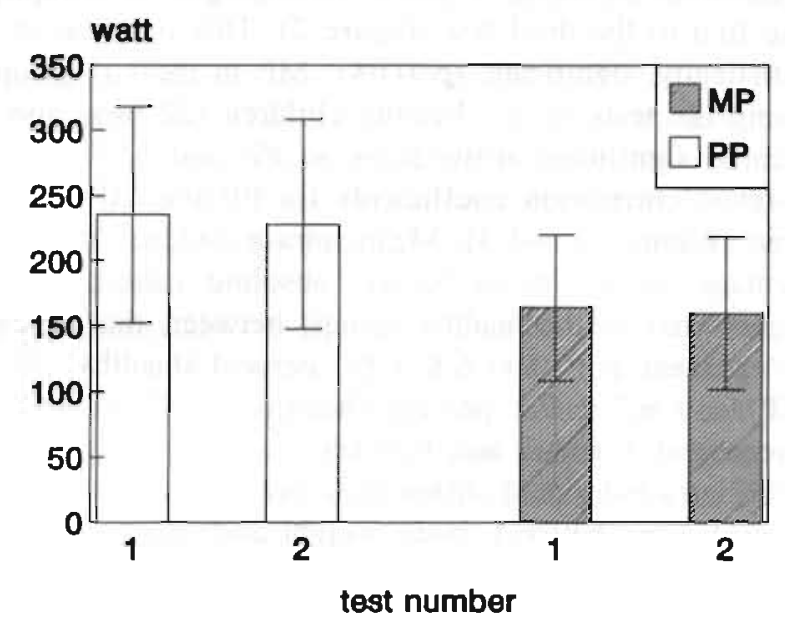

I vs 2 PP: $r_{s}=0.96(p<0.001)$ MP: $r_{s}=0.92(p<0.001)$

\section{Isokinetic muscle strength}

In Table III, flexion and extension PT $(\mathrm{Nm})$, test-retest correlation coefficients, and intra-individual differences (as a percentage of mean PT), are presented for the diflerent speeds during the 2 tests. The isokinetic strength test could not be performed in 4 children of the $\mathrm{CP}$ group, because muscle strength was too weak. In the $\mathrm{CP}$ children ( 5 boys, 3 girls; all diplegic), there were no significant differences in flexion and extension PT between the 2 tests. In the healthy children ( 21 boys, 17 girls), flexion and extension PT at $30 \% \mathrm{~s}$ and flexion PT at $60 \%$, were in the second test lower (on average 4 percent, $p<0.05$ ) than in the first test. Test-retest correlation coefficients were at all speeds lower in the CP group than in the healthy group. Intra-individual differences (as a percentage of the mean PT; absolute intra-individual differences were similar in both groups) were significantly higher $(\mathrm{p}<0.01)$ in the CP group than in the healthy group at $60 \%$ (flexion) and at $120 \%$ (flexion and extension).

At $30 \%$ and $60 \%$, PT in the CP group was on average 25 percent $(\mathrm{p}<0.05)$ higher in the least affected leg than in the most affected leg. At $120 \%$, there was no significant difference between both legs. In the healthy children, comparisons between dominant and non-dominant leg yielded no consistent results.

Because higher correlations were found between height and PT (CP: mean $r_{s}$ over the different speeds $=0.53 \pm 0.06$; healthy: mean $r_{s}=0.89 \pm 0.03$ ) than between weight and PT (CP: mean $r_{s}=0.46 \pm 0.07$; healthy: mean $r_{s}=0.83 \pm$ $0.03)$. PT data between the ( $P$ and healthy group were compared when expressed per $\mathrm{cm}$ body height. Flexion and extension PT/cm were on average (over the 3 test-velocities) respectively 53 percent and 48 percent $(p<0.001)$ lower in the CP 
children than in the healthy children. Only $2 \mathrm{CP}$ children (numbers 2 and 4, Table I), had PT values within the range of their healthy peers.

Table III. Mean scores (SD) of knee flexion and extension peak torque, test-retest correlation coefficients $\left(r_{s}\right)$, and intra-individual difference (1.D.) during 2 tests in 8 cerebral palsied (CP) children and 38 healthy $(\mathrm{H})$ children

\begin{tabular}{|c|c|c|c|c|c|c|c|c|c|c|c|}
\hline & \multirow[b]{2}{*}{$\begin{array}{c}\text { Speed } \\
(\% / s)\end{array}$} & \multicolumn{5}{|c|}{ Flexion } & \multicolumn{5}{|c|}{ Extension } \\
\hline & & $\begin{array}{l}\text { test } 1 \\
(N m)\end{array}$ & & $\begin{array}{l}\text { test } 2 \\
(\mathrm{Nm})\end{array}$ & $r_{s}$ & $\begin{array}{l}\text { I.D. } \\
(\%)\end{array}$ & $\begin{array}{l}\text { test } 1 \\
(\mathrm{Nm})\end{array}$ & & $\begin{array}{r}\text { test } 2 \\
(\mathrm{Nm})\end{array}$ & $r_{s}$ & $\begin{array}{l}\text { I.D. } \\
\text { (\%) }\end{array}$ \\
\hline \multirow{3}{*}{$\mathrm{CP}$} & 30 & $\begin{array}{l}23.7 \\
(9.1)\end{array}$ & & $\begin{array}{c}21.9 \\
(10.0)\end{array}$ & $0.84^{\circ}$ & $\begin{array}{c}25.1 \\
(26.7)\end{array}$ & $\begin{array}{l}41.3 \\
(15.7)\end{array}$ & & $\begin{array}{c}39.5 \\
(16.7)\end{array}$ & $0.71^{\dagger}$ & $\begin{array}{r}25.3 \\
(25.3)\end{array}$ \\
\hline & 60 & $\begin{array}{c}21.2 \\
(10.1)\end{array}$ & & $\begin{array}{l}20.2 \\
(8.8)\end{array}$ & $0.75^{\circ}$ & $\begin{array}{c}29.9 \\
(20.0)\end{array}$ & $\begin{array}{c}39.4 \\
(19.5)\end{array}$ & & $\begin{array}{c}39.8 \\
(17.4)\end{array}$ & 0.55 & $\begin{array}{c}29.6 \\
(24.9)\end{array}$ \\
\hline & $120^{1}$ & $\begin{array}{r}18.3 \\
(8.2) \\
\end{array}$ & & $\begin{array}{l}19.0 \\
(7.8) \\
\end{array}$ & $0.65^{\dagger}$ & $\begin{array}{c}32.1 \\
(27.4) \\
\end{array}$ & $\begin{array}{l}27.1 \\
(9.7) \\
\end{array}$ & & $\begin{array}{c}30.8 \\
(12.8)\end{array}$ & 0.42 & $\begin{array}{c}33.8 \\
(27.6)\end{array}$ \\
\hline \multirow{3}{*}{$\mathrm{H}$} & 30 & $\begin{array}{c}49.6 \\
(20.5)\end{array}$ & $\$$ & $\begin{array}{l}47.1 \\
(19.1)\end{array}$ & $0.88^{\circ}$ & $\begin{array}{c}14.7 \\
(13.9)\end{array}$ & $\begin{array}{c}75.4 \\
(32.7)\end{array}$ & $\S$ & $\begin{array}{c}72.2 \\
(32.7)\end{array}$ & $0.95^{\circ}$ & $\begin{array}{l}11.6 \\
(9.2)\end{array}$ \\
\hline & 60 & $\begin{array}{c}47.1 \\
(19.2)\end{array}$ & $\S$ & $\begin{array}{c}45.3 \\
(19.2)\end{array}$ & $0.90^{\circ}$ & $\begin{array}{c}12.5 \\
(11.5)\end{array}$ & $\begin{array}{c}73.6 \\
(29.2)\end{array}$ & & $\begin{array}{c}70.9 \\
(31.9)\end{array}$ & $0.90^{\circ}$ & $\begin{array}{c}17.1 \\
(14.2)\end{array}$ \\
\hline & 120 & $\begin{array}{c}44.4 \\
(19.3)\end{array}$ & & $\begin{array}{c}43.3 \\
(18.7)\end{array}$ & $0.91^{\circ}$ & $\begin{array}{c}15.9 \\
(14.9)\end{array}$ & $\begin{array}{l}59.8 \\
(24.6)\end{array}$ & & $\begin{array}{c}58.2 \\
(24.0)\end{array}$ & $0.92^{\circ}$ & $\begin{array}{c}12.7 \\
(12.7)\end{array}$ \\
\hline
\end{tabular}

" $p<0.001,{ }^{\dagger} p<0.01,{ }^{8} p<0.05 ;{ }^{\circledR} n=7$

For flexion at $60 \%$ and $120 \%$, and extension at $120 \%$ s: I.D. is significantly different $(p<0.01)$ between $\mathrm{CP}$ and healthy.

\section{Discussion}

The aim of the present study was to establish the reliability of tests to determine peak aerobic power, anaerobic power, and isokinetic muscle strength in young spastic CP children. Comparable tests were performed in a group of healthy controls.

In comparison with representative samples of the Dutch population of the same age (27), the healthy children are on average heavy for their height (boys on average $3 \mathrm{~kg}$ heavier than the mean weight for height; girls $4 \mathrm{~kg}$ ). The healthy girls are also tall for their age (on average $3 \mathrm{~cm}$ taller than standards of attained height in Dutch children). The $\mathrm{CP}$ children are, in comparison with the I)utch reference data (27), small for their age (boys on average $2 \mathrm{~cm}$ smaller than reference data; girls on average $4 \mathrm{~cm}$ ) and heavy for their height (boys on average $5 \mathrm{~kg}$, girls $7 \mathrm{~kg}$ heavier than the mean weight for height of Dutch children). The short stature of the $\mathrm{CP}$ children is in conformity with previously published reports $(28,31)$. The high weight for height in the CP children has also been found in the study of Berg and Isaksson (6) in severely handicapped CP children. Because of a possibly different relationship between skinfold thicknesses and body fat in ('P 
and healthy children (7), no calculations of body fat and fat-free mass were performed.

\section{Peak aerobic power}

Absolute values of peak aerobic power of the healthy children of the present study are in agreement with cycle ergometry studies as presented by Bar-Or (2) and Washington et al. (32). When expressed per $\mathrm{kg}$ body mass, peak aerobic power of the healthy children of the present study is about 20 percent lower, but this is probably due to the relatively high body weight in the present study. The $\mathrm{CP}$ children had on average only about 50 percent of the aerobic power (in absolute terms and per $\mathrm{kg}$ body mass) of the healthy children. This subnormal aerobic power in $\mathrm{CP}$ is in agreement with previous reports $(2,3,14,20,21)$.

The significantly lower peak $\mathrm{HR}$ in the $\mathrm{CP}$ children than in the healthy children suggests that, peak aerobic performance during leg cycling was attained at a lower level of cardiorespiratory stress in the $\mathrm{CP}$ group than in the healthy group. Apparently, aerobic exercise testing by means of cycle ergometry in these children is restricted by non-cardiorespiratory factors.

The results obtained during the different tests suggest that, both in the CP and healthy group, the peak aerobic power tests are reliable. The significantly higher intra-individual difference (as a percentage of the mean) in the $\mathrm{CP}$ children indicates that, at individual level, the aerobic test is less suitable in CP children than in healthy children. Berg and Bjure (5) compared maximal work loads obtained by cycle ergometry on 2 occasions (with a mean of 14 days between the tests) in slightly handicapped $\mathrm{CP}$ children $(\mathrm{n}=12)$. Considerable improvements were found during the second test in some subjects, but this is probably due to the fact that no habituation test was included in the study.

\section{Anaerobic power}

In the present study, the optimal braking force was determined by trial and error. Using an individually determined force-velocity curve (22.26). might have resulted in better predictions of the optimal braking force. However, for practical reasons, it was not possible to perform force-velocity tests in the children. Nevertheless, the trial and error procedure yielded, in our opinion, reasonable predictions of the optimal braking force.

PP (in absolute units) in the healthy children is in good agreement with studies in healthy children in Canada and Israel (3). MP is in comparison with these studies on average about 15 to 20 percent lower (particularly in the boys). When expressed per $\mathrm{kg}$ body mass, PP and MP are respectively about 8 percent and 23 percent lower than the data of Bar-Or (2), but this may partly be explained by the relatively high body weight in the present study. Anaerobic performance in the $\mathrm{CP}$ children was distinctly subnormal when compared with the healthy children, which is in agreement with the study of Parker et al. (25).

The high test-retest correlation coefficients (ranging from 0.90 to 0.96 ) found in the present study, indicate that the WAnT is highly reliable in young $\mathrm{CP}$ 
children and healthy children. These high test-retest correlations of the WAnT are in agreement with studies in healthy subjects, patients with chronic obstructive lung disease, and patients with neuromuscular disease, including children with spastic CP $(4,30)$.

PP showed a tendency to increase with repeated testing in the CP children, an effect that was not seen in the healthy group. Although the increase did not reach statistical significance $(\mathrm{p}=0.08)$, the possibility of a gradual increase in PP with repeated testing over a short time, can not be excluded. Intra-individual differences (as a percentage of the mean) tended to be higher (ns) in the C.P than in the healthy children. This suggests that, at individual level, the WAnT may be less suitable in CP children than in healthy children.

\section{Isokinetic muscle strength}

Because the purpose of this study was to establish the reliability of isokinetic strength testing, no corrections were made for the effect of gravity on the lower limb. The 'real' values for knee flexion PT are therefore expected to be somewhat lower, whereas strength of the knee extensors is expected to be underestimated $(33,15)$.

PT measurements at $30 \%$ in the healthy children of the present study show good agreement with previously reported results in healthy children of the same age in the USA (17). Results at $120 \% \mathrm{~s}$ are about 10 to 15 percent higher in the present study. To our knowledge, there is no literature available on PT of the knee flexors and extensors at $60 \% \mathrm{~s}$ in healthy children, nor on PT measurements in young children with spastic CP. Similar to the results we found on aerobic and anaerobic power, PT in the $\mathrm{CP}$ children is extremely low when compared with their healthy peers.

From studies of Alexander and Molnar (1) and Molnar et al. (23), it can be concluded that, in young children ( 7 to 15 years) with normal intelligence and mild mental retardation, isokinetic muscle strength testing is a reliable and reproducable technique. Results of the healthy children of the present study confirm this high reliability of isokinetic strength testing. However, data of our study can not quite be compared with the studies of Alexander and Molnar $(1,23)$, because they established the test-retest reliability on different days, whereas in the present study the within-day reliabilty was assessed.

In the CP children, flexion and extension PT can be measured reliably at 30 $\%$, but extension PT can not be measured reliably at higher test-velocities. A possible explanation for this may be that the coordination of agonist and antagonist muscles is more impaired at higher velocities than at lower velocities (this may also explain the lack of difference in PT between least affected and most affected leg at $120 \%$ s). However, when the test-velocity of $30 \%$ is used, isokinetic strength testing seems to provide an objective, safe (muscles can not be overloaded), and reliable method to determine torque generating capabilites in young spastic $\mathrm{CP}$ children. Because of the higher intra-individual differences in the CP children than in the healthy children, the test seems, at individual level, less suitable in CP children than in healthy children. 


\section{Conclusion}

Results of the present study indicate that, like in healthy children, peak aerobic power, anaerobic power, and isokinetic muscle strength (at $30 \%$ s), can be measured reliably in young children with spastic cerebral palsy. At individual level, the tests seem to be less suitable in CP children than in healthy children. This may possibly be explained by attention deficits, which are known to occur in $\mathrm{CP}$ (8). These findings have important implications for the use of the described physical capacity tests in CP children. The tests are valuable for rehabilitation research in groups of children with $\mathrm{CP}$ (for example evaluation of sports or physical therapy programs). In clinical settings however, one should be careful with the interpretation of the test results.

It is evident that the measured variables are distinctly subnormal in most of the $\mathrm{CP}$ children when compared with their healthy peers. Only $3 \mathrm{CP}$ children had test-outcomes within the normal range. Possible explanations for this may be agonist/antagonist cocontraction, low muscle mass (especially of the fast-twitch fibers), the presence of contractures, detraining, and attention deficits.

\section{Acknowledgements}

We wish to express our thanks to all the children and their parents who participated in this study and also to Laudy Janssens and Yvonne Burggraaff for their help during data collection. We also thank the children's rehabilitation center Franciscusoord in Valkenburg and the Heilige Geest school in Maastricht for their cooperation. The study was supported by the 'Moederstichting ter Behartiging van de Belangen van het Gebrekkige kind.'

\section{References}

1. Alexander, J., G. E. Molnar. Muscular strength in children: preliminary report on objective standards. Arch. Phys. Med. Rehub. 54:424-427, 1973.

2. Bar-Or, O. Pediatric sports medicine for the practitioner. From physiologic principles to elinical applicutions. New York: Springer-Verlag, 1983.

3. Bar-Or, O. Pathophysiological factors which limit the exercise capacity of the sick child. Med. Sici. Sports Exer. 18:276-282, 1986.

4. Bar-Or, O. The Wingate Anaerobic Test: an update on methodology, reliability and validity. Sports Medicine 4:381-394, 1987.

5. Berg. K., J. Bjure. Methods for evaluation of the physical working capacity of school children with cerebral palsy. Acta Puediatr. Scand. 204(suppl): 15-26, 1970.

6. Berg. K., B. Isaksson. Body composition and nutrition of school children with cerebral palsy: Acia Paediatr. Scand. 204(suppl):41-69, 1970.

7. Berg-Emons van den, H. J. G., M. A. van Baak, K. R. Westerterp. Skinfold measurements in cerebral palsy and healthy controls. Arch Dis. Child. (submitted).

8. Binder, H., G. D. Eng. Rehabilitation management of children with spastic diplegic cerebral palsy, Arch. Phys. Med. Rehab. 70:481-489, 1989. 
i Brinkmann, J. R, T. A. Hoskins. Physical conditioning and altered self-concept in rehabilitated hemiplegic patients. Phys. Ther. 59:859-865, 1979.

10. Brown, A. Review: Physical fitness and cerebral palsy. Child: care, health and development 1:143-152, 1975.

11. Cruickshank, W. M. Cerebral palsy. New York: Syracuse University Press, 1966.

12. Cybex Isolated-joint testing \& exercise, a handbook for using Cybex II and the U.B.X.T.. CYBEX Ronkonkoma, New York, 1983.

13. Dotan, R., O. Bar-Or. Climatic heat stress and performance in the Wingate Anaerobic Test. Eur. J. Appl. Phys. 44:237-243, 1980.

14. Dresen, M. H. W., H. Vermeulen, B. J. Netelenbos, H. Krot. Physical work capacity and classroom attention of handicapped and non-handicapped children. Int. J. of Rehabil. Res. 5:5-12, 1982.

15. Fillyaw, M., T. Bevins, L. Fernandez. Importance of correcting isokinetic peak torque for the effect of gravity when calculating knee flexor to extensor muscle ratios. Phys. Ther. 66:23-28, 1986.

16. Gamstorp, I. Pediatric Neurology. London: Butterworths, 1985.

17. Gilliam, T. B., J. F. Villanacci, P. S. Freedson, S. P. Sady. Isokinetic torque in boys and girls ages 7 to 13: effect of age, height and weight. Res. Quarterly 50: 599-609, 1979.

18. Hislop, H. J., J. J. Perrine. The isokinetic concept of exercise. Phys. Ther. 47:114-117, 1967.

19. Ingram, T. T. S. The neurology of cerebral palsy. Arch. Dis. Child. 41:337-357, 1966.

20. Lundberg, A. Maximal aerobic capacity of young people with spastic cerebral palsy. Dev. Med. Child Neurol. 20:205-210, 1978.

21. Lundberg. A. Longitudinal study of physical working capacity of young people with spastic cerebral palsy. De'v. Med. Child Neurol. 26:328-334, 1984.

22. Mil van, E., N. Schoeber, R. Calvert, O. Bar-Or. Prediction of optimal braking force for the wingate test during arm cranking in children and adolescents with neuromuscular disabilities. Pediatr. Exerc. Science 5:481, 1993 (abstract).

23. Molnar, G. E., J. Alexander, N.Gutfeld. Reliability of quantitative strength measurements in children. Arch. Phys. Med. Rehab. 60:218-221, 1979.

24. Olow, I., K. Berg. School children with cerebral palsy at Bräcke Östergärd Pediatric Habilitation Centre. Acta Paediatr. Scand. 204(suppl):7-13, 1970.

25. Parker, D. F., L. Carriere, H. Hebestreit, O. Bar-Or. Anaerobic endurance and peak muscle power in children with spastic cerebral palsy. Am. J. Dis. Child 146:1069-1073, 1992.

26. Praagh van, E., N. Fellmann, M. Bedu, G. Falgairette, J. Coudert. Gender difference in the relationship of anaerobic power output to body composition in children. Podiatr. Exerc. Science, 2:336-348, 1990.

27. Roede, M. J.. J. C. van Wieringen. Growth diagrams 1980. Netherlands third nationwide survey. Tijdschr. Soc. Gezondheidsz. 63(suppl):1-34, 1985.

28. Ruby, D. O., W. D. Matheny. Comments on growth of cerebral palsied children. J. Am. Diel. Assoc. 40:525-527, 1962.

29. Thistle, H. G., H. J. Hislop, M. Moffroid, E. W. Lowman. Isokinetic contraction: A new concept of resistive exercise. Arch. Phis. Med. Rehab. 48:279-282, 1967.

30. Tirosh, E., O. Bar-Or, P. Rosenbaum. New muscle power test in neuromuscular disease. Am. J. Dis. Child. 144:1083-1087. 1990.

31. Tobis, J. S., P. Saturen, G. Larios, A. O. Posniak. Study of growth patterns in cerebral palsy. Arch. Phys. Med. Rehab. 42:475-481, 1961.

32. Washington, R. L., J. C. van Gundy, C. Cohen, H. M. Sondheimer, R. R. Wolfe. Normal aerobic and anaerobic exercise data for North American school-age children. J. Pediatr. 112:223-233, 1988.

33. Winter, D. A., R. P. Wells, G. W. Orr. Errors in the use of isokinetic dynamometers. Eur. J. Appl. Physiol. 467:397-408, 1981. 


\section{General description of the training study}

\section{Subjects}

Twenty children (11 boys, 9 girls) with spastic cerebral palsy (CP) between 7 and 13 years of age participated. Nineteen children were day students at the children's rehabilitation center Franciscusoord in Valkenburg (normal intelligence and mild mental retardation); one child was a full-board student. Nineteen children were Caucasian, 1 child was born in Sri Lanka. The children were classified according to Hagberg (in Olow and Berg, 5) and Cruickshank (3) by a physician at Franciscusoord (Table I). When legs and feet were more affected than arms and hands, children were classified as diplegic $(n=16)$; children with a greater affliction of the upper part of the body than of the lower part, were classified as tetraplegic $(n=4)$. In 2 diplegic children, a mixed form of spasticity and ataxia was present. Half of the children was ambulant, the other half wheelchair-bound. The children and their parents were informed of all aspects of the study and written consent was obtained. The study was approved by the Medical Ethics Committees of the University of Limburg and the Cooperating Rehabilitation Centers Limburg.

\section{Experimental design (see also Figure 1)}

The project lasted 2 years and included 2 training periods of 9 months. At the beginning of the first year (in September. after the summer holidays), the children were matched pairwise for physical ability. mental function, and if possible, lor age, gender and body composition. After matching, the children of each pair werc randomly assigned to an experimental group $\left(\mathrm{EXP}_{4 \mathrm{x}}, \mathrm{n}=10\right)$ or a control group $(\mathrm{CON}, \mathrm{n}=10) . \mathrm{EXP}_{4 \mathrm{x}}$ participated in a 9-month training program, with 45 -min exercise sessions 4 times per week above the normal school and therapy program. whereas CON had no extra physical training (the school program included two 45-min gymnastic lessons per week; therapy programs were based on personal 
Table I. Classification of the cerebral palsied children

\begin{tabular}{|c|c|c|c|c|c|c|}
\hline \multirow[b]{2}{*}{$\mathrm{Nr}$} & \multirow[b]{2}{*}{$\operatorname{Sex}^{8}$} & \multicolumn{3}{|c|}{ CP classification } & \multicolumn{2}{|c|}{ Severity $^{\dagger}$} \\
\hline & & Tonus & $\begin{array}{l}\text { Abnormal } \\
\text { movements }\end{array}$ & Distribution & $\begin{array}{l}\text { Grade } \\
1-3\end{array}$ & $\begin{array}{l}\text { Way of } \\
\text { ambulation }\end{array}$ \\
\hline 1 & $M$ & hyper & - & diplegia & 1 & ambulant \\
\hline 2 & $M$ & hyper & - & diplegia & 1 & ambulant \\
\hline 3 & $\mathrm{~F}$ & hyper & - & diplegia & 1 & ambulant \\
\hline 4 & M & hyper & - & diplegia & 2 & ambulant \\
\hline 5 & $\mathrm{~F}$ & hyper & - & diplegia & 1 & ambulant \\
\hline 6 & $M$ & liyper & - & diplegia & 2 & ambulant \\
\hline 7 & $\mathrm{~F}$ & hyper & ataxia & diplegia & 2 & ambulant \\
\hline 8 & $\mathbf{M}$ & hyper & ataxia & diplegia & 2 & ambulant \\
\hline 9 & $\mathrm{~F}$ & hyper & - & diplegia & 2 & wheelchair \\
\hline 10 & $\mathrm{~F}$ & hyper & - & diplegia & 2 & wheelchair \\
\hline II & $\mathrm{F}$ & hyper & - & diplegia & 3 & wheelchair \\
\hline 12 & $\mathrm{~F}$ & hyper & - & diplegia & 3 & wheelchair \\
\hline 13 & $\mathbf{M}$ & hyper & - & diplegia & 2 & wheelchair \\
\hline 14 & $\mathrm{~F}$ & hyper & - & diplegia & 3 & wheelchatir \\
\hline 15 & $\mathbf{M}$ & hyper & - & tetraplegia & 3 & wheelchair \\
\hline 16 & $M$ & hyper & - & tetraplegia & 3 & wheelchair \\
\hline 17 & M & hyper & - & tetraplegia & 3 & wheelchair \\
\hline 18 & $\mathbf{M}$ & hyper & - & tetraplegia & 3 & wheelchair \\
\hline 19 & $\mathbf{M}$ & hyper & - & diplegia & 2 & ambulant \\
\hline 20 & $\mathrm{~F}$ & hyper & - & diplegia & 2 & ambulant \\
\hline
\end{tabular}

Matched pairs consist of index numbers 1 and 2,3 and 4, etc.

- according to the classification of Hagberg (in Olow and Berg, 5)

' graduation according to Cruickshank (3)

I may appear normal except that the precision of the movement may be impaired

3 unable to care for all his bodily needs because he is unable to walk unassisted, talk clearly or has little use of his hands

2 in between $I$ and 3

M $=$ male; $F=$ female

needs and varied from no therapy to more than 2.5 hours per week). Because one boy of $\mathrm{EXP}_{4 \mathrm{x}}$ (index number 19) wanted to quit training after 3 weeks (he felt that the program was too intensive), we changed him and his control (index number 20) from groups. Because this happened in the very beginning of the training study, we do not expect this to have interfered with the results.

Training activities consisted of predominantly aerobic exercises such as cycling, wheelchair-driving, running, swimming, training on a 'flying-saucer', and mat exercises. Habitual diets of the children were not changed during the study years.

Measurements were performed in both $\mathrm{EXP}_{4 \mathrm{x}}$ and $\mathrm{CON}$ before the training program started $\left(\mathrm{T}_{0}\right.$, September/October), after $\mathrm{EXP}_{4 \mathrm{x}}$ had trained for 2 months $\left(\mathrm{T}_{2}\right.$, December), and after 9 months of training ( $\mathrm{T}_{9}$, June/July). 
After the summer holidays ( 2 months), the children of both $\mathrm{EXP}_{4 \mathrm{x}}$ and CON were given the opportunity to participate in the next training program, with a practically more feasible training frequency of 2 times $45 \mathrm{~min}$ per week. Eight children of $\operatorname{EXP}_{4 x}$ and all children of CON participated $\left(\operatorname{EXP}_{2 x t o v} n=17\right.$ : one child (index number 2) was excluded from analysis because of surgery during the training program). Two children of $\mathrm{EXP}_{4 \mathrm{x}}$ (index numbers 3 and 9) quit the program because of lack of motivation and necessity to spend more time on school tasks. The training activities and measurements in the second year were, in general, similar to the design in the first year. For practical reasons, swimming was not included as a trainirg activity in the second year.

The training attendancy was $84 \%$ (range $78 \%$ to $88 \%$ ) throughout the first year and $75 \%$ (range $54 \%$ to $94 \%$ ) throughout the second year.

Fig. I. Schematic presentation of the study design (training periods are dark)

Month

\begin{tabular}{|c|c|c|c|c|c|}
\hline 0 & & 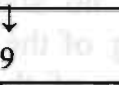 & $\begin{array}{l}\downarrow \\
12\end{array}$ & & $\begin{array}{r}\downarrow \\
22 \\
\end{array}$ \\
\hline & $\begin{array}{c}\operatorname{EXP}_{4 x} \\
n=10\end{array}$ & \multirow{2}{*}{$\begin{array}{l}\text { Holi- } \\
\text { days }\end{array}$} & \multirow{2}{*}{\multicolumn{2}{|c|}{$\begin{array}{c}\mathbf{E X P}_{2 \times 10} \\
\mathrm{n}=17\end{array}$}} & \\
\hline & $\begin{array}{l}\mathrm{CON} \\
\mathrm{n}=10\end{array}$ & & & & \\
\hline $1_{0}$ & $\begin{array}{l}\downarrow \\
T_{2}\end{array}$ & $T_{9}$ & $\mathrm{~T}_{0}$ & $\begin{array}{l}\downarrow \\
\mathrm{T}_{2}\end{array}$ & $T_{3}$ \\
\hline
\end{tabular}

\section{Training intensity}

Heart rate (HR) was measured (Sport Tester PE3000, Polar Electro, Kempele, Finland) randomly during the training sessions to get an impression of the training intensity. Training intensity was described as the percentage of time HR was $\geq 70 \%$ of the heart rate reserve (=difference between peak heart rate (assessed by a progressive cycling or arm cranking test) and heart rate during sleep). This measure indicates the relative exertion in the same way as the percentage of the maximal oxygen uptake (1).

Mean HR (bts/min) during the training sessions in the first year was $135 \pm 10$; in the second year $138 \pm 14$. Percentages of time during training spent at $\geq 70 \%$ of the heart rate reserve were respectively $49 \pm 17$ and $58 \pm 20$.

Many children achieved during the training sessions higher heart rates than their 'peak' HR. The reason for this is that not all children were able to cycle on the ergometer and had to perform arm cranking tests $(n=7)$, whercas during training these children performed various activities with a higher intensity than arm cranking (particularly cycling on their own adjusted bikes and training on a flying-saucer). In addition, some ambulant children achieved during running 
activities much higher heart rates than during ergometer cycling. Therefore, the calculated percentages of time spent at $\geq 70 \%$ of the heart rate reserve are an overestimation of the actual training intensity. However, considering the large improvements in aerobic power (chapter 8), training activities must have been performed at an adequate intensity.

\section{Measurement of body composition}

Body weight was obtained, while wearing light clothing, on a chair scale (Seca, Germany). Height measurements were taken with subjects standing against a wall, or if unable to stand, while lying on a bed with a wooden T-square or flexible tape. Thickness of 4 skinfolds (biceps, triceps, subscapular, suprailiac) was measured with a Servier Caliper at the non-dominant side of the body. FM was calculated according to Durnin and Rahaman (4).

Table II presents the physical characteristics of the study groups at the beginning of the study. There were no statistically significant differences between $\mathrm{EXP}_{4 \mathrm{x}}$ and CON at the beginning of the study. In comparison with representative samples of the Dutch population of the same age (6), the CP children are on average short for their age (on average 5\% smaller) and heavy for their height (half of the children was more than $20 \%$ heavier than the mean weight for height of Dutch children (6). This is in agreement with previous reports $(2,7,8)$.

Table II. Characteristics of the subjects at the beginning of the study

\begin{tabular}{lcc}
\hline & $\begin{array}{c}\operatorname{EXP}_{4 \mathrm{x}}(\mathrm{n}=10) \\
4 \delta, 69\end{array}$ & $\begin{array}{c}\operatorname{CON}(\mathrm{n}=10) \\
7 \delta, 39\end{array}$ \\
\hline Age $(\mathrm{y})$ & $9.5 \pm 1.6$ & $8.8 \pm 1.1$ \\
Height $(\mathrm{cm})$ & $130.7 \pm 11.2$ & $130.6 \pm 9.4$ \\
Weight $(\mathrm{kg})$ & $33.8 \pm 14.3$ & $31.3 \pm 7.7$ \\
Sum 4 skinfolds $(\mathrm{mm})$ & $37.4 \pm 18.1$ & $28.9 \pm 9.1$ \\
Fat $(\%)$ & $21.8 \pm 6.1$ & $17.9 \pm 5.0$ \\
Fat mass $(\mathrm{kg})$ & $8.1 \pm 6.2$ & $5.7 \pm 2.2$ \\
Fat-free mass $(\mathrm{kg})$ & $25.7 \pm 8.3$ & $25.5 \pm 6.1$ \\
Body mass index $\left(\mathrm{kg} / \mathrm{m}^{2}\right)$ & $19.0 \pm 4.2$ & $18.1 \pm 2.6$ \\
& & \\
\hline
\end{tabular}

Data are mean $\pm \mathrm{SD}$

\section{References}

1. Åstrand, P. O., K. Rodahl. Textbook of work physiology. Physiological bases of exercise. Singapore: McGraw-Hill Book Co, 1986.

2. Berg, K., B. Isaksson. Body compostion and nutrition of school children with cerebral palsy. Acta Paediatr. Scand. 204(suppl):41-52, 1970.

3. Cruickshank, W. M. Cerebral palsy. New York: Syracuse University Press, 1966. 
4. Durnin, J. V. G. A., M. M. Rahaman. The assessment of the amount of fat in the human body from measurements of skinfold thickness. Br. J. Nutr. 21:681-689, 1967.

5. Olow, I., K. Berg. School children with cerebral palsy at Bräcke Östergảrd Pediatric Habilitation Centre. Acta Paediatr. Scand. 204(suppl):7-13, 1970.

6. Roede, M. J., J. C. van Wieringen. Growth diagrams 1980. Netherlands third nationwide study. Tijdschr. Soc. Gezondheidszorg 63(suppl):1-34, 1985.

7. Ruby, D. O., W. D. Matheny. Comments on growth of cerebral palsied children. J. Am. Dietet. Assoc. 40:525-527, 1962.

8. Tobis, J. S., P. Saturen, G. Larios, A. O. Posniak. Study of growth pattems in cerebral palsy. Arch. Phys. Med. Rehab. 42:475-481, 1961. 


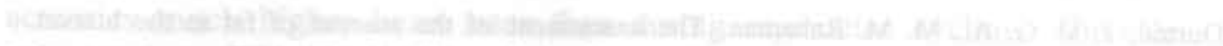

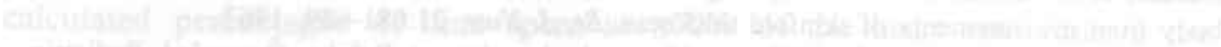

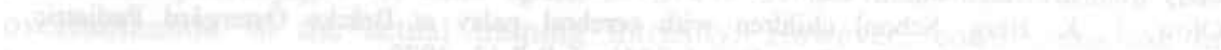

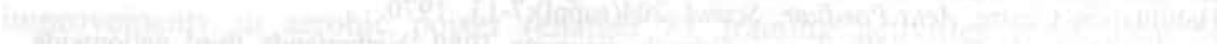

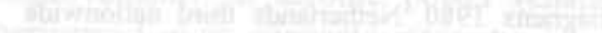

(2)

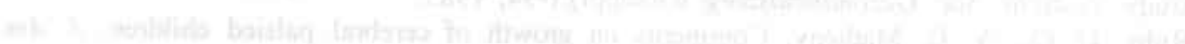




\title{
Physical training of school children with spastic cerebral palsy: effects on daily physical activity and fat mass
}

H. J. G. van den Berg-Emons ${ }^{\text {I }}$, M. A. van Baak ${ }^{2}$, L. Speth ${ }^{3}$, and W. H. M. Saris ${ }^{2}$

Departments of Movement Sciences ${ }^{1}$ and Human Biology'. I Iniversity of I.imburg, PO Box 616, 6200 MD Maastricht. The Netherlands and the children's rehabilitation center Franciscusoord ${ }^{i}$, Onderstestraat 29.6301 KA Villkinburg a/d Geul, The Netherlands

Arch. Phys. Med. Rehab. [submitted].

\begin{abstract}
Effects of two 9-month sports programs (4 or 2 sessions per week) on level of daily physical activity (PA) and fat mass (FM) were assessed in spastic cerebral palsied (CP) children $(n=20,9.2 \pm 1.4 \mathrm{y}$ ), randomly assigned to an experimental and control group after matching. The ratio of total daily energy expenditure (TEE) to sleeping or resting metabolic rate (SMR or RMR) was used as an index for level of PA. Four sessions per week tended to increase PA ratio after 9 months from $1.34 \pm 0.25$ to $1.55 \pm 0.18(\mathrm{p}=0.07)$, but changes were not significantly different versus controls. Two sessions per week had no effect on PA level. FM increased continuously in the control group (after 9 months $+1.1 \pm 1.6$ $\mathrm{kg}, \mathrm{p}<0.05$ ), whereas the experimental groups showed no changes. It was concluded that although training has a limited effect on PA in CP children, it may prevent deterioration in body composition.
\end{abstract}




\section{Introduction}

Adiposity is frequently observed in cerebral palsy (CP) $(1,4,11,12,14,18)$ and reduced physical activity (PA) is believed to be a major determinant in this health problem. In previous studies, it was shown that CP children are extremely hypoactive compared to their healthy counterparts $(6,7)$. These two observations may cause a negative spiral: hypoactivity $\rightarrow$ reduction in functional ability and increase in body fat $\rightarrow$ further hypoactivity. Besides detrimental effects on the performance of activities of daily life, the hypoactivity in $\mathrm{CP}$ children may also reduce the effectiveness of rehabilitation programs.

It is attractive to postulate that an adequate therapeutic measure is to increase the level of daily PA by special sports programs, tailored to the residual ability of the child. However, whether and to what extent sports programs are effective in increasing daily PA in CP children has not been studied. Because of the distinctly subnormal aerobic capacity of $\mathrm{CP}$ children $(2,8,11,17)$, the intensity of sport activities in CP children will be small compared to achieved levels in healthy children. Therefore, increases in total daily energy expenditure (TEE) due to training itself, are expected to be relatively limited. On the other hand, training of ('P children has been shown to result in considerable improvements (30-35\%) of the aerobic power $(3,9)$. This may lead to an increase in more intense (absolutely) activities during the training sessions and therefore to reasonable additions to 'l $F$. It might also be hypothesized that a better physical fitness stimulates CP children to be more intensively active outside the training hours.

The aim of the study was to assess whether 9-month, predominantly aerobic, sports programs (4 or 2 sessions per week) are effective in increasing the level of daily PA in school children with spastic $\mathrm{CP}$ and whether this has favourable effects on fat mass (FM).

Methods (for experimental design and subjects see Figure 1 and chapter 6)

\section{Level of daily PA}

The level of daily PA was calculated as the ratio of TEE to sleeping metabolic rate (SMR) or TEE to resting metabolic rate (RMR).

In the first year, SMR was measured in children who wanted and were able to stay overnight in a respiration chamber $(n=12)$; in the other children $(n=8)$, RMR was measured by means of a ventilated hood. Because the respiration chambers were not operative during the second year (laboratory moved to a new building), all children had RMR measurements during this period.

The respiration chamber (21), an open-circuit indirect calorimeter $\left(14 \mathrm{~m}^{3}\right)$, was furnished with a bed, chair, table, TV, telephone, intercom and toilet. The chamber was ventilated with fresh air at about $40 \mathrm{~L} / \mathrm{min}$ and air temperature was maintained at $20{ }^{\circ} \mathrm{C}$. Volume of outgoing air was determined by means of a dry gas meter (Schlumberger type G6. Dordrecht. The Netherlands) and gas was analysed with a paramagnetic $\mathrm{O}$, analyzer (Servomex type OA 184, Crowborough. Fngland) and an infrared $\mathrm{CO}_{2}$ analyzer (Hartman \& Braun type URAS 3G, 
Frankfurt, Germany). An on-line micro-computer controlled the gas sampling system. PA was monitored by means of a radar system, based on the Doppler principle. SMR was calculated according to Weir (22), over a period in which radar activity was lowest and subjects were asleep.

RMR was determined under standard conditions in a comfortably warm room by an open-circuit ventilated hood system (Oxycon Beta, Mijnhardt, The Netherlands). Children were transported to the university by car and any form of intensive exercise was avoided. Measurements were performed between 7:30 and 9:00 AM, after having fasted for 12 hours. After a period of 5 min bed rest, RMR was measured during $20 \mathrm{~min}$ while the children watched TV or listened to stories (supine position). RMR was calculated according to Weir's formula (22). In order to assess the difference between SMR and RMR, RMR was also measured in 12 children in the moming after the measurement of SMR ( $\mathrm{T}_{9}$, first study year).

TEE was determined by the heart rate (HR) method, which has been shown to be suitable to predict TEE in groups of CP children (7). Children were fitted with the HR instrumentation (Sport Tester PE3000, which recorded HR at 1-min intervals) at about 9:00 AM and it was worn continuously until they went to bed (in experimental groups HR recording was performed on a training day).

In each child the relation between $\mathrm{HR}$ and $\mathrm{VO}_{2}$ was established under standardized conditions during each measurement period. In the ambulant children $(n=10), 4$ calibration points were obtained by simultaneous measurements of HR and $\mathrm{VO}_{2}$ during sitting, standing, and cycling on an ergometer (Universal Ergostat Fleisch, Metabo, Epalinges, Switzerland) at $30 \%$ and $70 \%$ of their previously assessed peak aerobic capacity (progressive cycling test). In wheelchair-bound children who were able to cycle $(\mathrm{n}=3), 3$ calibration points were obtained: during sitting and cycling at $30 \%$ and $70 \%$. Wheelchair-bound children who were not able to cycle $(n=7)$, were measured during sitting and arm cranking (at $30 \%$ of their peak capacity for work with 2 arms). Arm cranking tests were performed on the Fleisch ergometer with $1 \mathrm{arm}$, while the children were sitting in their own wheelchair beside the ergometer. It was impossible to measure $\mathrm{HR}$ and $\mathrm{VO}_{2}$ at higher intensities in the arm cranking group, because when the resistance was increased, the children lowered the cranking speed and no increases in workload, $\mathrm{HR}$ and $\mathrm{VO}_{2}$ were attained. $\mathrm{VO}_{2}$ was measured using a face mask connected to a Jacger EOS-sprint analyzer (Jaeger Nederland, Breda, The Netherlands) and HR was taken from an ECG monitor. An equilibration period of 2 min was allowed for each activity, followed by a 4-min sampling period. The calibration point for each activity was computed as the mean of the 4-min sampling period for HR and $\mathrm{VO}$.

TEF was calculated from HR, according to the 'FLEX' principle (19). FLEX $\mathrm{HR}$ in the ambulant group was defined as the mean of the highest HR during standing and the lowest HR during cycling. Oxygen uptake during rest was calculated as the mean $\mathrm{VO}_{2}$ of lying (measured in respiration chamber or by the ventilated hood), sitting and standing. Energy expenditure (FE) over periods of the daytime when HR was $\leq$ FLEX HR was calculated on basis of this mean $\mathrm{VO}_{2}$. When $\mathrm{HR}$ was above FLEX $\mathrm{HR}, \mathrm{EE}$ was derived from the min-by-min recorded HR and the subjects calibration curve obtained on the ergometer. FLEX 
HR in the wheelchair-bound children who were able to cycle was defined as the mean of the highest HR during sitting and the lowest HR during cycling. In the arm cranking group, FLEX. HR was defined as the mean $\mathrm{HR}$ for sitting. $\mathrm{VO}_{2}$ during rest was calculated as the mean $\mathrm{VO}_{2}$ of lying (respiration chamber or ventilated hood) and sitting. For periods of daytime when HR was $\leq$ FLEX HR, EE was calculated on basis of this mean $\mathrm{VO}_{2}$; when HR was above FLEX HR, $\mathrm{EE}$ was derived from the min-by-min recorded $\mathrm{HR}$ and the calibration curves obtained during cycling or during sitting and arm cranking. TEE was computed by summing the estimated EE from daytime HR (using an energy equivalent of $20.50 \mathrm{~kJ} / \mathrm{L}_{2}$ ) and adding SMR or RMR for sleeping hours.

In addition, physical activities of the children were observed (only in first year) during school time from 9:00 AM till 3:30 PM (in $\mathrm{EXP}_{4 \mathrm{x}}$, the observation was performed on a training day). Every minute the type of PA was recorded (same observer for the different measurement periods). Activities were qualified as 'lower-intensity' (LI: lying, sitting, standing) or 'higher intensity' (HI: wheelchair-driving, independent transfer from wheelchair to chair, walking, running, cycling, swimming, creeping). Also, the parents/guardians (P) and teachers $(\mathrm{T})$ of the children were asked (both years) by a questionnaire whether, in their opinion, there had been changes in level of PA versus $T_{0}$ (child has become more active, less active. or has remained the same).

\section{Fat mass}

Thickness of 4 skinfolds (biceps, triceps, subscapular, suprailiac) was measured with a Servier Caliper at the non-dominant side of the body. FM was calculated according to Durnin and Rahaman (13).

Fig. 1. Schematic presentation of the study design (training periods are dark)

Month

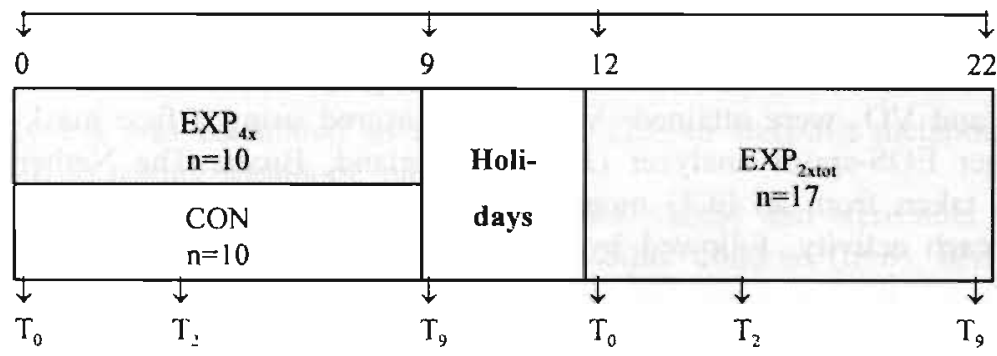

\section{SMR/RMR}

HR/EF

Observation PA

Questionnaire P

Questionnaire T

Fat mass

Aerobic power

HR during training 


\section{Statistical analysis}

Data are expressed as mean $\pm \mathrm{SD}$. Comparisons between data were made using the Wilcoxon test for paired observations, the Mann-Whitney $U$ test for unpaired observations, and the Chi-square test for frequencies $(\alpha=0.05)$. To establish the effects of 4 exercise sessions per week, data of $\operatorname{EXP}_{4 x}(n=10)$ were compared with CON $(n=10)$. The effects of 2 exercise sessions per week were established by comparing the control children of the first year with themselves in the second year. Because one child of this group had to quit training because of surgery, this comparison was made on 9 children $\left(\mathrm{EXP}_{2 \mathrm{x}}\right.$ versus $\left.\mathrm{CON}, \mathrm{n}=9\right)$. Also the results of the total experimental group of the second year are presented $\left(\operatorname{EXP}_{2 \times 10}, n=17\right)$ and compared with $\operatorname{CON}(\mathrm{n}=10)$. To establish the effects of the summer holidays on PA as reported by the parents/guardians and on FM, results at $T_{0}$ of the second year were compared with $T_{9}$ of the first year. Such a comparison could not be made for the PA ratios and PA as reported by teachers, since the methods to determine the ratios differed between the 2 study years and children had different teachers in both years.

\section{Results}

Peak aerobic power (in watt/kgFFM, progressive cycling or arm cranking test) in $\mathrm{EXP}_{4 \mathrm{x}}$ was improved after 9 months by $35 \%(\mathrm{p}<0.01)$ from $0.91 \pm 0.83$ to $1.23 \pm$ 0.80 ; in $\operatorname{EXP}_{2 \times}$ by $21 \%(p<0.01)$ from $0.99 \pm 0.77$ to $1.20 \pm 0.89$ and in $\operatorname{EXP}_{2 x \text { tot }}$ by $20 \%(p<0.01$ ) from $0.97 \pm 0.77$ to $1.16 \pm 0.83$ (see also chapter 8 ).

\section{Level of daily PA}

In the children who had both SMR and RMR measurements ( $n=12)$, RMR (5.11 $\pm 1.22 \mathrm{MJ} / \mathrm{d}$ ) was on average $16 \%$ (range $-4 \%$ to $+57 \%$ ) higher $(\mathrm{p}<0.01$ ) than SMR (4.42 $\pm 0.74 \mathrm{MJ} / \mathrm{d})$. Because of the non-systematic intra-individual differences, it was not possible to deduce SMR from RMR or vice versa. Therefore, the calculation of PA ratios differs between children, and ratios can not be compared between groups.

Four exercise sessions per week $\left(\mathrm{EXP}_{4 \times}\right.$, Table I) resulted after 9 months in an average increase in PA level (on a training day) versus $T_{0}$ of $0.21 \quad(=16 \%$, $\mathrm{p}=0.07$ ). $\mathrm{PA}$ levels in CON showed no significant increases versus $\mathrm{T}_{6}$. Differences in the changes in PA levels between $\mathrm{EXP}_{4 \mathrm{x}}$ and CON were however not statistically significant (also the area under the curve of changes from base-line did not differ significantly between $\mathrm{EXP}_{4 \mathrm{x}}$ and $\mathrm{CON}$ ). EE added (above resting) by a 45 -min training session was $0.28 \pm 0.17 \mathrm{MJ}(10.9 \pm 6.5 \mathrm{~kJ} / \mathrm{kgFFM})$ at $\mathrm{T}_{2}$, and $0.47 \pm 0.26 \mathrm{MJ}(16.9 \pm 7.8 \mathrm{~kJ} / \mathrm{kgFFM})$ at $\mathrm{T}_{9}(\mathrm{p}<0.05)$. The extra EE during training at $T_{1}$, represents an average increase of about 0.10 unit in the PA ratio on a training day.

During the program with 2 exercise sessions per week ( $\operatorname{EXP}_{2 x}$, Table I), changes in PA levels were similar to the changes in PA in the year without 
training (CON). EE added (above resting) by a 45-min training session was 0.41 . $\pm 0.32 \mathrm{MJ}(12.6 \pm 6.7 \mathrm{~kJ} / \mathrm{kgFFM})$ at $\mathrm{T}_{2}$ and $0.37 \pm 0.23 \mathrm{MJ}(11.1 \pm 4.6$ $\mathrm{kJ} / \mathrm{kgFFM}$ ) at $\mathrm{T}_{9}$ (ns). The extra EE during training at $\mathrm{T}_{9}$ represents an average increase of about 0.06 unit in the PA ratio on a training day. PA levels of $\mathrm{EXP}_{2 \times \text { xot }}$ at $T_{9}$ were increased versus $T_{0}$ with $9 \%(p<0.05)$, but this was similar to the changes in $\mathrm{CON}$.

Table I. Level of daily PA (calculated as the ratio of total daily energy expenditure (TEE) to sleeping or resting metabolic rate (SMR or RMR)), in children who participated in a 9-month training program (EXP $4 x+4$ times per week; $\operatorname{EXP}_{2 x}$ and $\mathrm{EXP}_{2 \text { rot }} 2$ times per week) and in children who had no extra exercise (CON)

\begin{tabular}{l|cc|cc|c}
\hline & $\begin{array}{c}\mathrm{CON} \\
(\mathrm{n}=10)\end{array}$ & $\begin{array}{c}\mathrm{EXP}_{4 \mathrm{x}} \\
(\mathrm{n}=10)\end{array}$ & $\begin{array}{c}\mathrm{CON} \\
(\mathrm{n}=9)\end{array}$ & $\begin{array}{c}\mathrm{EXP}_{2 \times} \\
(\mathrm{n}=9)\end{array}$ & $\begin{array}{c}\mathrm{EXP}_{2 x+10} \\
(\mathrm{n}=17)\end{array}$ \\
\hline $\mathrm{T}_{0} \cdot \mathrm{T}_{2}$ & $1.24 \pm 0.21$ & $1.34 \pm 0.25$ & $1.26 \pm 0.22$ & $1.20 \pm 0.17$ & $1.18 \pm 0.20$ \\
$\mathrm{~T}_{3} \cdot$ & $1.34 \pm 0.21$ & $1.31 \pm 0.10$ & $1.32 \pm 0.21$ & $1.25 \pm 0.08$ & $1.18 \pm 0.14$ \\
\hline
\end{tabular}

- $\mathrm{T}_{0}$ : base-line, $\mathrm{T}_{2}$ : after 2 months, $\mathrm{T}_{9}$ : after 9 months; ${ }^{\dagger} \mathrm{p}=0.07$ versus $\mathrm{T}_{0},{ }^{\S} \mathrm{p}<0.05$ versus $\mathrm{T}_{0}$

There were no significant differences in percentage of time spent with 'HI' activities between $\operatorname{EXP}_{4 \mathrm{x}}$ and $\mathrm{CON}$ at $\mathrm{T}_{0} \cdot \mathrm{EXP}_{4 \mathrm{x}}$ showed a significant increase in ' $\mathrm{HI}$ ' activities during the training program versus $\mathrm{T}_{0}$ : at $\mathrm{T}_{0}$. $18 \pm 8 \%$ of the total observed time was spent with 'HI' activities, at $\mathrm{T}_{2} 25 \pm 8 \%(\mathrm{p}<0.05)$ and at $\mathrm{T}_{9} 25$ $\pm 8 \%(\mathrm{p}<0.01)$. At $\mathrm{T}_{2}$, these 'HI' activities were observed within the training sessions for $10 \pm 2 \%$ of the total time, at $T_{9}$ for $11 \pm 2 \%$. CON had no significant changes in percentage of observed time spent with ' $\mathrm{HI}$ ' activities: at $\mathrm{T}_{0}, 21 \pm$ $13 \%$, at $T_{2} 22 \pm 11 \%$, and at $T_{9} 16 \pm 8 \%$. The difference in the change in ' $\mathrm{HI}$ ' activities from $T_{0}$ to $T_{9}$ between $\operatorname{EXP}_{4 x}$ and CON was significant $(p<0.05)$.

At $T_{9}$ in the first year, parents/guardians of the children of $\mathrm{EXP}_{4 \mathrm{x}}$ reported that $7(=70 \%)$ children had become more physically active versus $T_{0}(\mathrm{PA}$ in 3 children had remained the same), whereas in CON an increase in PA in $2(=20 \%)$ children was reported ( 1 child had become less active; 7 had remained the same). The difference in the changes in PA between $\operatorname{EXP}_{4 x}$ and CON from $T_{0}$ to $T_{9}$ just failed to reach statistical significance $(p=0.07)$. There were no further differences in changes in PA as observed by parents/guardians or teachers between experimental and control groups.

\section{Fat mass}

FM (Figure 2) increased continuously $(\mathrm{p}<0.05)$ in $\mathrm{CON}$ during the study year $\left(\mathrm{T}_{9}\right.$ versus $T_{0}:+1.1 \pm 1.6 \mathrm{~kg}$ ), whereas $F M$ in the experimental groups showed no changes. The difference in the change in FM from $T_{0}$ to $T_{2}$ between $C O N$ and $\mathrm{EXP}_{2 \mathrm{x}}$ was significant $(\mathrm{p}<0.05)$ (between $\mathrm{CON}$ and $\mathrm{EXP}_{4 \mathrm{x}} \mathrm{p}=0.09$; between $\mathrm{CON}$ and $\mathrm{EXP}_{2 \text { xtot }} \mathrm{p}=0.06$ ). There were no significant differences in the changes in FM from $T_{0}$ to $T_{9}$ between the experimental groups and CON (also the area under the curve of changes from base-line did not differ significantly between the groups). 
After the summer holidays $\left(\mathrm{T}_{12}\right), \mathrm{FM}$ in $\mathrm{EXP}_{4 \mathrm{x}}$ was significantly $(\mathrm{p}<0.05)$ higher $(+0.7 \pm 0.7 \mathrm{~kg})$ compared to before the summer holidays $\left(\mathrm{T}_{9}\right)$. Changes in $\mathrm{FM}$ in $\mathrm{EXP}_{2 \mathrm{xtot}}$ were significantly different $(\mathrm{p}<0.05)$ between children who had also trained during the first year $(n=8, \triangle F M$ after 9 months is $+0.9 \pm 0.9 \mathrm{~kg}, \mathrm{~ns})$ and children who had not trained during the first year $(n=9, \triangle F M$ after 9 months is $-0.3 \pm 0.9 \mathrm{~kg}, \mathrm{~ns})$.

Fig. 2. Changes in fat mass $(\mathrm{kg})$ in children who participated in the training program (EXP ${ }_{4 \times} 4$ times per week; $\mathrm{EXP}_{2 \mathrm{x}}$ and $\mathrm{EXP}_{2 \mathrm{xtor}} 2$ times) and in children who had no extra exercise (CON)

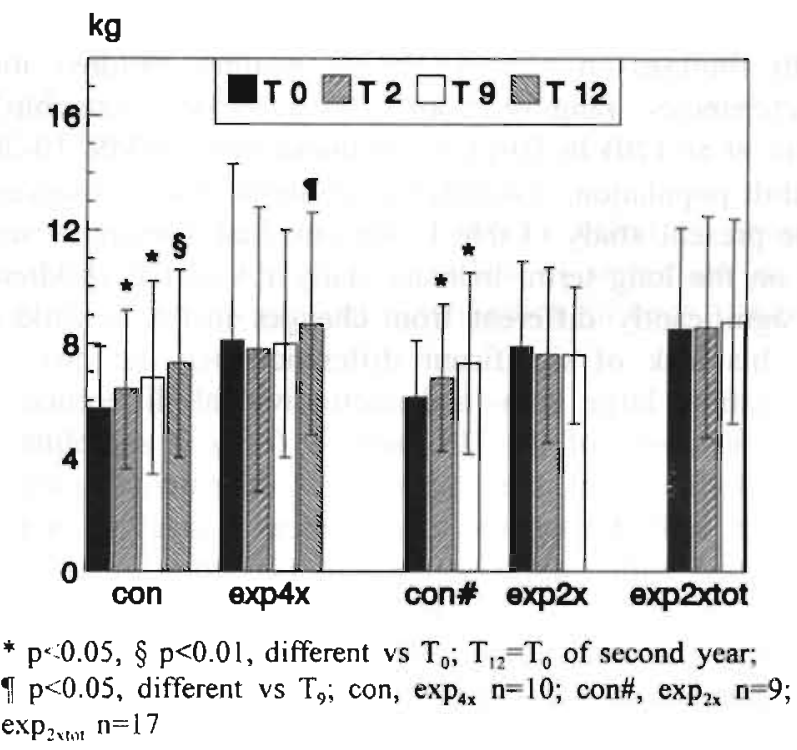

\section{Discussion}

The aim of the study was to assess the effects of physical training on the level of daily PA and FM in school children with spastic CP. An experimental controlled design was used, which is rather unique in training studies in CP. It was not possible to match the children for level of daily PA, because the HR method is not suitable to predict TEE on an individual level $(7,16)$. However, using 'physical ability' as primary matching criterion, resulted in our opinion in pairs of children with reasonably comparable levels of daily PA.

In a previous study in which the HR method was compared with the doubly labeled water technique in $9 \mathrm{CP}$ children (7), it was concluded that monitoring the HR during 3 days is preferable to obtain a close group estimate of TEE. Because of practical reasons, it was not possible to measure HR in the present study during more than 1 day in each measurement period, which may have reduced the accuracy of the TEE prediction. 
Levels of daily PA in healthy children in The Netherlands (7 to 10 years) and Northern Ireland ( 7 to 12 years), were found to be respectively $1.83 \pm 0.23$ and $1.77 \pm 0.24(6,16)$. Although different methods were used to assess PA, results of the present study indicate that the CP children are considerably less active than healthy children, which is in agreement with measurements of daily PA with doubly labeled water in a smaller group of diplegic and tetraplegic CP children $(6,7)$.

\section{Effects of training on level of daily PA}

The large intra-individual differences between SMR and RMR in the CP children are in line with findings in 6 to $12 \mathrm{y}$ old healthy children measured in our laboratory (discrepancies ranging from $-2 \%$ to $+54 \%$, unpublished data) and findings of Blaak et al. (10) in 10-11 y old obese boys (RMR 10-20\% higher than SMR). In the adult population, a difference of about $5 \%$ is observed (15).

Results of the present study (Table I) indicate that 4 exercise sessions (45-min) per week may, on the long term, increase daily PA in CP children. although this effect was not significantly different from changes in PA in children who had no extra training. This lack of significant difference may be due to the relatively small study population, large intra- and interindividual differences in PA, and the possibly reduced accuracy of the HR method (only 1 sampling day). Also the observation of activities and the impressions of parents/guardians suggest an increase in level of daily PA on the long term as a result of 4 training sessions. No effects were found with 2 exercise sessions per week.

The increase in PA level in $\mathrm{EXP}_{4 \times}$ at $\mathrm{T}_{9}$ can be accounted for about $50 \%$ by the direct energy cost of training and for about $50 \%$ by an increase in EE outside the training hour, in agreement with findings of Blaak et al. (10) in obese boys. The increase in EE outside the training hour suggests that training may have stimulated the CP children to be more active during daily life. CON showed an increase of 0.10 in PA level after 9 months (Table I), but the increase was not statistically significant. However, because of the small sample size, large intra- and interindividual differences in PA and the reduced accuracy of the HR method, it cannot be excluded that CP children increase their PA throughout a school year independent of training. Therefore, the increase in PA level outside the training hour as observed in $\mathrm{EXP}_{4 \mathrm{x}}$, may have been unrelated to the training program.

It can be concluded that training (45-min sessions 4 times per week) may, on the long term, increase levels of daily PA in spastic CP children. However, although peak aerobic power in $\mathrm{EXP}_{4 x}$ was improved considerably after 9 months, the increase in PA as a consequence of the training intervention, is relatively limited. After 9 months the average PA level on a training day was 1.55 , but to achieve in CP children a level of 1.8 (as found in healthy children $(6,16)$ ), as much as daily 2.5 hours of aerobic training are needed (assuming an energy level comparable to what was achieved at $T_{9}$ in first year). This is not feasible, which means that sports programs can only partly restore the deficit in PA in CP children. Therefore, CP children will never have equal opportunities for growth and development when compared with healthy peers. 


\section{Effects of training on fat mass}

The present study implies that, although changes in FM were not significantly different between experimental and control groups on the long term (may be due to small study population, large intra- and interindividual differences in FM), physical training may prevent deterioration in body composition in CP children. Two 45-min sessions per week seem to be sufficient in this respect. The finding that the control children showed significant increases in FM (Figure 2) is in agreement with the study of Dresen (12). According to Saris (20), the mean gain in FM in healthy Dutch children is about $0.5 \mathrm{~kg}$ per year at $8-10$ years of age. The mean gain in the control group was considerably higher than these reference values, namely $1.5 \mathrm{~kg}$ per year. FM in the experimental groups remained constant throughout the training program, in contrast with Berg (5) who found significant increases in FM in CP children participating in a training program.

In conclusion, although training has only a limited effect on restoring the deticit in PA in CP children, regular physical exercise is important in young children with spastic CP because it may prevent deterioration in body composition.

\section{Acknowledgements}

We thank all the children and their parents who participated and the staff of the children's rehabilitation center Franciscusoord (Valkenburg a/d Geul). We also thank Donnie de Barbanson, Eugene Rameckers, and Marcel Coenen for taking care of many training sessions, and Karin Schmets, Nicole Schoeber, Carola Leygraaf, and Peter Rasenberg for their help during data collection and assistance during the training sessions.

\section{References}

1. Bandini, L. G., D. A. Schoeller, N. K. Fukagawa, L. J. Wykes, W. H. Dietz. Body composition and energy expenditure in adolescents with cerebral palsy or myelodysplasia. Pediatr. Res. 29:70-77, 1991.

2. Bar-()r, O. Pediatric sports medicine for the practitioner. From physiologic principles to clinical applications. New York: Springer Verlag, 1983.

3. Berg, K. Effect of physical training on school children with cerebral palsy. Acta Purdiutr. Scand. 204(suppl):27-33, 1970.

4. Berg, K., B. Isaksson. Body composition and nutrition of school children with cerebral palsy. Acta Paediatr. Scand. 204(suppl):41-52, 1970.

5. Berg. K. Effect of physical activation and of improved nutrition on the body composition of school children with cerebral palsy. Acta Paediatr. Scand. 204(suppl):53-69, 1970.

6. Berg-Emons van den, H. J. G., W. H. M. Saris, D. C. de Barbanson, K. R. Westerterp, A. Huson, M. A. van Baak. Daily physical activity of school children with spastic diplegia and of healthy control subjects. J. Pediatr. 127:578-584, 1995. 
7. Berg-Emons van den, H. J. G., W. H. M. Saris, K. R. Westerterp, M. A. van Baak. Heart rate monitoring to assess energy expenditure in children with reduced physical activity. Med. Sci. Sports Exerc. (in press).

8. Berg-Emons van den, H. J. G., M. A. van Baak, D. C. de Barbanson, L. Speth, W. H. M. Saris. Reliability of tests to determine peak aerobic power, anaerobic power, and isokinetic muscle strength in spastic cerebral palsied childen. Dev. Med. Child Neurol. (accepted).

9. Berg-Emons van den, H. J. G., M. A. van Baak, L. Speth, W. H. M. Saris. Physical training of school children with spastic cerebral palsy: effects on aerobic power, anaerobic power and isokinetic muscle strength. Med. Sci. Sports Exerc. (submitted).

10. Blaak, E. E., K. R. Westerterp, O. Bar-Or, L. J. M. Wouters, W. H. M. Saris. Total energy expenditure and spontaneous activity in relation to training in obese boys. $\mathrm{Am} . J$. Clin. Nutr. 55:777-782, 1992.

11. Brown, A. Review: physical fitness and cerebral palsy. Child: care, health and development 1:143-152, 1975.

12. Dresen, M. H. W. Physical training of handicapped children. Physical and psychological effects. Amsterdam, 1983 (thesis).

13. Durnin, J. V. G. A., M. M. Rahaman. The assessment of the amount of fat in the human body from measurements of skinfold thickness. Br. J. Nutr. 21:681-689, 1967.

14. Eddy, T. P., A. L. Nicholson, E. F. Wheeler. Energy expenditures and dietary intakes in cerebral palsy. Dev. Med. Child Neurol. 7:377-386, 1965.

15. Goldberg, G. R., A. M. Prentice, H. L. Davies, P. R. Murgatroyd. Overnight and basal metabolic rates in men and women. Eur. J. Clin. Nutr. 42:137-144, 1988.

16. Livingstone, M. B. E., W. A. Coward, A. M. Prentice, et al. Daily energy expenditure in free-living children: comparison of heart-rate monitoring with the doubly labeled water $\left({ }^{2} \mathrm{H}_{2}{ }^{18} \mathrm{O}\right)$ method. Am. J. Clin. Nutr. 56:343-352, 1992.

17. Lundberg, A. Longitudinal study of physical working capacity of young people with spastic cerebral palsy. Dev. Med. Child Neurol. 26:328-334, 1984.

18. Phelps, W. M. Dietary requirements in cerebral palsy. J. Amer. Diet. Assoc. 27:869-876, 1951.

19. Saris, W. H. M., I. Boeijen, H. Elvers, T. de Boo, R. A. Binkhorst. Determining the individual variation in energy metabolism in 8 -year-old children by two prediction methods. Nutr. Rep. Int. 26:35-42, 1982.

20. Saris, W. H. M., A. M. Noordeloos, A. M. Ringnalda, M. A. van 't Hof, R. A. Binkhorst. Reference values for aerobic power of healthy 4- to 18 - years old Dutch children. In: Binkhorst, R. A., H. C. G. Kemper, W. H. M. Saris, editors. Children and exercise XI. Champaign, IL: Human Kinetics, 1985.

21. Schoffelen, P. F. M. W. H. M. Saris, K. R. Westerterp, F. Ten Hoor. Evaluation of an automatic indirect calorimeter for measurement of energy balance in man. In: Van Es, A. J. H., editor. Human energy metabolism: Physical activity and energy expenditure measurements in epidemiological research based upon direct and indirect calorimetry. Wageningen: Euro Nut Report 5:51-54, 1984.

22. Weir, J. B. New methods for calculating metabolic rate with special reference to protein metabolism. J. Physiol. 109:1-9, 1949. 


\section{Physical training of school children with spastic cerebral palsy: effects on aerobic power, anaero- bic power and isokinetic muscle strength}

H. J. G. van den Berg-Emons ', M. A. van Baak ${ }^{2}$, L. Speth ${ }^{3}$, and W. H. M. Saris ${ }^{2}$

Departments of Movement Sciences ${ }^{1}$ and Human Biology ${ }^{2}$, University of Limburg, PO Box 616, 6200 MD Maastricht, The Netherlands and the children's rehabilitation center Franciscusoord ${ }^{3}$, Onderstestraat 29, $6301 \mathrm{KA}$ Valkenburg a/d Geul, The Netherlands

Med. Sci. Sports Exerc. [submitted].

\section{Abstract}

Effects of two 9-month sports programs (45-min aerobic exercise sessions, 4 or 2 times per week) on peak aerobic power, anaerobic power (cycling or arm cranking test), and isokinetic strength of the knee extensors and flexors (Cybex) were assessed in cerebral palsied (CP) children with spastic diplegia/tetraplegia $(n=20$, mean \pm SD age $9.2 \pm 1.4 \mathrm{y})$, randomly assigned to an experimental and control group after matching. After 9 months, training with a frequency of 4 sessions per week, increased peak aerobic power considerably $(p<0.01)$ by on average $35 \% \quad(p<0.05$ versus control). Two sessions per week resulted after 9 months in an increase $(p<0.01)$ in peak aerobic power of $21 \%(p=0.17$ versus control). Results also suggest that training has a favourable effect on isokinetic muscle strength. No training-related effects were found on anaerobic power. It was concluded that aerobic training is recommendable in young children with spastic CP. 


\section{Introduction}

Children with cerebral palsy $(\mathrm{CP})$ have a distinctly subnormal aerobic power, anaerobic power, and muscle strength in comparison with healthy peers $(3,7,11$, $13,15,22,25$ ), which partly may be caused by low levels of daily physical activity (PA). In previous studies in CP children (8-10), it was shown that these children are extremely hypoactive compared to their healthy counterparts. Increasing the level of daily PA in these children by special sports programs, might therefore be effective in improving their physical fitness.

A number of studies is available on the effects of training on aerobic power and muscle strength in CP $(2,6,13,16,18,21,23,24,26,29)$, but most of them concern heterogeneous and older age groups and training programs often last for a relatively short period (4-10 weeks). Furthermore, control groups are usually not included. To our knowledge, no studies exist concerning effects of training on anaerobic power in $\mathrm{CP}$.

The aim of the study was to assess the effects of 9-month sports programs (4 or 2 sessions per week) on peak aerobic power in young children with spastic diplegia and spastic tetraplegia. Although the program consisted mainly of aerobic exercise, also the effects on anaerobic power and isokinetic muscle strength were studied. An experimental controlled design was used.

Methods (for experimental design and subjects see Figure 1 and chapter 6)

\section{Peak aerobic power}

Peak aerobic power was measured in a progressive maximal aerobic test (based on the McMaster All-Out Progressive Continuous Cycling and Arm Test (3)) on a mechanically braked calibrated ergometer (Universal Ergostat Fleisch, Metabo, Epalinges, Switzerland). Depending on their physical ability, children performed a crcling test $(n=13)$ or arm cranking test $(n=7)$. Resistance was increased every 2 min with a variable load, depending on the ability of the child, until the child was unable to continue pedaling. Individual protocols were constructed such that the total exercise time ranged between 8 and $12 \mathrm{~min}$. No fixed pedaling rate was required, the number of revolutions was recorded. The test was preceded by a warm-up (5 min) and verbal encouragement was given throughout the test. Peak aerobic power was defined as the highest power output over the two min of a load. When the child could not complete two min of the final load, peak aerobic power was calculated as the mean of the power of the penultimate stage and the final stage. Peak HR (Sport Tester PE3000) was defined as the highest average HR over the last min of a load.

In addition, in the second year, we had the opportunity to assess peak oxygen uptake in the cycling group in a separate test. Oxygen uptake was measured using a face mask connected to a Jaeger EOS-sprint analyzer (Jaeger Nederland, Breda, The Netherlands) and HR was taken from an ECG monitor. It turned out to be impossible to perform this measurement in the arm cranking group, because, 
when sitting behind the ergometer, the distance between cranks and face was so small that the cranks constantly hit the tube that connected the mask with the analyzer.

\section{Anaerobic power}

Anaerobic performance was measured on the calibrated Fleisch ergometer by the Wingate Anaerobic cycling or arm cranking Test (WAnT). A detailed description of the WAnT is given by Bar-Or (4) and Dotan and Bar-Or (14). Briefly, the WAnT is a 30-s cycling test at all-out speed, against a constant braking force. By trial and error, the force was determined which elicited the highest power (=optimal braking force). The test was preceded by a warm-up ( $5 \mathrm{~min}$ ) and verbal encouragement was given. Pedal revolutions were registered continuously. Two performance indices were calculated: peak anaerobic power (PP: the highest power at any 5-s period; reflects the ability of the limb muscles to produce high mechanical power in a short time (4)) and mean anaerobic power (MP: power throughout the 30 -s test; reflects the ability to sustain high power (4)).

\section{Isokinetic muscle strength}

Muscle strength was determined by an isokinetic device (Cybex II, Ronkonkoma, USA), recording strength as torque in $\mathrm{Nm}(20,27)$. Torque determinations were made on the extensor and flexor muscles of the knees at $30^{\circ} / \mathrm{s}$. The test was conducted while the child was seated with thigh and pelvis stabilized. All measurements were performed at the damping levels recommended in the Cybex Testing Manual (12). After a warm-up $(5 \mathrm{~min})$, each subject performed 5 maximal contractions with the least affected leg, starting with extension. Verbal encouragement was given to exert maximal effort. After repositioning the apparatus, the subject completed the above procedures for the most affected leg. Peak torque (PT) was defined as the maximum torque generated by the subject throughout one series of repetitions. Because of technical problems, strength measurements were only performed in the second study year.

\section{Statistical analysis}

Data are expressed as mean $\pm \mathrm{SD}$. Comparisons between data were made using the Wilcoxon test for paired observations and the Mann-Whitney $U$ test for unpaired observations $(\alpha=0.05)$. Bivariate correlations were performed by Spearman's rank order correlation. To establish the effects of 4 sessions per week on aerobic and anaerobic power, data of $\operatorname{EXP}_{4 x}(n=10)$ were compared with CON $(n=10)$. The effects of 2 sessions per week on aerobic and anaerobic power were established by comparing the control children of the first year with themselves in the second year. Because one child of this group had to quit training because of surgery, this comparison was made on 9 children $\left(\mathrm{EXP}_{2 x}\right.$ versus $\left.\mathrm{CON}, \mathrm{n}=9\right)$. Also the results of the total experimental group of the second year are presented 
$\left(\mathrm{EXP}_{2 \text { xtot }}, \mathrm{n}=17\right)$ and compared with $\mathrm{CON}(\mathrm{n}=10)$. To establish the effects of the summer holidays on the fitness parameters, results at $T_{0}$ of the second year were compared with $T_{9}$ of the first year. For isokinetic strength measurements, only effects of 2 sessions per week $\left(\mathrm{EXP}_{2 \times \mathrm{xol}}\right)$ were established; no comparisons could be made with controls.

Fig. 1. Schematic presentation of the study design (training periods are dark)

Month

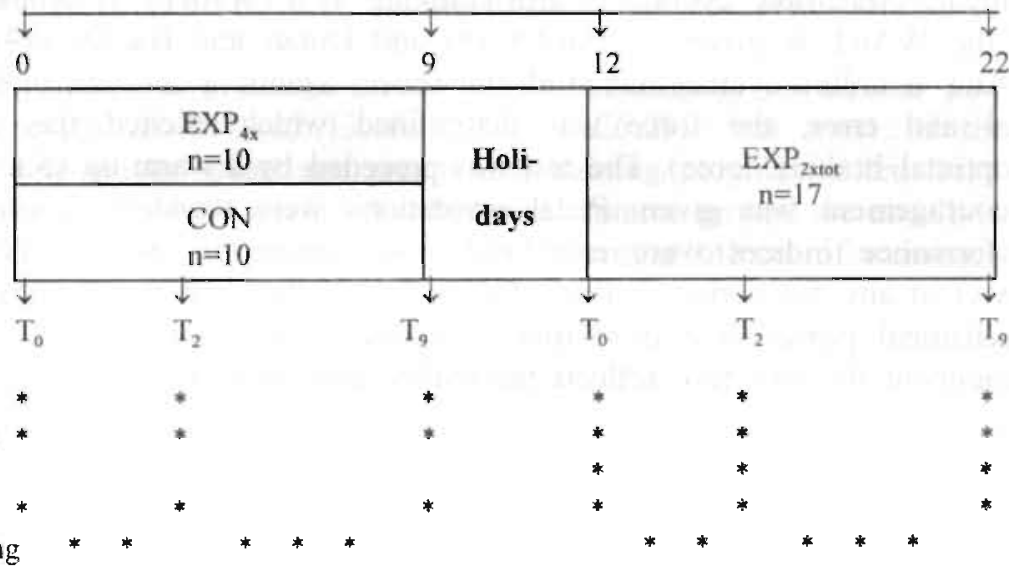

\section{Results}

\section{Peak aerobic power}

Because there was a significant relation between fat-free mass (FFM) and peak aerobic power (Spearman correlation 0.55, $\mathbf{p}<0.01$ ), peak aerobic power is presented in watt per $\mathrm{kg} \mathrm{FFM} \mathrm{(Table} \mathrm{I).} \mathrm{There} \mathrm{were} \mathrm{no} \mathrm{significant} \mathrm{differences} \mathrm{in}$ base-line aerobic power between the experimental and control groups. After 9 months of training, peak aerobic power in $\mathrm{EXP}_{4 \mathrm{x}}$ had increased $(\mathrm{p}<0.01)$ by $35 \%$ ( 9 children showed an increase varying from $+15 \%$ to $+376 \%$; I child showed a decrease of $9 \%$ ). During the summer holidays, peak aerobic power in $\operatorname{EXP}_{4 x}$ decreased significantly $(\mathrm{p}<0.01)$ by $17 \%$. There were no significant changes in CON. Changes in peak aerobic power from $T_{0}$ to $T_{9}$ were different $(p<0.05)$ between $\mathrm{EXP}_{4 \mathrm{x}}$ and $\mathrm{CON}$.

During the second year, $\operatorname{EXP}_{2 x}$ showed an increase $(\mathrm{p}<0.01)$ in peak aerobic power at $\mathrm{T}_{9}$ of $21 \%$ (all children showed an increase varying from $+2 \%$ to $+268 \%$ ), but this change was not significantly different versus CON ( $\mathrm{p}=0.17)$. Peak aerobic power in $\operatorname{EXP}_{2 x+o t}$ had increased $(\mathrm{p}<0.01)$ at $\mathrm{T}_{9}$ by $20 \%$ ( 16 children showed an increase varying from $+2 \%$ to $+268 \%$; 1 child showed a decrease of $6 \%$ ), not significantly different $(\mathrm{p}=0.23)$ versus $\mathrm{CON}$ (there was also no significant difference in the area under the curve of changes from base-line between $\mathrm{EXP}_{2 \mathrm{x}}$ and $\mathrm{CON}$ and between $\mathrm{EXP}_{2 \times \mathrm{tot}}$ and $\mathrm{CON}$ ). Increases in $\mathrm{EXP}_{2 \mathrm{xtot}}$ were similar in the children who had also trained during the first year $(n=8$, peak 
aerobic power came back to values similar to ones just before the summer holidays) and in the children who had had no training in the first year $(\mathrm{n}=9)$.

Table I. Peak aerobic power (watt per kg FFM), in children who participated in a 9-month training program (EXP ${ }_{4 x} 4$ times per week; $\mathrm{EXP}_{2 \mathrm{x}}$ and $\mathrm{EXP}_{2 \text { xot }} 2$ times per week) and in children who had no extra exercise $(\mathrm{CON})$

\begin{tabular}{l|cc|ccc}
\hline & $\begin{array}{c}\mathrm{CON} \\
(\mathrm{n}=10)\end{array}$ & $\begin{array}{c}\mathrm{EXP}_{4 \mathrm{x}} \\
(\mathrm{n}=10)\end{array}$ & $\begin{array}{c}\mathrm{CON} \\
(\mathrm{n}=9)\end{array}$ & $\begin{array}{c}\mathrm{EXP}_{2 \times} \\
(\mathrm{n}=9)\end{array}$ & $\begin{array}{c}\mathrm{EXP}_{2 \text { rot }} \\
(\mathrm{n}=17)\end{array}$ \\
\hline $\mathrm{T}_{0}{ }^{*}$ & $1.11 \pm 0.96$ & $0.91 \pm 0.83$ & $1.03 \pm 0.98$ & $0.99 \pm 0.77$ & $0.97 \pm 0.77$ \\
$\mathrm{~T}_{2}{ }^{*}$ & $1.01 \pm 0.84$ & $1.02 \pm 0.82$ & $0.90 \pm 0.82$ & $1.08 \pm 0.86$ & $1.03 \pm 0.75$ \\
$\mathrm{~T}_{9}{ }^{\circ}$ & $1.17 \pm 0.94$ & $1.23 \pm 0.80^{\dagger}$ & $1.06 \pm 0.92$ & $1.20 \pm 0.89^{\star}$ & $1.16 \pm 0.83^{\dagger}$ \\
$\mathrm{T}_{12}{ }^{\circ}$ & $1.15 \pm 0.88$ & $1.02 \pm 0.76^{\S}$ & & & \\
\hline
\end{tabular}

- $T_{0}$ : base-line, $T_{2}$ : after 2 months, $T_{9}$ : after 9 months, $T_{12}$ : after 12 months $\left(=T_{0}\right.$ of second year); 'p $<0.01$, versus $T_{0} ;{ }^{\prime} p<0.01$, versus. $T_{9}$,

Absolute increases in peak aerobic power after 9 months of training were on average (over both programs) 0.32 watt $/ \mathrm{kgFFM}$ in the cycling group and 0.18 watt $\mathrm{kgFFM}$ in the arm cranking group $(\mathrm{p}=0.06)$. Proportionally, these effects were larger $(\mathrm{p}<0.05)$ in the arm cranking group $(+129 \%)$ than in the cycling group $(+23 \%)$. Also effects on peak HR were different $(p<0.05)$ between the cycling and arm cranking group: peak HR (bts/min) in the cycling group remained constant during the training program (175 \pm 13 at $T_{0}$ and $176 \pm 11$ at $\mathrm{T}_{9}$, ns), whereas peak $\mathrm{HR}$ in the arm cranking group tended to increase during training ( $125 \pm 9$ at $T_{0}$ and $143 \pm 18$ at $T_{9}, p=0.06$ ).

Peak oxygen uptake $\left(\mathrm{ml} / \mathrm{min} \mathrm{kgFFM}^{-1}\right)$, measured during the second year in the cycling group $(n=9)$, increased by $22 \%(\mathrm{p}<0.05)$ from $31.8 \pm 7.8$ at $T_{0}$ to 38.2 \pm 8.5 at $T_{9}$. Increase in peak aerobic power (per $\mathrm{kg} \mathrm{FFM}$ ) from $T_{0}$ to $T_{9}$ in this group was $16 \% \quad(\mathrm{p}<0.05)$. Respiratory quotients (RQ) during maximal work remained constant during the year $\left(0.93 \pm 0.05\right.$ at $T_{0}$ and $0.94 \pm 0.06$ at $T_{9}$, ns).

\section{Anaerobic power}

Because there was a significant correlation between FFM and anaerobic power (Spearman correlations between FFM and PP and between FFM and MP were respectively 0.55 and $0.58(p<0.01)$ ), anaerobic power is presented in watt per $\mathrm{kg}$ FFM (Table II). There were no significant differences in base-line anaerobic power between the experimental and control groups. In $\mathrm{EXP}_{4 \mathrm{x}}$, both PP and MP tended to be higher $(p=0.06)$ at $T_{9}$ compared to $T_{0}$ by respectively $15 \%$ and $11 \%$. CON showed similar increases in PP and MP at $\mathrm{T}_{9}$ as $\operatorname{EXP}_{4 \mathrm{x}}(11 \%$ and $13 \%$ respectively, $\mathrm{p}<0.05$ ). Changes in $\mathrm{PP}$ and $\mathrm{MP}$ in $\mathrm{EXP}_{2 \mathrm{x}}$ and $\mathrm{EXP}_{2 \times t o t}$ were also not significantly different from changes in CON. 
Table II. Peak anaerobic power (PP, watt per kg FFM) and mean anaerobic power (MP, watt per $\mathrm{kg}$ FFM) in children who participated in a 9-month training program (EXP 4 times per week; $\mathrm{EXP}_{2 \mathrm{x}}$ and $\mathrm{EXP}_{2 \mathrm{xtot}} 2$ times per week) and in children who had no extra exercise (CON)

\begin{tabular}{|c|c|c|c|c|c|}
\hline PP & $\begin{array}{c}\mathrm{CON} \\
(\mathrm{n}=10)\end{array}$ & $\begin{array}{l}\mathrm{EXP}_{4 x} \\
(n=10)\end{array}$ & $\begin{array}{l}\mathrm{CON} \\
(n=9)\end{array}$ & $\begin{array}{l}\mathrm{EXP}_{2 \mathrm{x}} \\
(\mathrm{n}=9)\end{array}$ & $\begin{array}{r}\operatorname{EXP}_{2 x+o t} \\
(n=17)\end{array}$ \\
\hline $\mathrm{T}_{0}^{*}$ & $2.35 \pm 1.75$ & $2.16 \pm 1.94$ & $2.12 \pm 1.69$ & $2.42 \pm 1.96$ & $2.32 \pm 1.89$ \\
\hline $\mathrm{T}_{2} \cdot$ & $2.26 \pm 1.63$ & $2.32 \pm 1.84$ & $2.11 \pm 1.65$ & $2.33 \pm 1.88$ & $2.19 \pm 1.69$ \\
\hline $\mathrm{T}_{9} \cdot$ & $2.60 \pm 1.86^{\dagger}$ & $2.49 \pm 1.94^{\S}$ & $2.36 \pm 1.81^{3}$ & $2.65 \pm 1.90$ & $2.67 \pm 2.07^{*}$ \\
\hline$T_{12}$ & $2.55 \pm 1.89$ & $2.41 \pm 1.83$ & & & \\
\hline MP & $\begin{array}{c}\mathrm{CON} \\
(\mathrm{n}=10)\end{array}$ & $\begin{array}{l}\operatorname{EXP}_{4 x} \\
(n=10)\end{array}$ & $\begin{array}{l}\mathrm{CON} \\
(\mathrm{n}=9)\end{array}$ & $\begin{array}{l}\operatorname{EXP}_{2 x} \\
(n=9)\end{array}$ & $\begin{array}{c}\operatorname{EXP}_{2 \times 10 t} \\
(n=17)\end{array}$ \\
\hline $\mathrm{T}_{0}{ }^{\prime}$ & $1.92 \pm 1.45$ & $1.77 \pm 1.58$ & $1.75 \pm 1.42$ & $1.99 \pm 1.63$ & $1.89 \pm 1.54$ \\
\hline $\mathrm{T}_{2}^{*}$ & $1.88 \pm 1.31$ & $1.76 \pm 1.40$ & $1.77 \pm 1.33$ & $1.87 \pm 1.48$ & $1.76 \pm 1.35$ \\
\hline $\mathrm{T}_{9}$ & $2.17 \pm 1.55^{\dagger}$ & $1.97 \pm 1.51^{5}$ & $2.03 \pm 1.56^{\dagger}$ & $2.10 \pm 1.51$ & $2.02 \pm 1.53$ \\
\hline $\mathrm{T}_{12}{ }^{\circ}$ & $2.12 \pm 1.60$ & $1.90 \pm 1.42$ & & & \\
\hline
\end{tabular}

- $\mathrm{T}_{0}$ : base-line, $\mathrm{T}_{2}$ : after 2 months, $\mathrm{T}_{9}$ : after 9 months, $\mathrm{T}_{12}$ : after 12 months $\left(=\mathrm{T}_{0}\right.$ of second year); $p<0.05,{ }^{5} p=0.06$, versus $T_{0}$

\section{Isokinetic muscle strength}

Because there were no significant correlations between anthropometric parameters (height, weight, FFM) and PT, nor between these parameters and the changes in PT during training, PT is presented in absolute units $(\mathrm{Nm}$, Figure 2). Flexion PT in the least affected leg in $\operatorname{EXP}_{2 \text { xtot }}$ was increased at $T_{2}$ by $32 \%(p<0.01)$ and at $T_{9}$ by $39 \%(\mathrm{p}<0.01)$. Flexion PT in the most affected leg was increased with $28 \%$ $(\mathrm{p}<0.01)$ at $\mathrm{T}_{2}$ and showed no further increases at $\mathrm{T}_{9}$. Increases in extension PT at $T_{9}$ were $12 \% \quad(p<0.05)$ and $24 \%(p<0.05)$ in respectively the least and most affected leg. There were no significant differences in the changes between children who had also trained in the first study year $(n=8)$ and children who had had no training in the first year $(n=9)$. 
Fig. 2. Changes in flexion and extension peak torque $(\mathrm{Nm})$ at $30^{\circ} / \mathrm{s}$ in children who participated in a 9-month training program with 2 exercise sessions per week $\left(\mathrm{EXP}_{2 \mathrm{xio}}, \mathrm{n}=17\right)$,

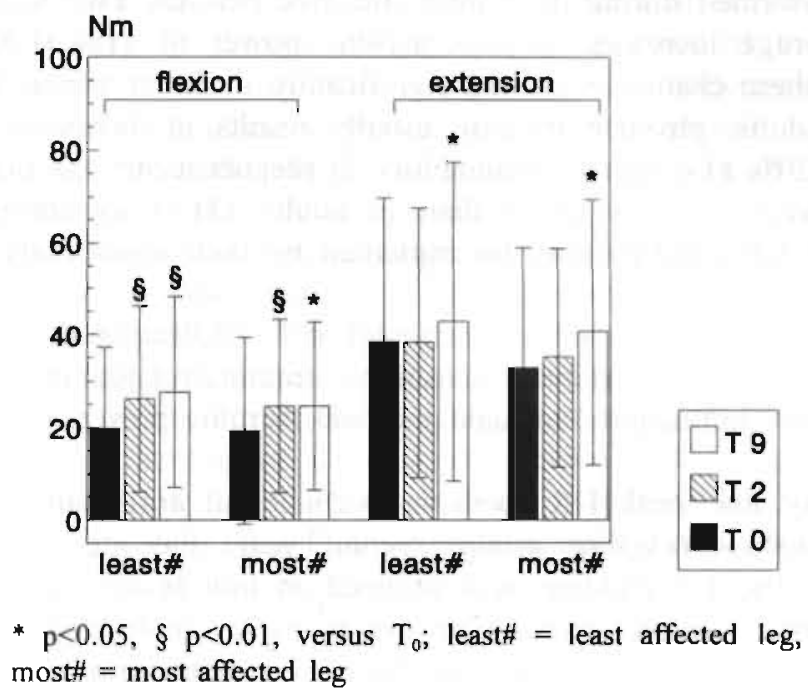

\section{Discussion}

The aim of the study was to assess the effects of aerobic training on peak aerobic power, anaerobic power, and isokinetic muscle strength in school children with spastic CP. An experimental controlled design was used, which is rather unique in training studies in CP. The used cycling tests and the isokinetic strength test have been found to be reliable (test-retest correlations varying from 0.71 to 0.96 ) in young children with spastic CP (7). Reliability of arm cranking tests has not been studied in CP children.

When compared with healthy Dutch children of the same age (7), test outcomes (aerobic and anaerobic power during cycling and strength of knee extensors and flexors) in the CP children are on average 50 to $60 \%$ lower. Only 3 children had test-outcomes on the 3 tests within the normal range. This distinctly subnormal physical fitness in $\mathrm{CP}$ children is in agreement with previous studies $(3,7$, $11,13,15.22,25)$.

\section{Effects on peak aerobic power}

Results of the present study indicate that aerobic training with a frequency of 4 sessions per week, has pronounced effects on peak aerobic power in (P' children (increase is on average $35 \%$ ), in agreement with previous studies $(2,6,18,21,29)$. Peak aerobic power in CON did not increase during the school year, indicating 
that habitual activity patterns in CP children, including gymnastic lessons, are not sufficient to induce improvements in aerobic power. At $T_{2}$, peak aerobic power in CON tended to decrease, which can be explained by the fact that these measurements were performed during the winter (inactive period). Two sessions per week resulted in average increases in peak aerobic power of $21 \%\left(\mathrm{EXP}_{2 \mathrm{x}}\right)$ and $20 \%$ $\left(\mathrm{EXP}_{2 \times 100}\right)$, but these changes were not significantly different versus CON.

In healthy adults, physical training usually results in increases of the aerobic power of 5 to $20 \%$ (1). Aerobic trainability in prepubescents, particularly in those less than 10 years old, is lower than in adults (3). Considering this, results obtained in the $\mathrm{CP}$ children may be explained by their abnormally low base-line levels of aerobic power.

Significant improvements were only found at $T_{9}$, indicating that periods of 4-10 weeks may be too short to induce measurable training-related improvements. The summer holidays significantly reduced the peak aerobic power, in agreement with Berg (6).

The relatively low peak HR (both in cycling and arm cranking groups) and maximal $\mathrm{RQ}$ values (cycling group, second year) indicate that peak aerobic performance in the $\mathrm{CP}$ children was attained at low levels of cardiorespiratory stress. Apparently, aerobic exercise testing in these children by means of cycle ergometry and arm cranking is restricted by non-cardiorespiratory factors.

During training, peak HR remained constant in the cycling group, whereas peak HR in the arm cranking group tended to increase with on average 14 $\mathrm{bts} / \mathrm{min}$. These results suggest that in the cycling group (in general less severely handicapped), the increase in peak aerobic power is caused by the oxygen effect (change in oxygen uptake at the same HR (5)), and in the arm cranking group (in general severely affected) by probably a combination of oxygen effect and muscle effect (difference in peak HR before and after training, due to improved muscle performance (5)). This finding is in agreement with the study of Berg (6) in severely handicapped CP children.

\section{Effects on anaerobic power}

Although training activities were predominantly aerobic, also effects on anaerobic performance were studied, because it may be hypothesized that aerobic training of children with low activity levels, might also induce increases in anaerobic power. However, results of the study do not support this hypothesis: increases in anaerobic power during the study years were similar in the experimental and control groups, indicating that they are independent of training. The increases in anaerobic power in the $\mathrm{CP}$ children are in agreement with findings of Bar-Or (3) and Falgairette (17) in healthy children and are probably due to qualitative changes in muscles with increasing age $(3,17)$. From the results obtained on anaerobic power. also the importance of including a control group in training studies in growing children becomes apparent. 


\section{Effects on isokinetic muscle strength}

Because the purpose of the study was to establish the effects of training on muscle strength, no corrections were made for the effect of gravity on the lower limb. The 'real' values for flexion PT are therefore expected to be somewhat lower, whereas strength of the extensors is expected to be underestimated $(19,28)$. In the wheeichair-bound children, it would have been preferable to measure also flexion and extension PT in the elbow, but children were to small to perform this measurement on the used Cybex device.

Results of the study suggest that, although no comparisons could be made with controls, aerobic training may increase isokinetic strength of the knee extensors and flexors in children with CP. Possible explanations for this increase in muscle strength may be increases in muscle mass, synchronization of motor unit recruitment, and a decrease in cocontraction of agonist and antagonist muscles. Significant improvements in torque of $25 \%$ (knee flexion and extension) and $59 \%$ (elbow extension) were also found by respectively MacPhail and Kramer (23) and McCubbin and Shasby (24) in CP children and adolescents, but their training programs consisted of isokinetic exercise.

In conclusion, aerobic training is effective in eliciting higher peak aerobic power and seems to increase isokinetic muscle strength in CP children. No effects of aerobic training are found on anaerobic power. The higher fitness may increase the effectiveness of rehabilitation programs, and may have positive effects on activities of daily life and social integration. Most pronounced effects of training on aerobic power were achieved with 4 sessions $(45 \mathrm{~min})$ per week. Because of strenuous therapy programs during school time, especially in severely affected children, this relatively high frequency of training during school hours may not be feasible. Participation in organized sports activities outside the rehabilitation center is therefore recommendable in addition to training activities at school. However, at the moment, the possibilities for handicapped children to be intensively active outside the rehabilitation center are limited. Therefore, much effort has to be invested in creating out-school training programs for handicapped children.

\section{Acknowledgements}

We wish to express our thanks to all the children and their parents who participated and the stafif of the children's rehabilitation center Franciscusoord (Valkenburg a/d Geul). We also thank Donnie de Barbanson, Eugene Rameckers, and Marcel Coenen for taking care of many training sessions, and Chantal Peeters and Martine Hoofwijk for their help during data collection and assistance during the training sessions. 


\section{References}

1. Ảstrand, P. O., K. Rodahl. Textbook of work physiology: Physiological bases of exercise. Singapore: MeGraw-Hill Book Co, 1986.

2. Bar-Or, O., O. Inbar, R. Spira. Physiological effects of a sports rehabilitation program on cerebral palsied and post-poliomyelitic adolescents. Med. Sci. Sports 8:157-161, 1976.

3. Bar-Or, O. Pediatric sports medicine for the practitioner. From physiologic principles to clinica! applications. New York: Springer Verlag, 1983.

4. Bar-Or, O. The Wingate Anaerobic Test: an update on methodology, reliability and validity. Sports Medicine 4:381-394, 1987.

5. Berg, K., J. Bjure. Methods for evaluation of the physical working capacity of school children with cerebral palsy. Acta Paediatr. Scand. 204(suppl):15-25, 1970.

6. Berg, K. Effect of physical training of school children with cerebral palsy. Acta Paediatr. Scand. 204(suppl):27-33, 1970.

7. Berg-Emons van den, H. J. G., M. A. van Baak, D. C. de Barbanson, L. Speth, W. H. M. Saris. Reliability of tests to determine peak aerobic power, anaerobic power, and isokinetic muscle strength in spastic cerebral palsied children and healthy controls. Dev. Med. Child Neurol. (accepted).

8. Berg-Emons van den, H. J. G., W. H. M. Saris, D. C. de Barbanson, K. R. Westerterp, A. Huson, M. A. van Baak. Daily physical activity of school children with spastic diplegia and of healthy control subjects. J. Pediatr. 127:578-584, 1995.

9. Berg-Emons van den, H. J. G., W. H. M. Saris, K. R. Westerterp, M. A. van Baak. Heart rate monitoring to assess energy expenditure in children with reduced physical activity. Med. Sci. Sports Exerc. (in press).

10. Berg-Emons van den, H. J. G., M. A. van Baak, L. Speth. W. H. M. Saris. Physical training of school children with spastic cerebral palsy: effects on daily physical activity and fat mass. Arch. Phys. Med. Rehab. (submitted).

11. Brown, A. Review: physical fitness and cerebral palsy. ('hild: care, health and development 1:143-152, 1975.

12. Cybex Isolated-joint testing \& exercise, a handbook for using Cybex Il and the U.B.X.T.. Cybex, Ronkonkoma, New York, 1983.

13. Damiano, D. L., C. L. Vaughan, M. F. Abel. Muscle response to heavy resistance exercise in children with spastic cerebral palsy. Dev. Med. Child Neurol. 37:731-739, 1995.

14. Dotan, R., O. Bar-Or. Climatic heat stress and performance in the Wingate Anaerobic Test. Eur. J. Appl. Physiol. 44:237-243, 1980.

15. Dresen, M. H. W., H. Vermeulen, B. J. Netelenbos, H. Krot. Physical work capacity and classroom attention of handicapped and non-handicapped children. Int. J. Rehabil. Res. 5:512. 1982.

16. Dresen, M. H. W., J. B. Netelenbos. Effects of a physical training program on physical efficiency, work capacity and classroom-attention of handicapped children. Int. J. Rehabil. Res. 6:289-299, 1983.

17. Falgairette, G., M. Bedu, N. Fellmann, E. Van Praagh, J. Coudert. Bio-energetic profile in 144 boys aged from 6 to 15 years with special reference to sexual maturation. Eur. J. Appl. Physiol. 62:151-156, 1991.

18. Fernandez, J. E., K. H. Pitetti. Training of ambulatory individuals with cerebral palsy. Arch. Phys, Med. Rehab, 74:468-472. 1993.

19. Fillyaw, M., T. Bevins, L. Femandez. Importance of correcting isokinetic peak torque for the effect of gravity when calculating knee flexor to extensor muscle ratios. Phys. Ther. $66: 23-28,1986$.

20. Hislop, H. J., J. J. Perrine. The isokinetic concept of exercise. Phys. Ther. 47:114-117, 1967.

21. Lundberg, A, C. Ovenfors, B. Saltin. Effect of physical training on schoolchildren with cerebral palsy. Acta Paediatr. Scand. 56:182-188, 1967. 
22. Lundberg, A. Longitudinal study of physical working capacity of young people with spastic cerebral palsy. Dev. Med. Child Neurol. 26:328-334, 1984.

23. MacPhail, H. E. A., J. F. Kramer. Effect of isokinetic strength-training on functional ability and walking efficiency in adolescents with cerebral palsy. Dev. Med. Child Neurol. 37:763775, 1995.

24. McCubbin, J. A., G. B. Shasby. Effects of isokinetic exercise on adolescents with cerebral palsy. Adapted Physical Activity Quarterly 2:56-64, 1985.

25. Parker, D. F., L. Carriere, H. Hebestreit, O. Bar-Or. Anaerobic endurance and peak muscle power in children with spastic cerebral palsy. A.J.D.C. 146:1069-1073, 1992.

26. Rintala, P., H. Lyytinen. De effecten van lichamelijke activiteiten op de lichamelijke conditie en motorische vaardigheden bij kinderen met infantiele encephalopathie. Bewegen \& Hulpverlening 3:200-207, 1988 [Dutch].

27. Thistle, H. G., H. J. Hislop, M. Moffroid, E. W. Lowman. Isokinetic contraction: A new concept of resistive exercise. Arch. Phys. Med. Rehab. 48:279-282, 1967.

28. Winter, D. A., R. P. Wells, G. W. Or. Errors in the use of isokinetic dynamometers. Eur. J. Appl. Physiol. 467:397-408, 1981.

29. Wormgoor, M. E. A., Y. H. J. Gierlings. Revalidatie van lichamelijk gehandicapten met behulp van sportactiviteiten in Noorwegen. Bewegen \& Hulpverlening 3:219-238, 1989 [Dutch]. 



\section{Physical training of school children with spastic cerebral palsy: effects on spasticity and mechani- cal efficiency}

H. J. G. van den Berg-Emons ', E. E. Roelofsen', M. A. van Baak ${ }^{2}$, M. R. Drost', and L. Speth

Departments of Movement Sciences ${ }^{1}$ and Iluman Biology: Iniversity of Limburg, PO Box 616, 6200 MD Maastricht. Ihe Nethorlands and the children's rehabilitation center Franciscusoord ${ }^{3}$, Onderstestraat 29,6301 KA Valkenburg a/d Geul, The Netherlands

Dev. Med. Child Neurol. [submitted].

\section{Abstract}

Effects of two 9-month sports programs (45-min aerobic sessions, 4 or 2 times per week) on spasticity and mechanical efficiency (ME) were assessed in spastic cerebral palsied (CP) children $(n=20,9.2 \pm 1.4$ y), randomly divided over an experimental and control group after matching. Spasticity was assessed by the Ashworth test (passive movements) and by surface electromyography (EMG, during cycling or arm cranking). Simultaneously to the EMG assessments, measurements of $\mathrm{ME}$ were performed. Aerobic training had no effect (positive nor negative) on spasticity during passive movements or ME. Training tended to (partly) normalize EMG patterns during cycling, but this was not supported by significant changes in calculated EMG parameters.

\section{Introduction}

Cerebral palsy (CP) is an inclusive term used to describe a number of chronic, non-progressive disorders of motor function, which occur in young children as a 
result of disease of the brain (19). Spasticity is the most common motor impairment, and accounts for approximately two-third to three-quarter of all children with CP (18). A widely accepted definition of spasticity is that of Lance (24): 'a motor disorder characterized by a velocity-dependent increase in tonic stretch refiexes ('muscle tone') with exaggerated tendon jerks, resulting from hyperexcitability of the stretch reflex, as one component of the upper motor neuron syndrome'.

Due to the increased muscle tone, mechanical efficiency (ME) in children with spastic CP is low. Impaired coordination of agonist and antagonist muscles, involuntary muscle activity, and postural stabilizing movements may also play a role $(3,6,26,27)$. Low $\mathrm{ME}$ in $\mathrm{CP}$ subjects is found during ergometry with the legs $(6,13,20,26,27)$ and with the arms $(2)$, and can be considered detrimental to the performing of activities of daily life.

In previous papers $(10,11)$, we described the effects of 9-month, predominantly aerobic training programs (4 or 2 sessions per week), on level of daily physical activity (PA), body composition, and fitness parameters (aerobic power, anaerobic power, muscle strength) in school children with spastic $\mathrm{CP}$. The present paper describes the effects of these programs on spasticity and ME. As was hypothesized by Lundberg (28), low physical activation might imply an insufficient intensity of stimulation for neuromuscular function which, by increasing spasticity, reflects itself in lower ME. Because young children with spastic $\mathrm{CP}$ are found to be extremely hypoactive when compared with healthy counterparts (8-10), increasing levels of daily PA by sports programs might result in reduced spasticity and improved ME. However, it is also possible that sports programs, and particularly strenuous programs, have deleterious effects on both parameters.

Methods (for experimental design and subjects see Figure 1 and chapter 6)

\section{Spasticity}

Measurements of spasticity were performed during passive movements (Ashworth test, both study years) and during cycling and arm cranking (EMG, only in second year; simultaneously to the measurement of ME).

\section{Spasticity during passive movements}

One of the methods that has been proposed for measuring muscle spasticity involves manually moving a limb through the range of motion to passively stretch specific muscle groups. Ashworth (1) has described a five-point ordinal scale for grading the resistance encountered during such passive muscle stretching:

$0=$ no increase in tone

$1=$ slight increase in tone giving a 'catch' when the limb was moved in flexion or extension

$2=$ more marked increase in tone but limb easily flexed

$3=$ considerable increase in tone - passive movement difficult 
$4=$ limb rigid in flexion or extension

Children were examined while lying on a bed (supine position) by the same, experienced investigator (physical therapist) at all time points. Passive movements of the limbs (extension/fiexion in hips, knees, ankles, shoulders, elbows, wrists; adduction/abduction in hips) were made (bilateral) and an average score was calculated. At the start of the experiment ( $T_{0}$ in first year), children were examined twice (within one week); the average of these measurements was used as the base-line score. During the other measurement periods, children were examined once.

\section{Spasticity during cycling and arm cranking}

Spasticity during cycling and arm cranking was, for practical reasons, only measured during the second study year. Cycling and arm cranking tests (lasting 6 min) were performed on a mechanically braked calibrated ergometer (Universal Ergostat Fleisch, Metabo, Epalinges, Switzerland), equipped with a tachometer to determine pedaling rates. Depending on their physical ability, children performed a cycling test $(n=13$, feet were fixed to the pedals with braces) or arm cranking test $(n=7)$. The aim was to exercise at $30 \%$ of their previously assessed peak aerobic capacity. No fixed pedaling rate was required, the actual load was calculated from the recorded pedaling rates and dosed load. Arm cranking tests were performed with $1 \mathrm{arm}$, while the children were sitting in their own wheelchair beside the ergometer. It turned out to be impossible to perform measurements while cranking with two arms, because, when sitting behind the ergometer, the distance between cranks and face was so small that the cranks constantly hit the tube that connected the mask with the gas exchange analyzer (for measurement of ME).

During cycling, EMG recordings were performed (on most affected side) in: 1) $\mathrm{m}$. rectus femoris (rf); 2) $\mathrm{m}$. biceps femoris (bf); 3) $\mathrm{m}$. tibialis anterior (ta); 4) $\mathrm{m}$. gastrocnemius medialis (gm). During arm cranking, EMG was recorded in 1) $\mathrm{m}$. biceps brachii (bb); 2) m. triceps brachii (tb); 3) extensor muscles of wrist (ex); 4) flexor muscles of wrist (fl). Muscle activity in the arm was measured on the least affected side, because most children were not able to crank with their most affected arm. Surface EMG was measured with a K-Lab kinesiological measuring system (K-Lab Kinesiologic Laboratory Systems, Amsterdam, The Netherlands). The electrodes ( $\mathrm{Ag} / \mathrm{AgCl}$ Medi-Trace) were placed $23 \mathrm{~mm}$ apart over the belly of each muscle. In order to register pedal position, a disk with notches (every $10^{\circ}$ ) was attached to the crank axle, with a source of light behind it (lowest position of the right pedal was defined as $0^{\circ}$ ). EMG and pedal position were sampled with a Labmaster $\mathrm{AD}$-converter. In the cycling group, muscle activity was measured during $20 \mathrm{~s}$ (sample frequency $500 \mathrm{~Hz}$ ) after the children had reached a regular pedaling rate (approximately after 3 minutes). In this period, about 10 rotations had to be made. During arm cranking, a longer measurement period was used ( 35 
$\mathrm{s}, 300 \mathrm{~Hz}$ ), because not all children could reach the minimum of 10 rotations in $20 \mathrm{~s}$.

\section{Qualitative description of EMG patterns}

The mean squared value, RMS/LE (linear envelope), was calculated off-line over 19 measure points which is equivalent to a calculation over about $40 \mathrm{~ms}$ (cycling) or $60 \mathrm{~ms}$ (arm cranking) and related to pedal position (not to time, since no fixed pedaling rate was required). EMG graphs were normalized by dividing the RMSvalues by the average activity of the muscle (=fraction of average activity). Smoothed individual patterns were obtained by averaging the data of 10 regular rotations for each recorded muscle.

\section{Quantitative description of EMG patterns}

In order to quantify the characteristics of the EMG patterns, the following parameters were calculated:

\section{Width of pattern}

The width of the pattern is the range of rotation in which the muscle is active. Muscles were defined as active when the fraction of the average activity was more than $75 \%$ (muscle activity varied from $25 \%$ to $225 \%$ of the average activity). For this subjective border was chosen because in standardized graphs of healthy children measured during cycling and arm cranking in our laboratory (Van Munster and Van Overveld, unpublished data), the $75 \%$ level clearly distinguished between activity and no-activity.

\section{Range of pallern}

The range of the pattern was obtained by calculating the difference between the lowest and the highest activity-value.

\section{3. $R^{*}$}

The quotient $\mathrm{R}=\left(\mathrm{I}_{1}\right) /\left(\mathrm{I}_{0}\right)$ has been used by Benecke et al. (5) to quantify the pathological widening of the EMG activity pattern of spastic patients during cycling. $I_{1}$ is the integral of the EMG during the normal recruitment period; $I_{0}$ is the integral of the EMG in the range of rotation in which normally - but not always in patients - a silent state of muscle occurs. $R$ decreases when the pathological activity increases.

In the present study, the normal recruitment period of the muscles was based on standardized graphs of healthy children measured in our laboratory (Van Munster and Van Overveld, unpublished data). Because $\mathrm{R}$ is sensitive for small changes in the borders between activity and no activity, the average muscle activity (per ${ }^{\circ}$ ) during the normal and pathological recruitment period was used:

$\mathrm{R}^{\prime \prime}=\left(\mathrm{I}_{1 \text { average }}\right) /\left(\mathrm{I}_{0 \text { average }}\right)$.

\section{Co-contraction index}

Co-contraction of the agonist and antagonist muscles acting across the same joint is considered as a means of achieving joint stability. However, in a too high 
extent, it is considered to be a cause of inefficient movement. Falconer and Winter (16) defined a co-contraction-index (CI):

$\mathrm{CI}=(2 *$ common area of contraction / area muscle $1+$ area muscle 2$) * 100 \%$. With increasing co-contraction, $\mathrm{CI}$ increases. CI was calculated for $\mathrm{rf}$ and bf and for ta and gm (cycling); for bb and tb and for ex and $\mathrm{fl}$ of the wrist (arm cranking).

\section{Mechanical efficiency}

$\mathrm{VO}_{2}(\mathrm{~L} / \mathrm{min}$ ) was measured during a 6-min cycling or arm cranking test (at $30 \%$ of peak aerobic capacity; in second year simultaneously to EMG measurement) using a face mask connected to a Jaeger EOS-sprint analyzer (Jaeger Nederland, Breda. The Netherlands). $\mathrm{VO}_{2}$ was computed as the mean of the last $4 \mathrm{~min}$ of a test. ME (net efficiency, in \%) was calculated according to Lundberg (27):

mechanical work rate performed (W) x $100 / 69.8 \times 4.9\left(\mathrm{VO}_{2 \text { work }}-\mathrm{VO}_{2 \text { basal }}\right)$, where 69.8 is the factor for conversion of calories per min into watts, and 4.9 is the calculated value in calories derived from the combustion of $1 \mathrm{~L}$ of oxygen in the presence of a normal diet. $\mathrm{VO}_{2 \text { basal }}$ was calculated as the mean $\mathrm{VO}_{2}$ during sitting on a (wheel) chair (average $\mathrm{VO}_{2}$ over $4 \mathrm{~min}$, after an equilibration period of $2 \mathrm{~min})$.

Fig. 1. Schematic presentation of the study design (training periods are dark)

Month

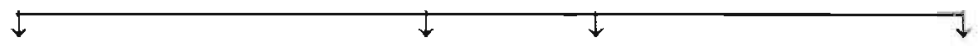

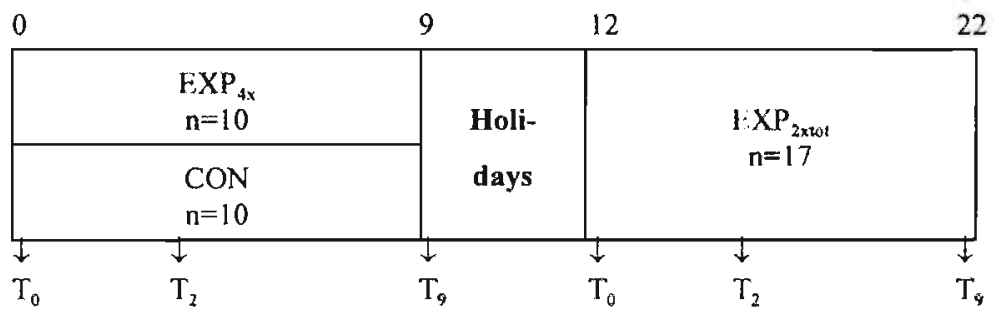

Ashworth test EMG ME Aerobic power

Fat mass

Training intensity

\section{Statistical analysis}

Data are expressed as mean $\pm \mathrm{SD}$. Comparisons between data were made using the Wilcoxon test for paired observations and the Mann-Whitney $U$ test for unpaired observations $(\alpha=0.05)$. To establish the effects of 4 exercise sessions per week on spasticity during passive movements (Ashworth test) and ME, data of $\operatorname{EXP}_{4 x}(n=10)$ were compared with CON $(n=10)$. The effects of 2 sessions per 
week on spasticity during passive movements and ME were established by comparing the control children of the first year with themselves in the second year. Because one child of this group had to quit training because of surgery, this comparison was made on 9 children $\left(\mathrm{EXP}_{2 \mathrm{x}}\right.$ versus $\left.\mathrm{CON}, \mathrm{n}=9\right)$. Also the results of the total experimental group of the second year are presented $\left(\mathrm{EXP}_{2 \times \mathrm{tot}}, \mathrm{n}=17\right)$ and compared with $\mathrm{CON}(\mathrm{n}=10)$. For spasticity during cycling and arm cranking (EMG), only effects of 2 sessions per week are established ( $\mathrm{n}=11$ ); no comparisons could be made with controls.

\section{Results}

Peak aerobic power (in watt $/ \mathrm{kgFFM}$, progressive cycling or arm cranking test) in $\mathrm{EXP}_{4 \times}$ was improved after 9 months by $35 \%(\mathrm{p}<0.01)$ from $0.91 \pm 0.83$ to $1.23 \pm$ 0.80 ; in $\operatorname{EXP}_{2 \mathrm{x}}$ by $21 \%(\mathrm{p}<0.01)$ from $0.99 \pm 0.77$ to $1.20 \pm 0.89$ and in $\operatorname{EXP}_{2 x w 1}$ by $20 \%(p<0.01)$ from $0.97 \pm 0.77$ to $1.16 \pm 0.83$ (see also chapter 8 ).

\section{Spasticity during passive movements (Ashworth test)}

There were no significant differences in base-line Ashworth scores between experimental and control groups, nor in changes in scores between $\operatorname{EXP}_{4 \mathrm{x}}$ and $\mathrm{CON}$ and $\mathrm{EXP}_{2 x}$ and $\mathrm{CON}$ (Table I). $\mathrm{EXP}_{2 x t o t}$ showed a significant $(\mathrm{p}<0.05)$ increase after 9 months of training, but this was not significantly different. from. changes in CON. There were no differences in changes between the cycling group and the arm cranking group.

Table I. Mean Ashworth scores in children who participated in a 9-month training program $\left(\mathrm{EXP}_{4 \times} 4\right.$ times per week; $\mathrm{EXP}_{2 \mathrm{x}}$ and $\mathrm{EXP}_{2 \times \mathrm{xil}} 2$ times per week) and in children who had no extra exercise (CON)

\begin{tabular}{|c|c|c|c|c|c|}
\hline & $\begin{array}{l}\mathrm{CON} \\
(n=10)\end{array}$ & $\begin{array}{l}\operatorname{EXP}_{4 x} \\
(n=10)\end{array}$ & $\begin{array}{l}\text { CON } \\
(n=9)\end{array}$ & $\begin{array}{l}\mathrm{EXP}_{2 x} \\
(n=9)\end{array}$ & $\begin{array}{c}\operatorname{EXP}_{2 \times 10 t} \\
(n=17)\end{array}$ \\
\hline $\mathrm{T}_{0} \cdot$ & $1.39 \pm 0.64$ & $1.31 \pm 0.59$ & $1.45 \pm 0.65$ & $1.43 \pm 0.33$ & $1.37 \pm 0.43$ \\
\hline $\mathrm{T}_{2} \cdot$ & $1.41 \pm 0.58$ & $1.30 \pm 0.58$ & $1.45 \pm 0.59$ & $1.51+0.44$ & $1.44 \pm 0.5 \mathrm{I}^{\dagger}$ \\
\hline $\mathrm{T}_{9}$ & $1.49 \pm 0.58$ & $1.39 \pm 0.62$ & $1.53 \pm 0.60$ & $1.54 \pm 0.55$ & $1.53 \pm 0.56^{8}$ \\
\hline
\end{tabular}

- $\mathrm{T}_{0}$ : hase-line, $\mathrm{T}_{2}$ : after 2 months, $\mathrm{T}_{9}$ : after 9 months; ${ }^{\dagger} \mathrm{p}=0.06,{ }^{8} \mathrm{p}<0.05$ versus $\mathrm{T}_{0}$

\section{Spasticity during cycling and arm cranking (EMG)}

The cycling group performed the submaximal tests at $39 \pm 12 \%$ of their peak aerobic capacity $(44.7 \pm 13.0 \mathrm{rpm})$; the arm cranking group at $74 \pm 49 \%(14.8 \pm$ $4.9 \mathrm{rpm}$ ). This relative workload and pedaling rate did not change significantly during the study years in both experimental and control groups. In Figures 2a-2d, the effects of training ( 2 sessions per week) on the average EMG patterns during cycling are shown. Particularly in of and bf (Figures $2 a$ and $2 b$ respectively), activity peaks showed a tendency to be more concise after training $\left(T_{2}\right.$ and $\left.T_{9}\right)$. 
Figures 2a-2d. Average electromyography (EMG) patterns during cycling in $\mathrm{m}$. rectus femoris $(a, n=7), m$. biceps femoris $(b, n=6)$, m. tibialis anterior $(c, n=7), m$. gastrocnemius medialis ( $d$, $\mathrm{n}=3$ ). $\mathrm{Y}$-axis: fraction of average EMG activity (\%); X-axis: pedal position ( $\%$, lowest position of right pedal is $0^{\circ}$ ). $T_{0}$ uninterrupted line, $T_{2} \cdots, T_{9}-\cdots$.

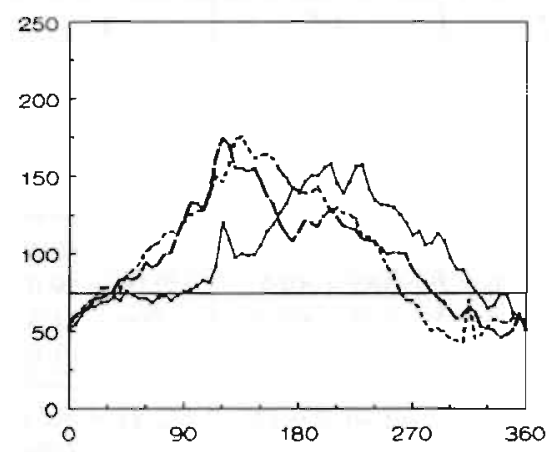

Fig. 2a. M. rectus femoris

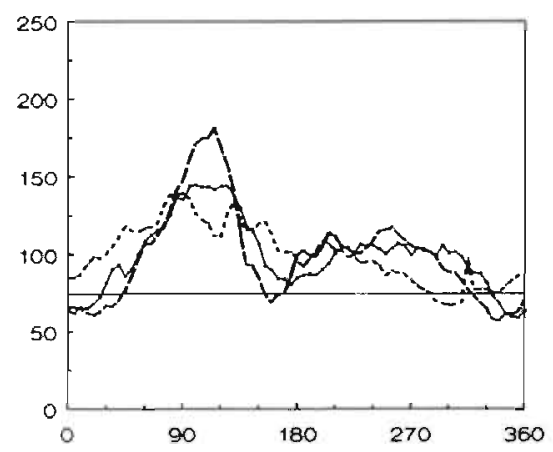

Fig. 2c. M. tibialis anterior

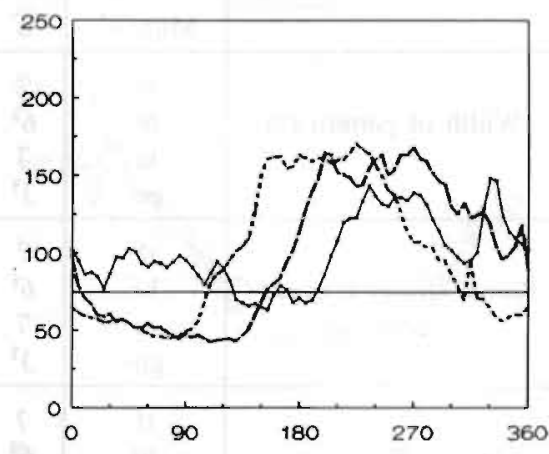

Fig. 2b. M. biceps femoris

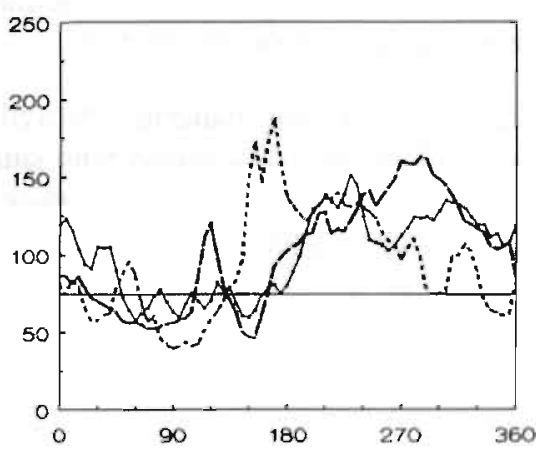

Fig. 2d. M. gastrocnemius medialis 
The parameters as presented in Table II show a decrease in width of pattern and $\mathrm{Cl}$, and an increase in the range and $\mathrm{R}^{\#}$. However, none of these changes was statistically significant.

Table II. Calculated electromyography (EMG) parameters in lower limb muscles during cyeling in children who participated in a 9-month training program (2 sessions per week)

\begin{tabular}{|c|c|c|c|c|c|}
\hline & Muscle ${ }^{\circ}$ & $n$ & $\mathrm{~T}_{0}^{+}$ & $\mathrm{T}_{2}^{\dagger}$ & $\mathrm{T}_{9}^{+}$ \\
\hline Width of pattern (") & $\begin{array}{l}\text { rf } \\
\text { bf } \\
\text { ta } \\
\text { gm }\end{array}$ & $\begin{array}{c}7 \\
6^{\S} \\
7 \\
3^{9}\end{array}$ & $\begin{array}{l}214 \pm 46.3 \\
188 \pm 64.6 \\
209 \pm 53.6 \\
218 \pm 37.9\end{array}$ & $\begin{array}{l}219 \pm 40.1 \\
167 \pm 29.1 \\
225 \pm 87.6 \\
167 \pm 13.1\end{array}$ & $\begin{array}{l}221 \pm 67.3 \\
173 \pm 40.4 \\
184 \pm 72.4 \\
190 \pm 28.6\end{array}$ \\
\hline $\begin{array}{c}\text { Range (fraction avera- } \\
\text { ge activity) }\end{array}$ & $\begin{array}{l}\text { rf } \\
\text { bf } \\
\text { ta } \\
\mathrm{gm}\end{array}$ & $\begin{array}{c}7 \\
6 \\
7 \\
31\end{array}$ & $\begin{array}{l}184 \pm 77.6 \\
213 \pm 96.0 \\
171 \pm 54.7 \\
178 \pm 47.3\end{array}$ & $\begin{array}{c}189 \pm 44.5 \\
203 \pm 59.3 \\
157 \pm 55.4 \\
192 \pm 9.4\end{array}$ & $\begin{array}{l}191 \pm 80.6 \\
219 \pm 59.0 \\
200+81.5 \\
218 \div 61.0\end{array}$ \\
\hline $\mathrm{R}^{\prime \prime}$ & $\begin{array}{l}\text { rf } \\
\text { bf } \\
\text { ta } \\
g m\end{array}$ & $\begin{array}{c}7 \\
6^{\$} \\
7 \\
3\end{array}$ & $\begin{array}{l}1.72 \pm 1.14 \\
1.13 \pm 0.47 \\
1.60 \pm 1.03 \\
1.17 \pm 0.43\end{array}$ & $\begin{array}{l}2.30 \pm 0.73 \\
2.06 \pm 0.49 \\
1.51 \pm 0.47 \\
1.61 \pm 0.19\end{array}$ & $\begin{array}{l}1.81 \pm 1.03 \\
2.08 \pm 0.86 \\
1.57 \pm 0.75 \\
1.36 \pm 0.45\end{array}$ \\
\hline Co-contraction index & $\begin{array}{c}\text { rf\&bf } \\
\text { ta\&gm }\end{array}$ & $\begin{array}{l}6^{3} \\
3^{1}\end{array}$ & $\begin{array}{l}71.9 \pm 10.3 \\
64.3 \pm 11.9\end{array}$ & $\begin{array}{c}73.7 \pm 14.7 \\
63.5 \pm 4.1\end{array}$ & $\begin{array}{l}64.6 \pm 17.1 \\
64.7 \pm 10.2\end{array}$ \\
\hline
\end{tabular}

- $\mathrm{rf}=\mathrm{m}$. rectus femoris, $\mathrm{bf}=\mathrm{m}$. biceps femoris, $\mathrm{ta}=\mathrm{m}$. tibialis anterior, $\mathrm{gm}=\mathrm{m}$. gastrocnemius medialis; ' $\mathrm{T}_{0}$ : base-line, $\mathrm{T}_{2}$ : after 2 months, $\mathrm{T}_{4}$ : after 9 months; ${ }^{\$}$ registrations were not succesful in 1 child at $T_{2}$; "registrations are missing in 4 children because the braces that fixed the feet to the pedals hindered the measurement

The arm cranking patterns showed no obvious changes during training (Figures 3a-3d). Because this group was small $(\mathrm{n}=4)$, no statistical analysis of the parameters could be performed. However, the trends in the parameters suggest a more pathological pattern during training (Table III). 
Figures 3a-3d. Average electromyography (EMG) pattems during arm cranking in $\mathrm{m}$. biceps brachii $(a, n=4)$, m. triceps brachii $(b, n=4)$, extensors of wrist $(c, n=4)$, flexors of wrist $(d, n=4)$. Y-axis: fraction of average EMG activity (\%); X-axis: pedal position $\left({ }^{\circ}\right.$, lowest position of right pedal is $\left.0^{\circ}\right)$. $T_{0}$ uninterrupted line, $T_{2} \cdots, T_{9}$---.

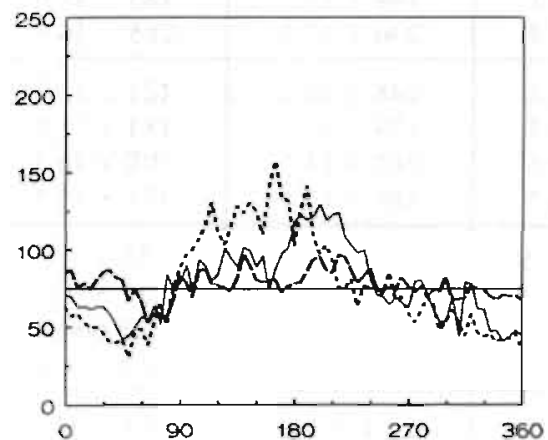

Fig. 3a. M. biceps brachii

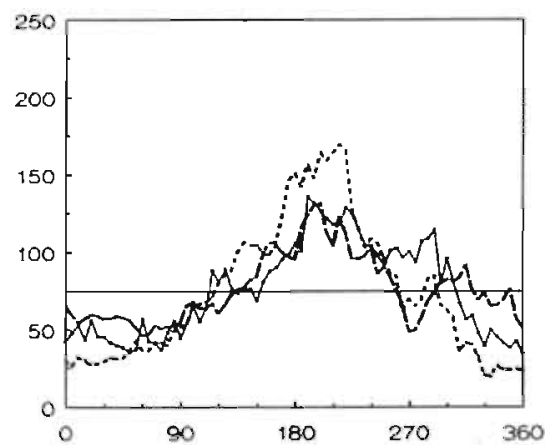

Fig. 3c. extensor muscles of wrist

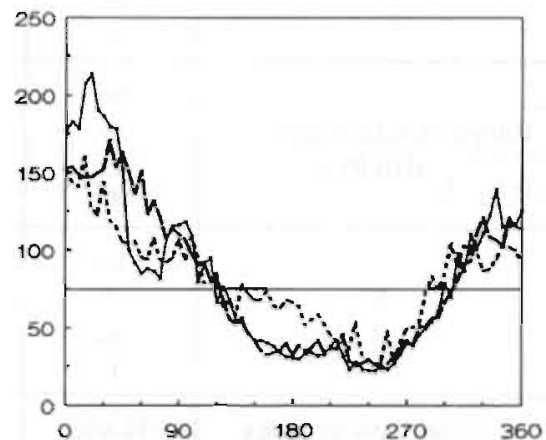

Fig. 3b. M. triceps brachii

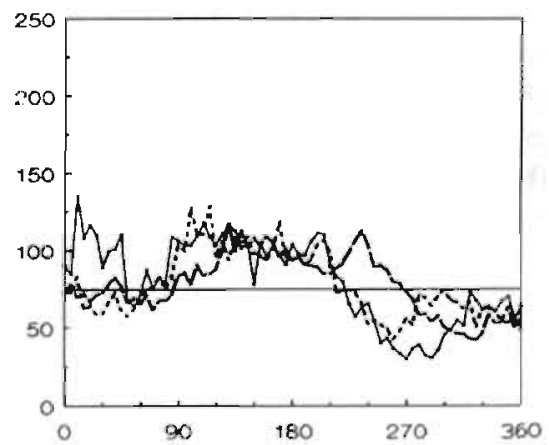

Fig. 3d. flexor muscles of wrist 
Table III. Calculated electromyography (EMG) parameters in upper limb muscles during arm cranking in children ( $\mathrm{n}=4$ ) who participated in a 9-month training program ( 2 sessions per week)

\begin{tabular}{c|c|c|c|c}
\hline & Muscle & $\mathrm{T}_{0}{ }^{+}$ & $\mathrm{T}_{2}{ }^{+}$ & $\mathrm{T}_{9}{ }^{+}$ \\
\hline \multirow{3}{*}{ Width of pattern $\left({ }^{\circ}\right)$} & bb & $176 \pm 67.0$ & $168 \pm 42.8$ & $294 \pm 52.1$ \\
& tb & $190 \pm 24.7$ & $183 \pm 14.4$ & $200 \pm 28.1$ \\
& ex & $184 \pm 48.1$ & $164 \pm 15.2$ & $185 \pm 43.0$ \\
& fl & $264 \pm 11.4$ & $236 \pm 47.2$ & $285 \pm 16.0$ \\
\hline \multirow{3}{*}{ Range (fraction average } & bb & $173 \pm 93.5$ & $248 \pm 48.1$ & $121 \pm 12.7$ \\
activity) & tb & $222 \pm 23.3$ & $173 \pm 97.7$ & $183 \pm 31.9$ \\
& ex & $256 \pm 24.5$ & $265 \pm 24.1$ & $198 \pm 40.5$ \\
& fl & $198 \pm 36.5$ & $169 \pm 12.4$ & $134 \pm 15.3$ \\
\hline \multirow{2}{*}{$\mathrm{R}^{*}$} & bb & $1.52 \pm 0.56$ & $1.82 \pm 0.53$ & $1.32 \pm 0.35$ \\
& tb & $1.36 \pm 0.36$ & $1.42 \pm 0.58$ & $1.32 \pm 0.60$ \\
& ex & $1.85 \pm 0.84$ & $2.59 \pm 0.84$ & $1.42 \pm 0.33$ \\
& fl & $1.72 \pm 0.87$ & $1.18 \pm 0.41$ & $1.11 \pm 0.47$ \\
\hline \multirow{2}{*}{ Co-contraction index } & bb\&tb & $58.4 \pm 9.6$ & $62.5 \pm 8.1$ & $71.1 \pm 11.2$ \\
& ex\&fl & $63.3 \pm 10.9$ & $71.7 \pm 3.9$ & $67.3 \pm 8.1$ \\
\hline
\end{tabular}

$\cdot b b=m$. biceps brachii, $t b=m$. triceps brachii, ex = extensors wrist, $\mathrm{fl}=$ flexors wrist

${ }^{\dagger} \mathrm{T}_{0}$ : base-line, $\mathrm{T}_{2}$ : after 2 months, $\mathrm{T}_{4}$ : after 9 months

\section{Mechanical efficiency}

Because in both $\operatorname{EXP}_{4 x}$ and CON there was a gap (ns) in ME between $T_{0}$ and $T_{2}$ (Table IV), it was concluded that ME measured at $T_{0}$ in the first study year was too low in both groups (probably because of excitement: it was the first time the children wore a face mask). Therefore, measurements at $T_{0}$ of the first year were excluded from further analysis, and $M E$ measured at $T_{2}$ was used as base-line. Base-line ME in the cycling group was $13.2 \pm 5.7 \%$, in the arm cranking group $8.4 \pm 3.8 \%(p=0.07))$. There were no significant differences in base-line ME between experimental and control groups. In both $\mathrm{EXP}_{4 \mathrm{x}}$ and $\mathrm{CON}, \mathrm{ME}$ remained unchanged after $T_{2}$. ME in $\operatorname{EXP}_{2 x}$ was increased $(p<0.05)$ at $T_{9}$ versus $T_{0}$, but this was not significantly different from changes in $\operatorname{CON}\left(T_{9}\right.$ versus $\left.T_{2}\right)$. There were no differences in changes between the cycling group and arm cranking group. 
Table $I V$. Mechanical efficiency (ME, in \%) in children who participated in a 9-month training program ( $\mathrm{EXP}_{4 \mathbf{x}} 4$ times per week; $\mathrm{EXP}_{2 \mathrm{x}}$ and $\mathrm{EXP}_{2 \mathrm{xtot}} 2$ times per week) and in children who had no extra exercise (CON)

\begin{tabular}{|c|c|c|c|c|c|}
\hline & $\begin{array}{c}\mathrm{CON} \\
(\mathrm{n}=9)^{\circ}\end{array}$ & $\begin{array}{l}\operatorname{EXP}_{4 x} \\
(n=9)^{\circ}\end{array}$ & $\begin{array}{c}\mathrm{CON} \\
(\mathrm{n}=8)^{\circ}\end{array}$ & $\begin{array}{l}\operatorname{EXP}_{2 x} \\
(n=8)^{9}\end{array}$ & $\begin{array}{c}\operatorname{EXP}_{2 x t o t} \\
(n=16)\end{array}$ \\
\hline $\mathrm{T}_{0}^{*}$ & $(10.6 \pm 4.0)^{\S}$ & $(10.4 \pm 5.6)^{5}$ & $(10.2 \pm 4.1)^{5}$ & $12.9 \pm 5.1$ & $12.7 \pm 5.9$ \\
\hline $\mathrm{T}_{2}^{\dagger}$ & $12.9 \pm 4.5$ & $11.4 \pm 6.2$ & $12.1 \pm 4.1$ & $12.9 \pm 4.7$ & $11.7 \pm 5.0$ \\
\hline $\mathrm{T}_{9}^{+}$ & $13.0 \pm 5.0$ & $11.2 \pm 5.9$ & $12.5 \pm 5.0$ & $13.4 \pm 6.4^{1}$ & $11.8 \pm 6.3$ \\
\hline
\end{tabular}

- One matched pair was excluded from analysis, because one child of this pair was not able to crank with one arm against resistance; ${ }^{+} \mathrm{T}_{0}$ : before program started, $\mathrm{T}_{2}$ : after 2 months, $\mathrm{T}_{9}$ : after 9 months; ${ }^{\S}$ excluded from analysis, see text; ${ }^{1} \mathrm{p}<0.05$ versus $\mathrm{T}_{0}$

\section{Discussion}

The aim of the study was to assess the effects of aerobic training on spasticity and $\mathrm{ME}$ in school children with spastic CP. An experimental controlled design was used, which is rather unique in training studies in $\mathrm{CP}$.

\section{Quantification of spasticity}

A broad range of techniques has been used in an attempt to quantify spastic hypertonia: clinical scales, electromyographic and biomechanical analysis of limb resistance to mechanical displacement, rectified surface electromyographic responses to perturbation or voluntary movement, gait analysis, electrophysiologic reflex studies $(12,21,24,30)$. However, no uniformly useful objective clinical measurements have emerged. Quantification of spasticity has been hampered by the remarkable variation in degrees of spasticity which occurs in an individual in response to emotional stimuli (discomfort, apprehension, anger) and physical stimuli (infection, overloading of bladder or bowel, presence of decubitus ulceration) (12).

\section{Effects of training on spasticity during passive movements}

The Ashworth test, a gross clinical scale which offers ease of measurement, has been widely used in the study of spasticity (21). However, the test provides only qualitative information, lacks temporal and interexaminer reproducibility, and suffers from a clustering effect where most of the patients are grouped within the middle grades (22). To avoid interexaminer variation, Ashworth tests in the present study were performed by the same investigator during the different measurement periods.

Mean Ashworth scores tended to increase during training (the increase in $\mathrm{EXP}_{2 \text { tot }}$ was significant $(\mathbf{p}<0.05)$ after 9 months $)$. However, scores in the controls showed similar increases, indicating that aerobic training has no effects on spasticity during passive movements as measured by the Ashworth test. We have 
no explanation for the increase in scores throughout the study years.

Only few studies exist concerning the effects of aerobic training on spasticity during rest or passive movements in CP. Wormgoor and Gierlings (36) found significant reductions of spasticity (as measured by the Ashworth test) in the hips and knees after a 4-week aerobic training program in CP adults. However, also in control subjects who had had no training, Ashworth scores tended (ns) to be decreased. From the study it is not clear whether the decrease in Ashworth scores is different between the experimental and control group. MacPhail and Kramer (29) found no significant changes in spasticity (also measured by the Ashworth test) after an 8-week strength-training program in CP adolescents. Spira (32) studied the effects of a one-year training program on the H-reflex in CP adolescents. From the results it was suggested that a period of controlled general activities, may reduce the spasticity of the lower limbs. However, after enlarging the study population and extending the follow-up to 12-30 months, no training related effects could be detected (33). Also no reductions of spasticity (as measured by surface EMG) were found by Rotzinger and Stoboy (31), after a one-year trampoline exercise program in diplegic CP children.

\section{Effects of training on spasticity during cycling and arm cranking}

Spastic muscles exhibit during voluntary movements a widening of the activity pattern in comparison with normal muscles, caused by both premature recruitment and delayed relaxation. Furthermore, activity patterns in spastic muscles are flatter than in normal muscles and impaired coordination between antagonist muscles exits $(4,5,21,23)$. To our knowlegde, no studies are available concerning training effects on spasticity during voluntary movement in $\mathrm{CP}$.

The changes in EMG patterns observed after training (2 sessions per week) in the cycling group (Figures $2 a$ and $2 b$ ), suggest normalization (partly) of the activity of the $\mathrm{m}$. rectus femoris and $\mathrm{m}$. biceps femoris during cycling. This normalization might be explained by synchronization of motor unit recruitment and a decrease in co-contraction. However, the normalization of the patterns was not supported by significant changes in the calculated EMG parameters (Table II), but this may be due to large intra- and interindividual differences. EMG patterns in the arm cranking group were unchanged after training, but changes in the parameters suggest a more pathological pattern as a result of training. However, cranking with one arm is not a natural movement for the children and was not included in the training program. Therefore, EMG registrations in the arm cranking group may not reflect the actual training effects.

\section{Effects of training on ME}

Net efficiency (work accomplished divided by energy expended above that at rest) is the most frequently used method in calculating efficiency. The method has however been criticized $(17,35)$ because the energy cost of moving the legs is not considered in the estimation of work done by the exercising subject (results in an 
underestimation of the true efficiency). Furthermore, base-line energy expenditure changes with increasing work rate (34). However, because the aim of the study was to assess the effects of training on ME, we do not expect this to interfere with the results.

ME in the cycling group was $13.2 \pm 5.7 \%$. ME during cycling in healthy Dutch children $(n=14,9.3 \pm 1.6$ y) measured in our laboratory (Van Munster and Van Overveld, unpublished data) was $20.1 \pm 4.2 \%$, indicating that $\mathrm{CP}$ children have a distinctly subnormal efficiency during cycling. This is in agreement with previous reports $(3,6,13,20,26,27)$. No effects of training on ME were found in the present study. Apparently, changes that may have occurred in patterns of muscle activity and EMG parameters, did not result in measurable changes in ME. Also the studies of Bar-Or et al. (2), Ekblom and Lundberg (15), Lundberg and Pernow (25) and MacPhail and Kramer (29) in CP adolescents reported no effects of training on ME. Dresen (14) found significant improvements in ME after intensification of the physical education lessons in CP children, but no effects were achieved with weekly one extra physical education lesson.

In conclusion, the present study indicates that aerobic training has no effect (positive nor negative) on spasticity during passive movements or ME (cycling or arm cranking) in young $\mathrm{CP}$ children. Aerobic training might improve EMG patterns during cycling, but this was not supported by significant changes in calculated EMG parameters.

\section{Acknowledgements}

We thank all the children and their parents who participated and the staff of the children's rehabilitation center Franciscusoord (Valkenburg a/d Geul). We also thank Donnie de Barbanson, Eugene Rameckers, and Marcel Coenen for taking care of many training sessions, and Danielle Van Munster and Florine Van Overveld for their help during data collection and assistance during the training sessions.

\section{References}

1. Ashworth, B. Preliminary trial of carisoprodol in multiple sclerosis. The Practitioner 192:540-542, 1964.

2. Bar-Or, O., O. Inbar, R. Spira. Physiological effects of a sports rehabilitation program on cerebral palsied and post-poliomyelitic adolescents. Med. Sci. Sports 8:157-J61, 1976.

3. Bar-Or, O. Pediatric sports medicine for the practitioner. From physiologic principles to clinical applications. New York: Springer-Verlag, 1983.

4. Bausenwein, I., P. Reeh, D. Stadler. Sport als Therapie bei Cerebralparesen. Schrifienreihe des Bundesministers fur Jugend, Familie und Gesundheid 38:4-216, 1977 [German].

5. Benecke, B. C., H. M. Meinck, J. Höhne. Electromyographic analysis of bicycling on an ergometer for evaluation of spasticity of lower limbs in man. In Desmedt, J. E. (editor): 


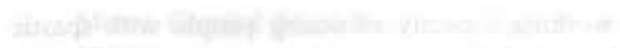

717

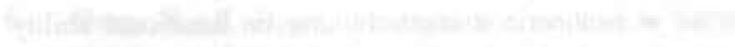

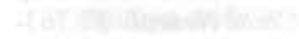

(1)

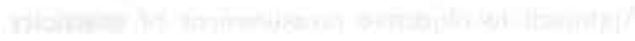




\section{General discussion and conclusions}

Individuals with various forms of physical and mental handicaps run the risk of becoming less physically activated as a result of their disease (3). The research in the present thesis has focussed on whether in young children with spastic cerebral palsy (CP) hypoactivity exists and consequently whether special physical activity (PA) programs are needed in this population (chapter 2). Furthermore, effects of PA programs in CP children were studied (chapters 6 to 9). It was hypothesized that, in case of hypoactivity in CP children, PA programs will increase the level of daily PA, and therefore lead to improvements in body composition, physical fitness (aerobic power, anaerobic power, isokinetic muscle strength), spasticity, and mechanical efficiency (ME). In addition, the validity of the heart rate (HR) method and skinfold measurements to determine total daily energy expenditure (TEE) and body fat (BF) respectively was assessed in CP children (chapters 3 and 4). Also a study was conducted to establish the reliability of tests to determine aerobic power, anaerobic power, and isokinetic strength of the knee extensors and flexors (chapter 5).

\section{Level of daily PA}

In the study described in chapter 2 of this thesis. the level of daily PA (ratio of TEE to sleeping metabolic rate (SMR)) was assessed in rather mildly affected diplegic CP children and healthy controls during a $24 \mathrm{~h}$ stay in a respiration chamber and under normal daily conditions (by the doubly labeled water (DLW) technique). Daily PA in a room-sized chamber was not different between both groups (PA levels were $1.46 \pm 0.14 \mathrm{MJ} / \mathrm{d}$ and $1.47 \pm 0.09 \mathrm{MJ} / \mathrm{d}$ in $\mathrm{CP}$ and healthy children respectively) and similar to PA ratios found in healthy adults during a stay in a respiration chamber (38). However, during normal daily life, PA in the healthy group was $25 \%(\mathrm{p}<0.01)$ higher than in the respiration chamber, whereas the CP children did not increase their PA levels compared to those 
when being confined to a $2 \times 3 \mathrm{~m}$ respiration chamber. As a consequence of this, free-living PA levels were $15 \%(\mathrm{p}<0.05)$ lower in CP children $(1.56 \pm 0.19)$ than in their healthy peers $(1.83 \pm 0.23)$.

Based on these results it can be concluded that, even in mildly affected young children with spastic diplegia, hypoactivity exists. Habitual activity patterns in these children, including physical education classes (45-min sessions 2 times per week) and individual therapy programs (varying from no therapy to more than 2.5 hours per week), are by far not enough to achieve PA levels comparable to the ones found in healthy children. Hypoactivity in CP children who are more severely affected than the children described in chapter 2 , and who are not able to ambulate, is probably even more drastic.

It is obvious that PA is a prerequisite for optimal growth and development of children and adolescents (32). It is the substrate of performance, i.e., muscular strength, motor tasks, and physical capacities in energy production and work output. Although there is little evidence for a significant relationship between PA and risk indicators for coronary heart disease (CHD) during childhood (22,31), children with high activity levels may continue to be active in later life and hence reduce the chance for developing $\mathrm{CHD}$. In view of this, it is extremely important to prevent $\mathrm{CP}$ children from becoming inactive and to give them the possibility to escape from the negative spiral of hypoactivity. Special sports programs are therefore highly recommendable in this population in order to achieve higher activity levels. We by no means imply that the PA levels we measured in healthy Dutch children (chapter 2) and levels that are found in healthy children in Northern Ireland (24) are optimal. However, because it is the only standard we have at the moment, sports programs in $\mathrm{CP}$ children should be aimed at achieving PA levels of about 1.8. We realize that this will not be an easy task. Because of the distinctly subnormal aerobic capacity, particularly in the severely affected children, increases in PA due to training itself are expected to be relatively limited. On the other hand, based on previous studies $(2,5,21,25,41)$, training in $\mathrm{CP}$ may result in considerable improvements of the aerobic power. This may on the long term lead to a sizable increase in absolute training intensity and therefore to reasonable additions to PA levels. Also, a better physical fitness may stimulate $\mathrm{CP}$ children to develop a more active life-style outside the training hours. However, again particularly in children with severe motor disorders, this effect is expected to be small because these children are often confined to an inactive life pattern (electric wheelchairs, transportation to school by buses, etc.).

\section{The training study}

In chapter 6, a general description of the 9-month training programs (45-min sessions, 4 or 2 times per week), study design, and study population ( 7 to 13 year old children with spastic diplegia/tetraplegia) is presented. To make and keep the training programs as attractive as possible, many different training activities were used, adapted to the individual capabilities of the children. In order to give the children the highest possible attention, training groups consisted of maximal 5 
children, and each session was accompanied by one trainer and one assistent. In general, children enjoyed the training sessions very much, which is also apparent from the high voluntary participation grade $(80 \%)$ of the original experimental group in the second training program.

Inherent to the procedure by which peak HR was established, it was not possible to make proper calculations on training intensity from HR recordings during training sessions. However, in view of the considerable training-related improvements in peak aerobic power (chapter 8), training activities must have been performed at an adequate intensity.

Fortunately, we were in the rather exceptional position to be able to compare a randomly assigned experimental group and control group in which subjects had no extra training, and therefore distinguish between training effects and natural course. Especially in studies concerning growing and developing children this is a prerequisite. However, in rehabilitation research, this kind of design is often practically not feasible because of small study populations. Furthermore, the project presented in this thesis was designed in a way that all children (also original controls) had the opportunity to participate in the training sessions for at least 9 months.

In 1980, the World Health Organization published the International Classification of Impairments, Disabilities and Handicaps (ICIDH), by which consequences of diseases can be classified (40). Impairment was defined as 'any loss or abnormality of psychological, physiological, or anatomical structure or function'. Disability is 'any restriction or lack (resulting from an impairment) of ability to perform an activity in the manner or within the range considered normal for a human being'. A handicap was defined as 'a disadvantage for a given individual, resulting from an impairment or disability, that limits or prevents the fulfilment of a role that is normal (depending on age, sex, and social and cultural factors) for that individual'. The training studies presented in this thesis were focussed on the impairment and disability level and describe short-term effects (after a training period of about 2 months) and long-term effects (after having trained for about 9 months).

\section{Effects of training}

Level of daily $P A$

The HR method to assess energy expenditure (EE) has been validated in adults with metabolic disorders (13), healthy adults $(9,10,12,14,23,33,37,39)$ and healthy children $(19,24)$. Because of reduced PA and limitations in calibration activities in $\mathrm{CP}$ children, it was hypothesized that TEE can not be predicted adequately from HR in this population. However, the study in extremely hypoactive CP children (TEE to resting metabolic rate (RMR) ratio was $1.28 \pm 0.23$ ) described in chapter 3 , does not confirm this hypothesis. Intra-individual differences between the HR method and the doubly labeled water technique were rather large, but random, and therefore resulting in a good group estimate of TEE $\left(\mathrm{TEE}_{\mathrm{hr}}=7.4 \pm 2.2 \mathrm{MJ} / \mathrm{d}\right.$; $\mathrm{TEE}_{\mathrm{dlw}}=7.4 \pm 2.1 \mathrm{MJ} / \mathrm{d}$ ). Besides, intra-individual differences were similar to 
discrepancies found in healthy children and adults with higher levels of daily PA $(12,19,23,24,33,37)$. It may be hypothesized that the effect of a low activity level on the accuracy of the HR method is twofold: because of the influence of several factors (emotional stress, posture) on the $\mathrm{HR}-\mathrm{VO}_{2}$ relation in the lower $\mathrm{HR}$ range, the accuracy of the HR method may be decreased. On the other hand, the relatively few bouts of activity in hypoactive subjects may counterbalance this effect. As was suggested by Saris (32), inaccuracy of the minute-by-minute HR method might namely be due to a slower return of $\mathrm{HR}$ than of $\mathrm{VO}_{2}$ to resting levels after bouts of exercise.

Based on the above described results, PA levels in the training study (chapter 7) were calculated by the HR method. Due to lack of sport testers, it was not possible to monitor the HR during more than 1 day in each measurement period. This may have recuded the accuracy of the TEE prediction, because 3 sampling days were found (chapter 3 ) to yield smaller intra-individual differences between $\mathrm{TEE}_{\mathrm{hr}}$ and $\mathrm{TEE}_{\mathrm{dlw}}$ than 2 sampling days (respectively $5.9 \pm 5.8 \%$ and $13.5 \pm$ $6.3 \%, \mathrm{p}=0.05$ ).

Results obtained on TEE to SMR (or RMR) ratios indicate that, although differences in changes between experimental and control groups were not statistically significant, a strenuous training program (4 sessions per week) may, on the long term, increase daily PA in CP children (Chapter 7). This finding was supported by observation of activities and impressions of parents/guardians. The rather mild training program with 2 sessions per week, had no effects on daily PA.

The increase in PA level from 1.34 to $1.55(\mathrm{p}=0.07)$, observed after 9 months of intensive training, seems reasonable. However, to achieve in CP children a level of 1.8 (as found in healthy Dutch children (chapter 2 of this thesis) and healthy children in Northern Ireland (24)), as much as 2.5 hours of aerobic training per day are needed. This high frequency and duration are not feasible, indicating that sports programs can only partly restore the deficit in PA in CP children. Therefore, when compared with their healthy peers, children with spastic $\mathrm{CP}$ will never have equal opportunities for growth and development. More research is needed to establish whether the increase in PA level of $16 \%(\mathrm{p}=0.07)$ as observed during the strenuous training program in the present study, is sufficient to induce positive effects on certain aspects of growth and development in CP children. Because osteoporosis is frequently observed in CP $(8,34)$, the effect on bone development is particularly important in this respect.

\section{Fat mass}

In the study described in chapter 4, BF as predicted from skinfold thicknesses was compared with $\mathrm{BF}$ determined from deuterium dilution $\left(\mathrm{D}_{2} \mathrm{O}\right)$ in both $\mathrm{CP}$ and healthy children. It was hypothesized that, because of a possibly subnormal density of fat-free mass (FFM) $(1,6,8.34$ ), available skinfold equations derived for healthy children, might lead to overestimations of $\mathrm{BF}$ in the $\mathrm{CP}$ population. In contrast with what was expected, sums of skinfolds in the CP children were related to a significantly lower $(p<0.05)$ water content per $\mathrm{kg}$ body weight than comparable sums in the healthy children. This resulted in considerable underesti- 
mations (absolute) of 6 to $8 \% \mathrm{BF}(\mathrm{p}<0.001)$ using equations of Durnin and Rahaman (16) and Slaughter et al. (35) respectively in the CP group, whereas in the healthy group no underestimations were observed. Therefore, it was concluded that, possibly because of a relatively large internal fat depot and a proportionally increased deposition of subcutaneous fat in the lower extremities, available skinfold equations for healthy children are not appropriate to predict BF in comparative studies between $\mathrm{CP}$ and healthy children.

Despite conclusions derived from the study described in chapter 4 , BF during the training programs (chapter 7) was predicted from skinfold thicknesses (method Durnin and Rahaman (16)). Because the aim of the study was to assess the effects of training, the use of the skinfold technique seems justified. However, one must be careful with the interpretation of the absolute amount of BF.

Although changes in FM did not differ significantly between experimental and control group after 9 months (possibly inherent to the small sample size and large intra- and interindividual differences), the study described in chapter 7 does suggest that aerobic training may prevent CP children from developing excessive body fatness. This is an important observation because adiposity -which is as debilitating in CP children as it is in healthy children- is frequently observed in the CP population $(1,6,11,15,17,29)$. However, more research is needed to establish the long-term effects of training on the development of adiposity. Because effects of training on FM were similar in both the strenuous and mild training program, it can be concluded that the preventive effect of training on adiposity in CP children, is already achieved with two 45-min sessions per week.

As was described in the general introduction (chapter 1), the literature is inconclusive on the effects of training on FM in CP. Dresen (15) compared changes in FM after a training program with changes in controls who had had no training. Similar to the results of the present study, no changes were observed in the experimental group, whereas FM in the control children was significantly increased. No effects of training were observed by Bar-Or et al. (2), whereas Berg (7) reported significant increases in FM after a training program in CP children and adolescents. However, no comparisons were made with controls who had had no training, which may explain the controversy with the present study and the study of Dresen (15). Therefore, it is of the utmost importance to use experimental controlled designs in future research.

\section{Peak aerobic power}

Peak aerobic power in the training study was established during leg cycling and arm cranking (chapter 8). As in healthy children, the cycle ergometer tests were found to be reliable in CP children, with test-retest correlations varying from 0.72 to 0.92 (chapter 5). Unfortunately. at the time of the reliability study, we had no arm cranking device at our disposal. Therefore, test-retest reliability has not been established during arm cranking.

As can be seen from chapter 8,4 exercise sessions per week are highly effective in improving peak aerobic power in CP children, which is in agreement with previous reports $(2,5,21,25,41)$. After 9 months, in 9 of the 10 children of the experimental group, considerable increases were observed varying from $15 \%$ 
to $376 \%$ (average increase was $35 \%, \mathrm{p}<0.01$ ). These changes were significantly different $(\mathrm{p}<0.05)$ versus the control group, in which aerobic power showed no changes after 9 months. The largest proportional improvements in the experimental group were found in the most severely affected children. One child showed a reduction in peak aerobic power after training. We have no explanation for this, for the child was highly motivated. Two exercise sessions per week also increased peak aerobic power with about $20 \%$ ( $<<0.01$ ). However, the improvement was not significantly different versus controls.

Regarding the relatively limited trainability of aerobic power in prepubescents (4), the large improvements described in the present thesis, can be explained by extremely low base-line levels. However, training effects on aerobic power can not be compared properly between $\mathrm{CP}$ and healthy children because different parameters are measured: aerobic performance in healthy children is restricted by cardiorespiratory factors, whereas in $\mathrm{CP}$ children local factors (spasticity, muscle strength) limit the performance. Therefore, peak aerobic power in CP children is attained at a much lower level of cardiorespiratory stress than in healthy children.

From the study on peak aerobic power, also the importance of long-lasting training programs ( $>2$ months) becomes apparent. At $T_{2}$, peak aerobic power in the experimental group tended to be increased, but significant effects were only achieved after 9 months. This need for long-lasting training programs is not typical for handicapped children; also in healthy children training periods lasting for at least 6-8 weeks are required to attain training effects (3). Furthermore, because an important aim of exercise programs for handicapped and healthy children alike is to form habits, to acquire skills, and to enjoy sports, not only physiologic goals but also educational goals should dictate the duration of a training program (3).

\section{Anaerobic power}

As was found for the test to determine peak aerobic power, the Wingate Anaerobic Cycling Test (WAnT) was found to be reliable in $\mathrm{CP}$ children (test-retest comelations varying from 0.90 to 0.95 , chapter 5). No effects of training were found on anaerobic power (chapter 8), which may be caused by the predominantly aerobic character of the program. Anaerobic performance in the experimental and control groups increased during the study in a similar way, probably due to qualitative changes in muscles with increasing age $(3,20)$. This finding again emphasizes the need for including control groups in studies with young children.

\section{Isokinetic muscle strength}

Isokinetic strength testing during knee extension and flexion was found to be reliable in $\mathrm{CP}$ children at $30 \%$ (test-retest correlations were 0.71 and 0.84 respectively, chapter 5 ). At higher test-velocities $(60 \% \mathrm{~s}$ and $120 \%$ ), no reliable measurements could be obtained on extension, which may be due to a more restricted reciprocal inhibition at higher velocities than at lower velocities. Because of technical problems with the Cybex device, strength measurements during the training study (chapter 8) were only performed in the second year. Therefore, data obtained on this parameter could not be compared between 
experimental and control groups. The results described in chapter 8 suggest that training with a frequency of 2 sessions per week may improve isokinetic strength of the knee extensors and flexors. Such improvement would be in agreement with studies of MacPhail and Kramer (27) and McCubbin and Shasby (28) in CP children and adolescents (purely isokinetic exercise). However, this should be confirmed in a controlled study.

\section{Spasticity}

Training had no effects (positive nor negative) on spasticity during passive movements as measured by the Ashworth test (chapter 9). Because this test is a rather gross measure, it may be hypothesized that the Ashworth test is not appropriate to establish effects of training on spasticity. However, at the moment, no other lowinterference and easy applicable methods are available. To our knowledge, the only training studies in $\mathrm{CP}$ in which the Ashworth test is used are of Wormgoor and Gierlings (41) and MacPhail and Kramer (27). In contrast with the findings of the present study, Wormgoor and Gierlings (41) reported significant reductions in Ashworth scores in CP adults after a 4-week training program. However, also in control subjects who had had no training Ashworth scores tended (ns) to be decreased. From the study it is not clear whether the decreases in Ashworth scores are different between the experimental and control group. MacPhail and Kramer (27) found no significant changes in Ashworth scores in CP adolescents after an 8-week strength-training program. During rest, no effects of training have been found on spasticity as measured by electromyography (EMG) and the Hreflex by Rotzinger and Stoboy (30) and Spira and Bar-Or (36) respectively.

In an attempt to quantify effects of training on spasticity during voluntary movements, EMG measurements were performed during cycling and arm cranking (chapter 9). As for isokinetic muscle strength, no controls were available. Training tended to (partly) normalize EMG patterns during cycling, but this was not supported by significant changes in calculated EMG parameters. Large intra- and interindividual differences may be responsible for this. Therefore, no clear conclusions can be drawn from this study on effects of training on spasticity during voluntary movements.

At the moment. no uniformly useful objective method is available to measure spasticity. Because the quantification of spasticity is extremely important in training studies in $\mathrm{CP}$, not only to detect possible favourable effects but also to avoid worsening, futurc research should be focussed on this topic.

\section{Mechanical efficiency}

Finally, no training-related changes in ME were detected after aerobic training (chapter 9), which is in agreement with earlier reports $(2,18,26)$. Possible changes that might have occurred in spasticity during voluntary movements, had apparently no measurable effects on ME. Dresen (15) reported significant improvements in MF: after training, but the program in her study was quite different (intensification of gymnastic lessons) from the one described in this thesis. 
The above described findings indicate that, although predominantly aerobic training is limited in restoring the deficit in PA in young children with spastic $\mathrm{CP}$, it has pronounced effects on peak aerobic power. Furthermore, aerobic training may be effective in preventing $\mathrm{CP}$ children from developing adiposity and in increasing isokinetic strength of the knee extensors and flexors. With the used methods, no negative effects of training have been observed, which is in line with impressions of the treating physician.

Although not studied in the project, the higher level of physical fitness may improve the performance of activities of daily life, and increase the effectiveness of rehabilitation programs. Furthermore, the increased fitness may stimulate the children to maintain a more active life-style in later life, which may have favourable effects on the development of CHD and osteoporosis. Therefore, aerobic training is an important therapeutic measure in addition to the traditional rehabilitation programs in $\mathrm{CP}$ children. However, not only the somatic benefits of training are important. As was clearly experienced during our study, most children enjoy training activities very much. Moreover, in contrast with other therapies, sports programs make handicapped children feel like 'normal' children: the child's ability is emphasized rather than the disability. This gives the tool even more value. Also, the increased fitness may help CP children to compete at higher levels with their healthy counterparts, which may affect the social integration in a positive way.

In order to prevent deterioration in physical functions as early in life as possible and to integrate sports in the habitual activity patterns, training programs should be started at an early age. Regarding the considerable improvements in peak aerobic power achieved during the rather strenuous training program, four 45-min exercise sessions per week are recommendable. However, because CP children (particularly the severely affected) often have strenuous therapy programs during school time, it may not be possible to integrate such an intensive training program completely within the school schedule. Therefore, children should be stimulated to participate in organized sports activities outside the rehabilitation center. However, at the moment, possibilities for handicapped children to be intensively active outside the rehabilitation center are limited. Therefore, much effort has to be invested in creating out-school training activities for this population.

\section{General conclusions}

1. Even in rather mildly affected children with spastic CP, hypoactivity exists. Levels of daily PA in CP children with severe motor disorders are extremely low when compared to healthy peers.

2. Despite low levels of PA and limitations in calibration activities, the HR method can provide a close group estimate of TEE in spastic CP children (3 sampling days is preferable). At an individual level, the method is less suitable. At the moment. HR monitoring seems to be the most appropriate method to 
predict TEE in large-scale activity studies for groups with extremely low levels of daily PA.

3. Skinfold equations derived for healthy children, are not appropriate to predict $\mathrm{BF}$ in comparative studies between $\mathrm{CP}$ and healthy children.

4. Cycle ergometer tesis to assess peak aerobic power and anaerobic power are reliable in groups of children with spastic CP. Isokinetic strength of the knee extensors and flexors can be measured reliably in this population at a low test speed $(30 \%)$.

6. Predominantly aerobic training has only a limited effect on restoring the deficit in PA in young CP children. However, in view of favourable effects on body composition, aerobic power and possibly isokinetic muscle strength, and the joy children experience during training, adapted sports activities should be added to the traditional rehabilitation programs. Four 45 -min sessions per week are recommendable.

7. Predominantly aerobic training has no effects (positive nor negative) on anaerobic power, spasticity during passive movements, and ME in young $\mathrm{CP}$ children. Training might improve cycling patterns, but no clear conclusions can be drawn from the present thesis on this parameter.

\section{Recommendations for further research in $\mathrm{CP}$}

-Future research should focus on establishing the presence of risk indicators for CHD (adiposity, hypertension, hypercholesterolemia) in CP children and its relation to PA. Also the effects of training on these risk inuicators and on the development of CHD in later life should be investigated.

-Objective low-interference methods to quantify body fat and spasticity should be (further) developed.

-Further randomized experimental controlled studies should be performed on the effects of training on isokinetic muscle strength, spasticity during voluntary movements, and the development of adiposity on the long-term. Also, training effects on bone development, performance of activities of daily life, social integration and mental well-being (handicap level) should be studied.

\section{References}

1. Bandini, L. G., D. A. Schoeller, N. K. Fukagawa, L. J. Wykes, W. H. Dietz Body composition and energy expenditure in adolescents with cerebral palsy or myelodysplasia. Pediatr. Res. 29:70-77, 1991. 
2. Bar-Or, O., O. Inbar, R. Spira. Physiological effects of a sports rehabilitation program on cerebral palsied and post-poliomyelitic adolescents. Med. Sci. in Sports, 8:157-161, 1976.

3. Bar-Or, O. Pediatric sports medicine for the practitioner. From physiologic principles to clinical applications. New York: Springer Verlag, 1983.

4. Bar-Or, O. Trainability of the prepubescent child. The Physician and sportsmedicine, 17:65-82, 1989.

5. Berg, K. Effect of physical training of school children with cerebral palsy. Acta Paediatr. Scand. 204(suppl):27-33, 1970.

6. Berg, K., B. Isaksson. Body composition and nutrition of school children with cerebral palsy. Acta Paediatr. Scand. 204(suppl):41-52, 1970.

7. Berg, K. Effect of physical activation and of improved nutrition on the body composition of school children with cerebral palsy. Acta Paediatr. Scand. 204(suppl):53-69, 1970.

8. Bleck, E. E. Orthopaedic management in cerebral palsy. Philadelphia: Lippincott, 1987: $121-141$.

9. Booyens, J., G. R. Hervey. The pulse rate as a means of measuring metabolic rate in man. Can. J. Biochem. Physiol. 38:1301-1309, 1960.

10. Bradfield, R. B., P. B. Huntzicker, G. J. Fruehan. Simultaneous comparison of respirometer and heart-rate telemetry techniques as measures of human energy expenditure. Am. I. Clin. Nuir. 6:696-700, 1969.

11. Brown, A. Review: physical fitness and cerebral palsy. Child: care, health and development 1:143-152, 1975.

12. Ceesay, S. M., A. M. Prentice, K. C. Day, et al. The use of heart rate monitoring in the estimation of energy expenditure: a validation study using indirect whole-body calorimetry. Br. J. Nutr. 61:175-186, 1989.

13. Christensen, C. C., H. M. M. Frey, E. Foenstelien, E. Aadland, H. E. Refsum. A critical evaluation of energy expenditure estimates based on individual $\mathrm{O}_{2}$ consumption / heart rate curves and average daily heart rate. Am. J. Clin. Nutr. 37:468-472, 1983.

14. Dauncey, M. J., W. P. T. James. Assessment of the heart-rate method for determining energy expenditure in man, using a whole-body calorimeter. Br. J. Nutr. 42:1-13, 1979.

15. Dresen, M. H. W. Physical training of handicapped children. Physical and psychological effects. [Thesis] Amsterdam, 1983.

16. Durnin, J. V. G. A., M. M. Rahaman. The assessment of the amount of fat in the human body from measurements of skinfold thickness. Br. J. Nutr. 21:681-689, 1967.

17. Eddy, T. P., A. L. Nicholson, E. F. Wheeler. Energy expenditures and dietary intakes in cerebral palsy. Dev. Med. Child Neurol. 7:377-386, 1965.

18. Ekblom, B., A. Lundberg. Effect of physical training on adolescents with severe motor handicaps. Acta Paediatr. Scand. 57:17-23, 1968.

19. Emons, H. J. G., D. C. Groenenboom, K. R. Westerterp, W. H. M. Saris. Comparison of heart rate monitoring combined with indirect calorimetry and the doubly labelled water $\left({ }^{2} \mathrm{H}_{2}{ }^{18} \mathrm{O}\right)$ method for the measurement of energy expenditure in children. Eur. J. Appl. Physiol. 65:99-103, 1992.

20. Falgairette, G., M. Bedu, N. Fellmann, E. Van Pragh, J. Coudert. Bio-energetic profile in 144 boys aged from 6 to 15 years with special reference to sexual maturation. Eur. J. Appl Physiol. 62:151-156, 1991.

21. Fernandez, J. E., K. H. Pitetti. Training of ambulatory individuals with cerebral palsy. Arch. Phys. Med. Rehabil. 74:468-472, 1993.

22. Kemper, H. C. G.: Growth and health in adolescents. Cienciskunde en Sport 13:18-22, 1980 [Dutch].

23. Livingstone, M. B. E., A. M. Prentice, W. A. Coward, et al. Simultaneous measurement of free-living energy expenditure by the doubly labeled water method and heart-rate monitoring. Am. J. Clin. Nutr. 52:59-65, 1990. 
24. Livingstone, M. B. E., W. A. Coward, A. M. Prentice, et al. Daily energy expenditure: in. free-living children: comparison of heart-rate monitoring with the doubly labeled water $\left({ }^{2} \mathrm{H}_{2}{ }^{17} \mathrm{O}\right)$ method. Am. J. Clin. Nutr. 56:343-352, 1992.

25. Lundberg, A., C-O. Ovenfors, B. Saltin. Effect of physical training on school children with cerebral palsy. Acta Paediatr. Scand. 56:182-188, 1967.

26. Lundberg. A., B. Pernow. The effect of physical training on oxygen utilization and lactate formation in the exercising muscle of adolescents with motor handicaps. Scand. $J$. ('lin. Lab. Inv. 26:89-96, 1970.

27. MacPhail, H. I . A., J. F. Kramer. Effect of isokinetic strength-training on functional ability and walking efliciency in adolescents with cerebral palsy. Dev. Med. Child Neurol. 37:763775. 1995.

28. McCubbin, J. A., G. B. Shasby. Effects of isokinetic exercise on adolescents witl cerebral palsy. Adapted Phisical Activity Quarterly 2:56-64, 1985.

29. Phelps, W. M. Dietary requirements in cerebral palsy. J. Am. Diet. Assoc. 27:869-876, 1951.

30. Rotzinger, H., H. Stoboy. Comparison between clinical judgement and electromyographic investigations of the effect of a special training program for CP children. Acta Paediatr. Belgica 28(suppl):121-128. 1974.

31. Saris, W. H. M. The assessment and evaluation of daily physical activity in children. A review. Acta Paediatr. Scand. 318(suppl):37-48, 1985.

32. Saris, W. H. M. Habitual physical activity in children: methodology and findings in health and disease. Med. Sci. Sports Exerc. 18:253-263, 1986.

33. Schulz, S., K. R. Westerterp, K. Brück. Comparison of energy expenditure by the doubly labeled water technique with energy intake, heart rate, and activity recording in man. Am. J. Clin. Nutr. 49:1146-1154, 1989.

34. Shaw, N. J., C. P. White, W. D. Fraser, L. Rosenbloom. Ostopenia in cerebral palsy. Arch. Dis. Child. 71:235-238, 1994.

35. Slaughter, M. H., T. G. Lohman, R. A. Boileau, et al. Skinfold equations for estimation of body fatness in children and youth. Hum. Biol. 60:709-723, 1988.

36. Spira, R., O. Bar-Or. An investigation of the ambulation problems associated with severe motor paralysis in adolescents. Influence of physical conditioning and adapted sports activities. Final report. Tel-Aviv: Z. Sohar-Cohen, 1975

37. Spurr, G. B., A. M. Prentice, P. R. Murgatroyd, G. R. Goldberg, J. C. Reina, N. T. Christman. Energy expenditure from minute-by-minute heart-rate recording: comparison with indirect calorimetry. Am. J. Clin. Nutr. 48:552-559, 1988.

38. Verboeket- van de Venne, W. P. H. G. Pattern of food intake, diet composition and human energy metabolism. An experimental approach. Maastricht, 1993 [Thesis].

39. Washbum, R. A., H. I. Montoye. Validity of heart rate as a measure of mean daily energy expenditure. Exerc. Physiol. 2:16l-172, 1986.

40. World Health Organization. International Classification of Impairments, Disabilities and Handicaps. Geneva: W.H.O., 1980.

41. Wormgoor, M. E. A., Y. H. J. Gierlings. Revalidatie van lichamelijk gehandicapten met behulp van sportactiviteiten in Noorwegen. Bewegen \& Hulpverlening 3:219-238, 1989 [Dutch]. 


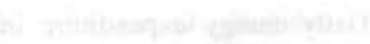

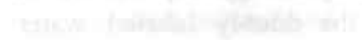

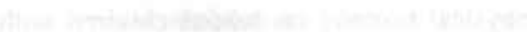




\section{Summary}

Physical activity is generally considered to be an important factor in the growth and development of children and adolescents. Levels of daily physical activity in. children with spastic cerebral palsy may be far from optimal because of the nature and severity of the disorder. The studies presented and discussed in this thesis were intended to assess whether and to what extent hypoactivity exists in young children with spastic cerebral palsy (diplegia/tetraplegia), and what effects special sports programs have on level of daily physical activity, body fat, physical fitness (aerobic power, anaerobic power, muscle strength), spasticity, and mechanical efficiency. Furthermore, the usefulness of heart rate monitoring and skinfold measurements to predict respectively total daily energy expenditure and body fat in the $\mathrm{CP}$ population was investigated. The reliability of tests to determine aerobic power, anaerobic power and isokinetic strength of the knee extensors and flexors was also studied (in both CP and healthy children).

In chapter 2 , levels of daily physical activity were compared between children with spastic diplegia and healthy controls. Although the cerebral palsied children were rather mildly affected, physical activity levels during normal daily life were significantly lower (by 15\%) than in the healthy children and were similar to levels when being confined to a room-sized chamber. Based on this finding, increasing the level of daily physical activity by special sports programs was recommended in the cerebral palsy population.

The heart rate method to predict total daily energy expenditure is expected to be less suitable in cerebral palsied children with low activity levels than in healthy children or healthy adults with respectively high or intermediate levels. Chapter 3 reports on the usefulness of the heart rate method in cerebral palsied children with extremely low physical activity. At group level, total daily energy expenditure predicted from heart rate showed good agreement with total daily energy expenditure determined from doubly labeled water. In individuals, discrepancies between both methods were rather large, but similar to discrepancies found in healthy subjects. It was concluded that also in groups with extremely low levels of physical activity, the relatively simple and inexpensive heart rate method is suitable to measure total daily energy expenditure.

Cerebral palsied children may have a lower density of fat-free mass than healthy children, due to increased total body water and osteoporosis. This might aflect the validity of body composition techniques in this population. In chapter 4 the usefulness of skinfold measurements to predict body fat in a comparative study between cercbral palsied and healthy children is described. Body fat as predicted from skinfold thicknesses was significantly lower than body fat determined by deuterium dilution in the cerebral palsied children, whereas in the healthy children this was not seen. It was concluded that available skinfold equations derived for healthy children are not appropriate to predict body fat in comparative studies between cerebral palsied and healthy children.

Chapter 5 reports on the reliability of measurements of peak aerobic power (cycle ergometry), anaerobic power (cycle ergometry), and isokinetic strength of the knee extensors and flexors (Cybex) in cerebral palsied and healthy children. At group level, cycle ergometer tests were reliable in both groups of children. 
The strength test in the cerebral palsy group was only reliable at a low test speed $(30 \%)$. At individual level, the tests seemed to be less suitable in cerebral palsied children than in their healthy peers (possibly due to attention deficits in cerebral palsy). The study described in chapter 5 also shows that the measured fitness parameters were distinctly subnormal in the cerebral palsied children.

Chapter 6 presents a general description of the design of the training study, the 9-month training programs (45-min predominantly aerobic sessions, 4 or 2 times per week), and the study population. Effects of the training programs are described in chapters 7-9.

The mild training program with 2 exercise sessions per week had no effect on level of daily physical activity (chapter 7), whereas the strenuous program (4 sessions per week) tended to increase physical activity levels on the long-term (after 9 months) by $16 \%$ (ns). However, the strenuous program was by far not successful in restoring the deficit in physical activity in the cerebral palsied children, indicating that these children will never have equal opportunities for growth and development when compared with healthy children. Fat mass remained unchanged in the experimental groups during both training programs, whereas fat mass in the control children increased continuously throughout the study (chapter 7). These results suggest that training is effective in preventing $\mathrm{CP}$ children from developing excessive body fatness, but effects on the long-term have to be investigated.

Peak aerobic power improved enormously during training (chapter 8). Four sessions per week resulted in a significant increase of $35 \%$; two sessions per week increased peak aerobic power significantly by about $20 \%$, but this change was not significantly different versus controls. Results obtained on strength measurements (chapter 8) suggest that training with a frequency of 2 sessions (45-min) per week, improved isokinetic strength of the knee extensors and flexors. However, this has to be confirmed in a controlled study. Predominantly aerobic training had no effect on anaerobic performance (chapter 8 ).

Chapter 9 reports on the effects of training on spasticity and mechanical efficiency. Training had no effect (positive nor negative) on spasticity during passive movements and mechanical efficiency. Cycling patterns tended to (partly) normalize during training (2 sessions per week), but this was not supported by significant changes in calculated electromyography parameters.

Based on the results obtained on body composition, aerobic power, isokinetic muscle strength, and the joy children experienced during training, sports programs (four 45-min sessions per week is preferable) were highly recommended in addition to the traditional rehabilitation programs in cerebral palsied children. 


\section{Samenvatting}

Lichamelijke activiteit wordt in het algemeen beschouwd als een belangrijke factor in de groei en ontwikkeling van kinderen en adolescenten. De dagelijkse lichamelijke activiteit van kinderen met spastische cerebrale parese kan, door de aard en ernst van hun handicap, te kort schieten. De in dit proefschrift beschreven onderzoeken zijn uitgevoerd teneinde na te gaan of, en in welke mate, hypoactiviteit voorkomt bij jonge kinderen met spastische cerebrale parese (diplegie/tetraplegie), en welke effecten speciale sportprogramma's hebben op de lichamelijke activiteit, het lichaamsvet, fitheid (aeroob vermogen, anaeroob vermogen, spierkracht), spasticiteit, en mechanische efficiëntie. Voorts is nagegaan of de hartfrequentie methode en huidplooidikte metingen geschikt zijn om respectievelijk het dagelijks energiegebruik en het lichaamsvet van cerebraal paretische kinderen te meten. Ook is onderzocht in hoeverre testen ter bepaling van het aeroob vermogen, anaeroob vermogen, en isokinetische kracht van de knie extensoren en flexoren betrouwbaar zijn (zowel in cerebraal paretische kinderen als in niet-gehandicapte kinderen).

In hoofdstuk 2 werd de hoeveelheid dagelijkse lichamelijke activiteit van kinderen met spastische diplegie vergeleken met die van niet-gehandicapte leeftijdsgenootjes. Alhoewel de cerebraal paretische kinderen relatief lichte beperkingen hadden, waren ze onder normale dagelijkse omstandigheden significant minder actief (15\%) dan de niet-gehandicapte kinderen. De hoeveelheid lichamelijke activiteit van de cerebraal paretische kinderen was onder normale dagelijkse omstandigheden zelfs niet hoger dan tijdens een verblijf in een kleine kamer. Uitgaande van deze resultaten werd geadviseerd om de dagelijkse lichamelijke activiteit van kinderen met spastische cerebrale parese te verhogen door middel van speciale sportprogramma's.

De verwachting is dat de hartfrequentie methode minder geschikt is om het dagelijks energiegebruik te bepalen van weinig actieve cerebraal parctische kinderen dan van niet-gehandicapte kinderen of volwassenen met veel of middelmatige lichamelijke activiteit. Hoofdstuk 3 beschrijft een onderzock naar de geschiktheid van de hartfrequentiemethode bij cerebraal paretische kinderen met extreem weinig lichamelijke activiteit. Op groepsnivo was het dagelijks energiegebruik voorspeld uit de hartfrequentie goed vergelijkbaar met het energiegebruik bepaald met de tweevoudig gemerkt water techniek. Op individueel nivo waren de discrepanties tussen beide methoden redelijk groot mair vergelijkbalar met discrepanties die gevonden zijn in studies bij niet-gehandicapte personen. Fir werd geconcludeerd dat ook in weinig actieve groepen, de relatief eenvoudige en goedkope hartfrequentiemethode geschikt is om het dagelijks energiegebruik te bepalen.

Het is mogelijk dat, door een grotere hoeveelheid lichaamswater en osteoporose, de dichtheid van de vet-vrije massa van cerebraal paretische kinderen lager is dan die van niet-gehandicapte kinderen. Dit zou de validiteit van lichaamssamenstellingstechnieken kunnen beïnvloeden. Hoofdstuk 4 beschrijft de geschiktheid van huidplooidikte metingen in een vergelijkingsstudie tussen cerebraal paretische kinderen en niet-gehandicapte kinderen. In tegenstelling tot wat werd verwacht was bij de cerebraal paretische kinderen de hoeveelheid lichaamsvet voorspeld uit 
huidplooien significant lager dan de hoeveelheid lichaamsvet bepaald met deuterium. Bij de niet-gehandicapte kinderen werd dit niet waargenomen. Er werd geconcludeerd dat beschikbare huidplooivergelijkingen voor niet-gehandicapte kinderen, niet geschikt zijn om lichaamsvet te voorspellen in vergelijkingsstudies tussen cerebraal paretische kinderen en niet-gehandicapte kinderen.

In hoofdstuk 5 wordt de betrouwbaarheid van metingen van het aeroob vermogen (fietsergometrie), anaeroob vermogen (fietsergometrie), en isokinetische kracht van de knie extensoren en flexoren (Cybex) beschreven in cerebraal paretische kinderen en niet-gehandicapte kinderen. Op groepsnivo waren de fietsergometertesten betrouwbaar in beide groepen. De spierkracht test was bij de cerebraal paretische kinderen alleen betrouwbaar op een lage test snelheid (30 $\%$ s). Op individueel nivo leken de testen minder geschikt te zijn bij de cerebraal paretische kinderen dan bij de niet-gehandicapte kinderen (waarschijnlijk door concentratie stoomissen in de cerebraal paretische groep). De studie die in hoofdstuk 5 wordt beschreven toont ook dat de waarden van de gemeten fitheidsparameters van de cerebraal paretische kinderen aanzienlijk lager waren dan die van de niet-gehandicapte kinderen.

Hoofdstuk 6 presenteert een algemene beschrijving van het design van de trainingsstudie, de 9 maanden durende sportprogramma's (voomamelijk aerobe trainingen, 4 of 2 keer per week 45 minuten), en van de kinderen die deelnamen. Effecten van de sportprogramma's worden beschreven in de hoofdstukken 7-9.

Het milde programma met 2 trainingen per week had geen effect op de lichamelijke activiteit (hoofdstuk 7), terwijl de hoeveelheid dagelijkse lichamelijke activiteit tijdens het intensieve programma (4 trainingen per week) op de lange termijn (na 9 maanden) toegenomen leek te zijn met 16\% (niet significant). Echter, het tekort aan lichamelijke activiteit bij cerebraal paretische kinderen kon slechts voor een klein gedeelte hersteld worden door het intensieve trainingsprogramma, wat aangeeft dat deze kinderen nooit dezelfde kansen zullen hebben voor groei en ontwikkeling in vergelijking met niet-gehandicapte kinderen. De hoeveelheid lichaamsvet veranderde niet in de experimentele groepen tijdens de twee trainingsprogramma's, terwijl het lichaamsvet in de kinderen die geen training hadden continu toenam tijdens de studie (hoofdstuk 7). Deze resultaten suggereren dat sportprogramma's adipositas bij cerebraal paretische kinderen kunnen voorkomen. Echter, effecten op de lange termijn moeten verder onderzocht worden.

Het piek aeroob vermogen verbeterde sterk door trainen (hoofdstuk 8). Vier trainingen per week resulteerde in een significante toename van 35\%; het piek aeroob vermogen nam door 2 trainingen per week significant toe met circa $20 \%$, maar dit was niet significant anders dan bij controle personen. De resultaten van de krachtmetingen (hoofdstuk 8) suggereren dat door training met een frequentie van 2 keer per week ( 45 minuten), de isokinetische kracht van de knie extensoren en flexoren toenam. Echter, dit resultaat dient bevestigd te worden in een gecontroleerde studie. Voomamelijk aerobe training had geen effect op het anaerobe prestatievermogen (hoofdstuk 8).

Hoofdstuk 9 beschrijft de effecten van training op spasticiteit en mechanische efficiëntie. Training had geen effect (geen positief maar ook geen negatief) op 
spasticiteit tijdens passieve bewegingen en mechanische efficiëntie. Fietspatronen leken (gedeeltelijk) te normaliseren tijdens het trainingsprogramma ( 2 trainingen per week), maar dit kon niet bevestigd worden met significante veranderingen in berekende electromyografische parameters.

Uitgaande van de resultaten met betrekking tot de lichaamssamenstelling, aeroob vermogen, isokinetische spierkracht, en het plezier dat kinderen beleven aan de trainingen, werd aanbevolen sportprogramma's (4 trainingen van 45 minuten per week) toe te voegen aan de traditionele revalidatieprogramma's van cerebraal paretische kinderen. 


\section{Abbreviations}

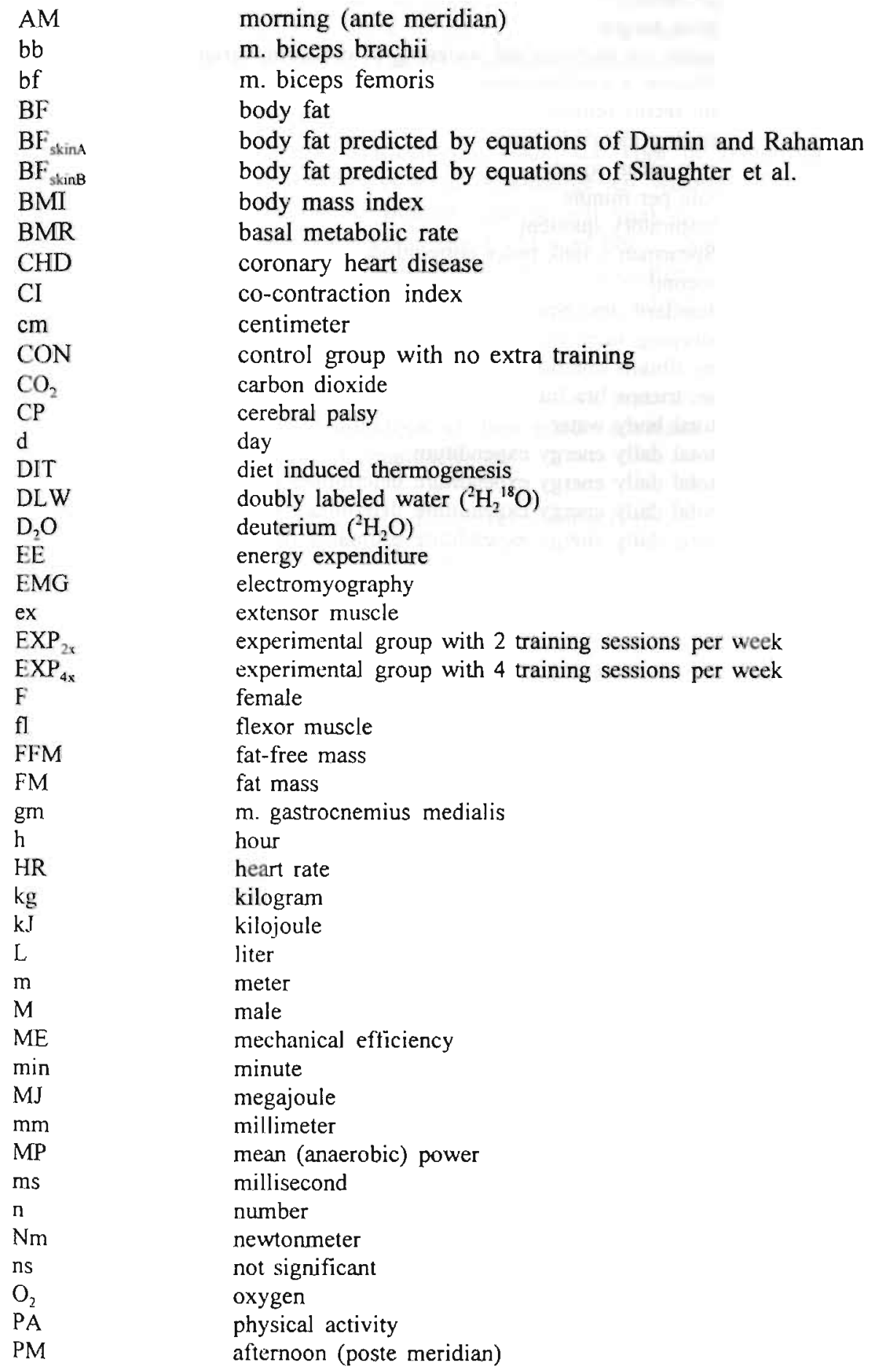

morning (ante meridian)

$\mathrm{m}$. biceps brachii

$\mathrm{m}$. biceps femoris

body fat

body fat predicted by equations of Durnin and Rahaman body fat predicted by equations of Slaughter et al. body mass index basal metabolic rate coronary heart disease co-contraction index centimeter control group with no extra training carbon dioxide cerebral palsy day diet induced thermogenesis doubly labeled water $\left({ }^{2} \mathrm{H}_{2}{ }^{18} \mathrm{O}\right)$ deuterium $\left({ }^{2} \mathrm{H}_{2} \mathrm{O}\right)$ energy expenditure electromyography extensor muscle experimental group with 2 training sessions per week experimental group with 4 training sessions per week female flexor muscle fat-free mass fat mass $\mathrm{m}$. gastrocnemius medialis hour heart rate kilogram kilojoule liter meter male mechanical efficiency minute megajoule millimeter mean (anaerobic) power millisecond number newtonmeter not significant oxygen physical activity afternoon (poste meridian) 


\begin{tabular}{|c|c|}
\hline PP & peak (anaerobic) power \\
\hline ppm & promille \\
\hline PT & peak torque \\
\hline $\mathrm{R}^{\prime \prime}$ & index for pathological widening of electromyography pattern \\
\hline $\mathrm{r}$ & Pearson's product moment correlation \\
\hline rf & m. rectus femoris \\
\hline RMR & resting metabolic rate \\
\hline RMS & root mean square \\
\hline rpm & rate per minute \\
\hline $\mathrm{RQ}$ & respiratory quotient \\
\hline$r_{s}$ & Spearman's rank order correlation \\
\hline $\mathrm{s}$ & second \\
\hline SD & standard deviation \\
\hline SMR & sleeping metabolic rate \\
\hline ta & m. tibialis anterior \\
\hline tb & m. triceps brachii \\
\hline TBW & total body water \\
\hline TEE & total daily energy expenditure \\
\hline $\mathrm{TEE}_{\text {cal }}$ & total daily energy expenditure determined in respiration chamber \\
\hline $\mathrm{TEE}_{\mathrm{dlw}}$ & total daily energy expenditure determined by doubly labeled water \\
\hline $\mathrm{TEE}_{\mathrm{hr}}$ & total daily energy expenditure estimated from heart rate \\
\hline TEE/SMR (RMR) & level of daily physical activity \\
\hline$T_{0}$ & time point before training program started \\
\hline $\mathrm{T}_{2}$ & time point after 2 months \\
\hline $\mathrm{T}_{9}$ & time point after 9 months \\
\hline W & work \\
\hline 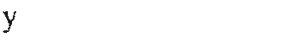 & year \\
\hline
\end{tabular}




\section{Nawoord}

Tijdens het onderzoek dat ik de afgelopen 4 jaar verrichtte, heb ik met heel veel mensen samengewerkt. Op deze plaats wil ik iedereen bedanken voor hun bijdrage aan de totstandkoming van dit proefschrift. Een antal mensen wil ik met name noemen.

Allereerst mijn co-promotor Marleen van Baak, die voor de dagelijkse begeleiding zorgde. Marleen, bedankt voor je deskundige en waardevolle adviezen, je enthousiasme en het feit dat je, ondanks dat je zelf vaak heel druk met proeven bezig was, toch altijd voor me klaar stond. $\mathrm{Al}$ was het 's morgens heel vroeg of 's avonds laat, altijd was je bereid om als taxichauffeur te fungeren. Jouw inbreng, zowel inhoudelijk als praktisch, is voor mij altijd een grote stimulans geweest.

Mijn promotores Wim Saris en Toon Huson wil ik bedanken voor hun hulp bij het totstandkomen van het onderzoek en hun goede adviezen en kritische kanttekeningen met betrekking tot de manuscripten.

Mijn proefpersoontjes van het Kinderrevalidatiecentrum Franciscusoord in Houthem (Valkenburg) zijn uiteraard de hoofdpersonen van het onderzoek en het proefschrift. Ook al was het niet altijd even leuk om al die plakkers en pleisters opgeplakt te krijgen, of om te fietsen met een masker op, toch bleven jullie ontzettend goed je best doen! Ik heb heel veel genoten van onze samenwerking; ik hoop dat voor jullie hetzelfde geldt en dat we elkaar in de toekomst nog eens zullen zien. Ook wil ik op deze plaats jullie ouders bedanken. Zonder hun enorme inzet zouden we heel veel metingen niet hebben kunnen uitvoeren. Bedankt! Ook alle niet-gehandicapte kinderen die aan het onderzoek hebben deelgenomen wil ik bedanken voor hun enthousiasme en inzet.

Vervolgens wil ik een aantal afdelingen van het Kinderrevalidatiecentrum Franciscusoord bedanken voor hun medewerking: de afdelingen fysiotherapic, assistenten paramedische dienst, medische dienst, school en bewegingsonderwijs, technische dienst en centrale planning. Met name wil ik noemen: Eugene Rameckers en Marcel Coenen voor het verzorgen van vele trainingen, Anny Adriaens voor haar hulp bij het organiseren van het onderzoek op Franciscusoord, Lucianne Speth voor haar interesse en kritische kanttekeningen met betrekking tot de manuscripten. Door het enthousiasme van jullie allen voelde ik me echt thuis op Franciscusoord!

Donnie de Barbanson wil ik bedanken voor de jarenlange prettige samenwerking. Heel wat nachtelijke uurtjes hebben we samen op het BMC doorgebracht in verband met respiratiekamerproeven. Misschien kunnen we ooit nog eens samen een boek schrijven over alles wat we hebben mecgemaakt tijdens het onderzoek, maar wat absoluut niets met wetenschap te maken had! 
De stagiaires Yvonne Burggraaff, Laudy Janssens, Nicole Schoeber, Karin Schmets, Florine van Overveld, Danielle van Munster, Carola Leygraaf, Martine Hoofwijk, Chantal Peeters, Renate Wigger, Eline Roelofsen en Peter Rasenberg, bedankt voor jullie inzet en enthousiasme!

De vakgroepen Bewegingswetenschappen en Humane Biologie wil ik bedanken voor de prettige samenwerking. Harrie Wandler voor het uitlezen van vele sporttesters in de beginfase van het onderzoek en de hulp bij het oplossen van technische problemen met de Cybex en EOS-sprint. Saskia Weeber en Désirée Brands voor het printen van vele files die ik vanuit Zeeland naar jullie opstuurde. Loek Wouters en Paul Schoffelen voor al jullie hulp bij de respiratiekamerproeven en Loek voor het analyseren van de urinemonsters.

Klaas Westerterp en Maarten Drost, bedankt voor jullie hulp bij het schrijven van de manuscripten.

De leden van de beoordelingscommissie: Prof. dr. H. Kuipers, Prof. W. H. Dietz, Prof. dr. J. Drukker, Dr. I. de Groot en Prof. dr. ir. J. D. Janssen, wil ik bedanken voor het kritisch doorlezen van het manuscript.

Tenslotte wil ik mijn ouders bedanken voor hun belangstelling en steun tijdens mijn studie en AIO-periode, mijn schoonouders voor de vele 'baby-sit' uurtjes, en last but not least Reggie en Kim: bedankt, ...gewoon voor alles. 


\section{Curriculum vitae}

Rita van den Berg-Emons werd geboren op 14 januari 1966 te Oploo. Na het behalen van het VWO diploma aan het Elzendaalcollege te Boxmeer, begon zij in september 1984 haar studie Gezondheidswetenschappen, met als afstudeerrichting Bewegingswetenschappen aan de Rijksuniversiteit Limburg te Maastricht, een studie die zij in september 1988 voltooide. In de periode van februari $1990 \mathrm{t} / \mathrm{m}$ februari 1991 was zij als toegevoegd onderzoeker werkzaam bij de vakgroep Bewegingswetenschappen (RL, Maastricht). In dat jaar verrichtte zij een aantal deelonderzoeken op het Kinderrevalidatiecentrum Franciscusoord te Valkenburg a/d Geul. Van 1 mei 1991 tot 30 april 1995 was zij als assistent in opleiding in dienst van de vakgroep Bewegingswetenschappen ( $\mathrm{RL}$, Maastricht). In nauwe samenwerking met de vakgroep Humane Biologie (RL, Maastricht) en het Kinderrevalidatiecentrum Franciscusoord (Valkenburg) werd gedurende deze tijd het in dit proefschrift beschreven onderzoek verricht (begeleiders: Prof. dr. ir. W. H. M. Saris, Dr. M. A. van Baak). 


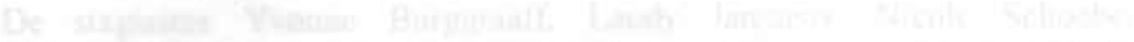

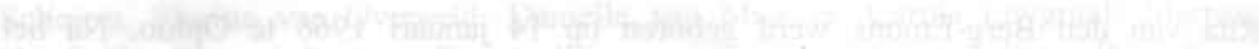

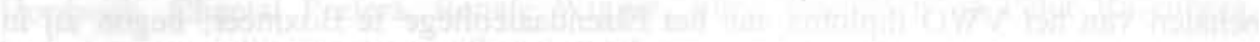

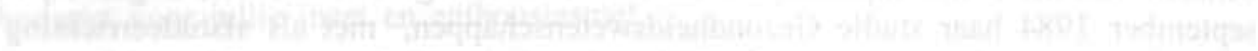

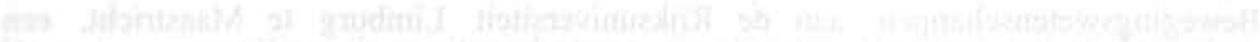

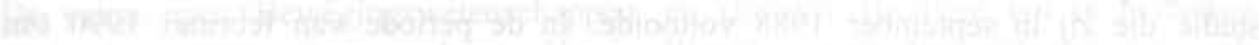

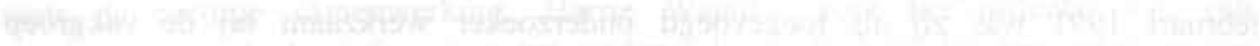

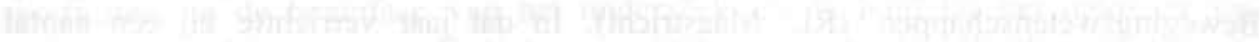

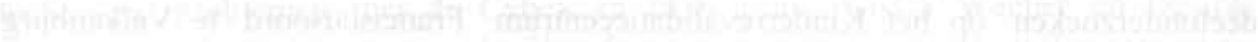

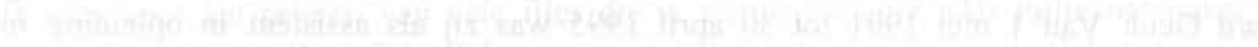

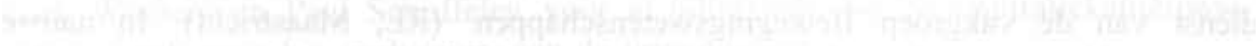

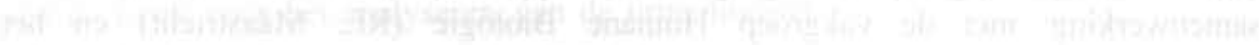

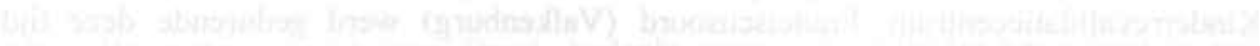

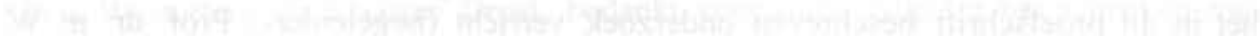




\section{Publications}

\section{Full papers}

Groenenboom. I). C.. H. J. G. Emons, K. R. Westerterp, W. H. M. Saris. Energiegebruik bij kinderen. Vergelijking van de hartfrequentiemethode met indirecte calorimetrie en de tweevoudig gemerkte water technick. Geneeskunde en sport 24:19-22. 1991.

Emons, H. J. G.. D. C. Groenenboom, Y. I. Burggraati, T. I.. E. Janssens, M. A. van Baak. Wingate Anaerobic Test in children with cerebral palsy. In: ('oudert. J., E. van Praagh (editors). (hildren and exercise XVI. Paris: Masson. 1992: 187-189.

Emons, H. J. G., D. C. Groenenboom, K. R. Westerterp. W. H. M. Saris. Comparison of heart rate monitoring combined with indirect calorimetry and the doubly labelled water method $\left({ }^{2} \mathrm{H}_{2}{ }^{18} \mathrm{O}\right)$ method for the measurement of energy expenditure in children. Eur. J. Appl. Phisiol. 65:99-103. 1992.

Berg-Emons van den. R. Sport door kinderen met spastische cerebrale parese. Beschrijving van een onderzoek naar de effecten van regelmatige lichamelijke inspanning op factoren als de dagelijkse lichamelijke activiteit, uithoudingsvermogen, lichaamsgewicht, vetgehalte en spierkracht. Nederlands Tijdschrift voor Kinderrevalidatie 2:15-17, 1994.

Berg-Emons van den, H. J. G., W. H. M. Saris, D. C. de Barbanson, K. R. Westerterp, A. Huson, M. A. van Baak. Daily physical activity of school children with spastic diplegia and of healthy control subjects. J. Pediatr. 127:578-584, 1995.

Berg-Emons van den, H. J. G., W. H. M. Saris, K. R. Westerterp, M. A. van Baak. Heart rate monitoring to assess energy expenditure in children with reduced physical activity. Med. Sci. Sports Exerc. (in press).

Berg-Emons van den, H. J. G., M. A. van Baak, D. C. de Barbanson, L. Speth, W. H. M. Saris. Reliability of tests to determine peak aerobic power, anaerobic power, and isokinetic muscle strength in spastic cerebral palsied children and healthy controls. Dev. Med. Child Neurol (accepted).

Berg-Emons van den, H. J. G., M. A. van Baak, K. R. Westerterp. Skinfold measurements in cerebral palsy and healthy controls. Arch. Dis. Child. (submitted).

Berg-Emons van den, H. J. G., M. A. van Baak, L. Speth, W. H. M. Saris. Physical training of school children with spastic cerebral palsy: effects on daily physical activity and fat mass. Phys. Med. Rehab. (submitted).

Berg-Emons van den, H. J. G., M. A. van Baak, L. Speth, W. H. M. Saris. Physical training of school children with spastic cerebral palsy: effects on. aerobic power, anaerobic power and isokinetic muscle strength. Med. Sci. Sports Exerc. (submitled).

Berg-Emons van den, H. J. G., E. E. Roelofsen, M. A. van Baak, M. R. Drost, L. Speth. Physical training of school children with spastic cerebral palsy: effects on spasticity and mechanical efficiency. Dev. Med. (hild Neurol. (submitted). 


\section{Abstracts}

Emons, H. J. G., D. C. Groenenboom, K. R. Westerterp, W. H. M. Saris. Comparison of heart rate monitoring with the ${ }^{2} \mathrm{H}_{2}{ }^{18} \mathrm{O}$ method for the measurement of energy expenditure in children. In: Beunen, G., J. Chesquiere, T. Reybrouck, A. L. Claessens (editors). Children and exercise, Schriftenreihe der Hamburg-Mannheimer-Stiftung für Informationsmedizin, band 4. Stuttgart: Ferdinand Enke Verlag, 1990.

Saris, W. H. M., H. J. G. Emons, D. C. Groenenboom, K. R. Westerterp. Discrepancy between $\mathrm{FAO} / \mathrm{WHO}$ energy requirements and actual energy expenditure levels in healthy 7-11 year old children. In: Beunen, G., J. Ghesquiere, T. Reybrouck, A. L. Claessens (editors). Children and exercise, Schriftenreihe der Hamburg-Mannheimer-Stiftung für Informationsmedizin, band 4. Stuttgart: Ferdinand Enke Verlag, 1990.

Groenenboom, D. C., T. L. E. Janssens, Y. I. Burggraaff, H. J. G. Emons, M. A. van Baak. Reliability of peak aerobic power during cycle ergometry in cerebral palsied children. In: Coudert, J., E. van Praagh (editors). Children and exercise XVI. Paris: Masson, 1992.

Emons, H. J. G., M. A. van Baak. Effect of training on peak aerobic power and anaerobic power in cerebral palsied children. Med. Sci. Sports Exerc. 25(suppl): 107, 1993.

Emons, H. J. G., M. A. van Baak. Effect of training on aerobic and anaerobic power and mechanical efficiency in spastic cerebral palsied children. Pediatric Exercise Science 5:412, 1993.

Emons, H. J. G., M. A. van Baak. Effect of training on body composition and sleeping metabolic rate in spastic cerebral palsied children. Pediatric Exercise Science 5:13, 1993.

Berg-Emons van den, H. J. G., M. A. van Baak, W. D. van Marken-Lichtenbelt, K. R. Westerterp, T. Huson, W. H. M. Saris. Assessment of body composition in children with spastic cerebral palsy and healthy children by deuterium dilution, skinfold thicknesses and bioelectric impedance. Pediatric Exercise Science, 1994.

Berg-Emons van den, H. J. G., W. H. M. Saris, D. C. de Barbanson, K. R. Westerterp, T. Huson, M. A. van Baak. Level of daily physical activity in children with spastic diplegia and healthy controls measured by doubly labeled water and indirect calorimetry. Pediatric Exercise Science, 1994. 

